Claremont Colleges

Scholarship @ Claremont

Spring 2021

\title{
The Influence of Community Cultural Wealth and Tauhi Va on the Navigation of Pacific Islanders in Science, Technology, Engineering and Mathematics (STEM)
}

\author{
Marlena Vi Wolfgramm \\ Claremont Graduate University
}

Follow this and additional works at: https://scholarship.claremont.edu/cgu_etd

\section{Recommended Citation}

Wolfgramm, Marlena Vi. (2021). The Influence of Community Cultural Wealth and Tauhi Va on the Navigation of Pacific Islanders in Science, Technology, Engineering and Mathematics (STEM). CGU Theses \& Dissertations, 234. https://scholarship.claremont.edu/cgu_etd/234. doi: 10.5642/cguetd/234

This Open Access Dissertation is brought to you for free and open access by the CGU Student Scholarship at Scholarship @ Claremont. It has been accepted for inclusion in CGU Theses \& Dissertations by an authorized administrator of Scholarship @ Claremont. For more information, please contact scholarship@cuc.claremont.edu. 
The Influence of Community Cultural Wealth and Tauhi Vā on the Navigation of

Pacific Islanders in Science, Technology, Engineering, and Mathematics (STEM)

By

Marlena Vi Wolfgramm

Claremont Graduate University and San Diego State University 
(c) Marlena Vi Wolfgramm, 2021.

All rights reserved 


\title{
Approval of the Dissertation Committee
}

This dissertation has been duly read, reviewed, and critiqued by the Committee listed below, which hereby approves the manuscript of Marlena Vi Wolfgramm as fulfilling the scope and quality requirements for meriting the degree of Doctor of Philosophy in Education.

\author{
Felisha Herrera Villarreal, Co-Chair
}

San Diego State University

Associate Professor of Postsecondary Education

\author{
Dina C. Maramba, Co-Chair \\ Claremont Graduate University \\ Associate Professor of Education
}

\author{
Marva Cappello \\ San Diego State University \\ Professor of Education
}

Susan J. Paik

Claremont Graduate University

Professor of Education 


\begin{abstract}
The Influence of Community Cultural Wealth and Tauhi Vā on the Navigation of Pacific Islanders in Science, Technology, Engineering and Mathematics (STEM)

By
\end{abstract}

\title{
Marlena Vi Wolfgramm
}

Claremont Graduate University and San Diego State University: 2021

My research examines the influence of community cultural wealth and tauhi vā on the navigation of Pacific Islanders (PIs) in STEM. The disaggregation of data on Asian American and Pacific Islanders (AAPIs) attaining STEM bachelor's degrees revealed that PIs (16\%) are represented half as much as Asian Americans (35\%) (NCES, 2020). Under the AAPI designation, PIs have been masked, underserved, and underresearched in higher education and STEM. For this reason, this study focuses on the educational trajectories and experiences of PIs in STEM to highlight their strengths and challenges to understand how better to serve and support PIs in STEM. In this phenomenological study, I used an asset-based framework; community cultural wealth and a PI cultural value, tauhi vā, to explore how PIs navigate STEM. The research questions for this study are (a) How do community cultural wealth and tauhi vā influence the navigation of Pacific Islanders in STEM? and (b) How does tauhi vā create vā specific to Pacific Islanders to wayfind STEM and develop community cultural wealth? This qualitative study included 31 participants who self-identified as Pacific Islander and were students and recent graduates in STEM. The methods used in this study included a brief demographic survey, an educational trajectory map, and a 60- to 90-minute semistructured artifact elicitation interview using talanoa. The main finding of this study was that the navigation of PIs in STEM was influenced by familial, 
aspirational, social, navigational, and resistant capital. After facing barriers such as inadequate advising, stereotype threat, and competitive and cutthroat STEM culture from peers, faculty, and staff, PI students maneuvered through the skill of wayfinding. PIs created vā (space) to relate, heal, and network with other PIs and individuals who had encountered similar experiences. PIs maintain vā through tauhi vā, or the caretaking of sociospatial relationships through reciprocity, thus developing Pacific Islander cultural capital to navigate STEM. This qualitative research is based on the successful navigation of PIs in STEM through an asset-based framework and cultural value to highlight the positive impact of PI cultural knowledge, PI identity, and nuances of PIs in STEM.

Keywords: Native Hawaiian and Pacific Islanders, Pacific Islanders, STEM, tauhi vā, vā, navigation, wayfinding, community cultural wealth 


\section{Dedication}

To my grandpa, Vitolio Tonga; my mother, Pasepa Vi Wolfgramm; my father, Walter P. Wolfgramm; my sisters, Ella Wolfgramm, Grethel Aguirre Wolfgramm, Leanne HowlettMcKay, Akosita Laulea, Vaioleola Fifita, and Elina Tomasi; my brothers, Sale and C. J. Wolfgramm; and the Mahi Boyz (Ka'ili Vi, Braulio, Walter, Fusiloa, and Baby J). 


\section{Acknowledgements}

I would like to acknowledge my family; my mother's and father's side of the family; my Oakland Tongan family and community; my LELE family (Lavi Uluave, Daniel Tecun, Ulysses Tongaonevai, Inoke and Tali Hafoka, Jake Fitsemanu); and my writing partners, Erica Aros, Leilani Funaki, and Dr. Kristina Moleni. I want to acknowledge my RESISTE family, Dr. Victoria Operana-Rodriguez and Dr. Gabi Kovats Sánchez, for teaching me how to conduct qualitative research, write up a paper, present at conferences, and for sharing your dissertation work and experiences with me. Thank you for letting me practice my dissertation proposal and defense during staff meetings and for giving me all the pep talks and encouragement.

To my advisor and co-chair, Dr. Felisha Herrera Villarreal, there are no words to express my gratitude. You believed in me when I did not believe in myself and pushed me to be who I was meant to be. To Dr. Dina C. Maramba, thank you for being my advisor and co-chair, for reminding me how important this work is, and for encouraging me when I wanted to give up. To my JDP program director, Dr. Marva Cappello, thank you for advocating for me on several occasions when I could not, and for making this happen. You have always made the JDP office feel like home and made me feel welcome. To Dr. Susan J. Paik, thank you for strengthening me when I was at my weakest.

I want to acknowledge the fellowship and grant funding from the SDSU University Graduate Fellowship, the Chancellor's Doctoral Incentive Program (CDIP) and support through RESISTE from the National Science Foundation. This work was supported by the National Science Foundation (DUE-1832528). Any opinions, findings, and conclusions or recommendations expressed in this material are those of the author(s) and do not necessarily reflect the views of the National Science Foundation. 


\section{Table of Contents}

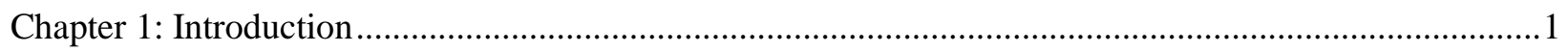

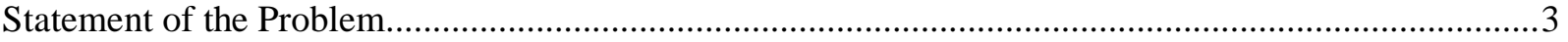

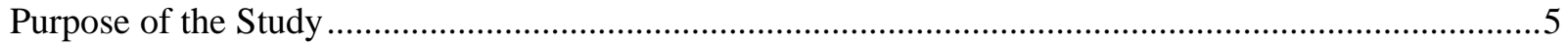

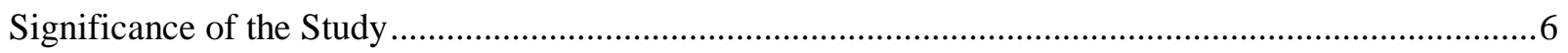

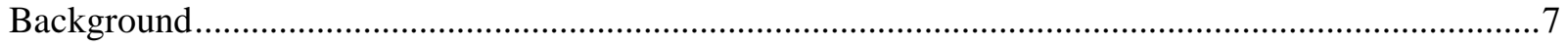

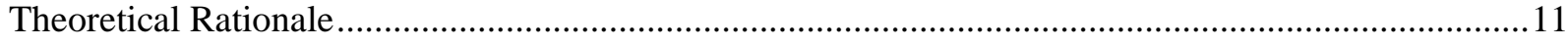

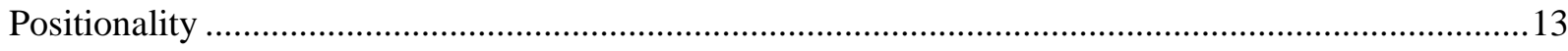

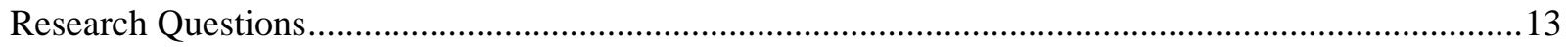

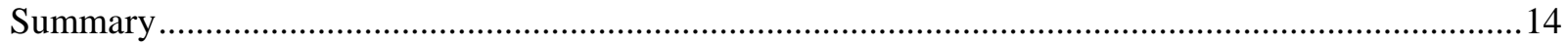

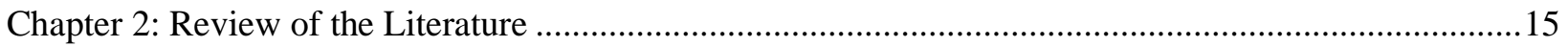

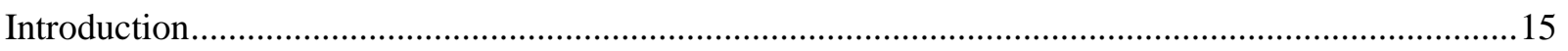

Literature Related to Navigation in STEM................................................................................... 16

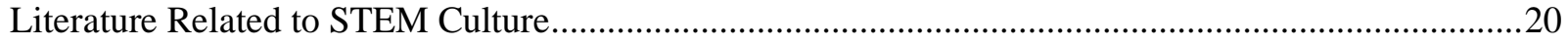

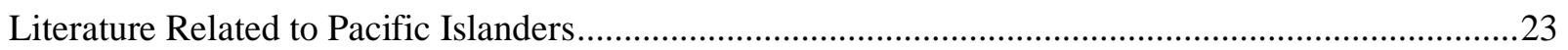

Literature on the Persistence of Underrepresented Students in STEM ............................................28

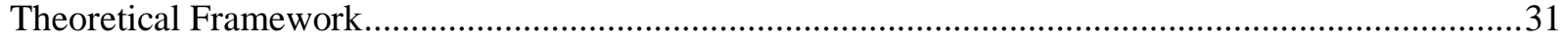

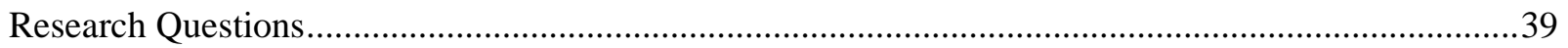

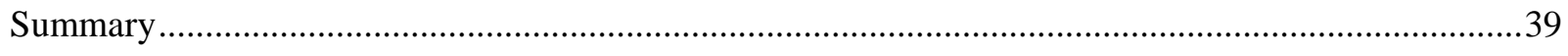

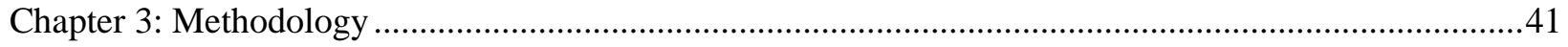

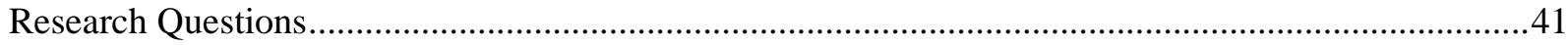

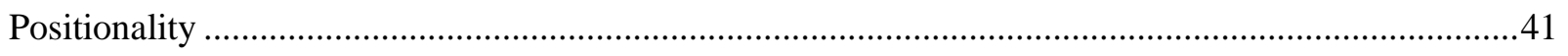

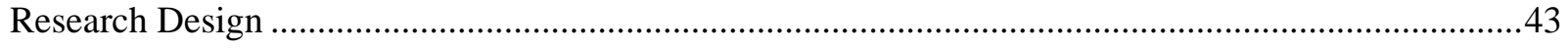

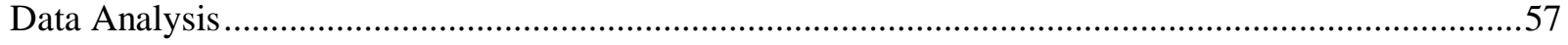

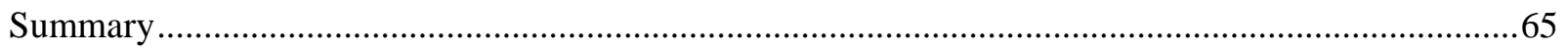

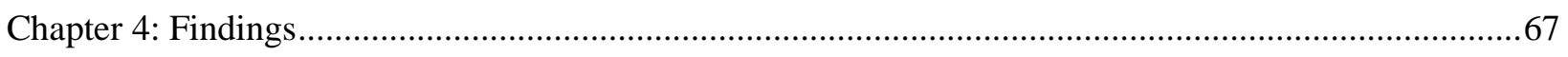

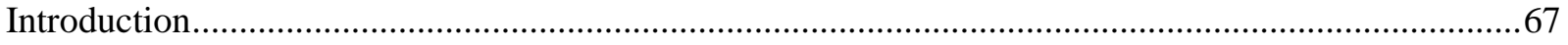

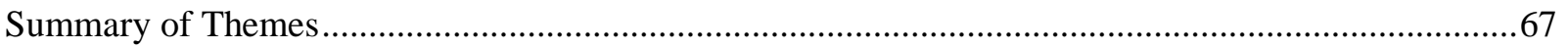

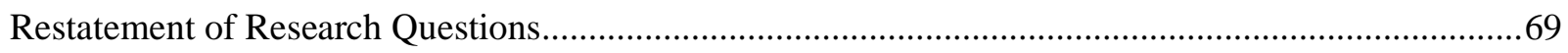


Theme 1: Navigation and Wayfinding: Following a Forged Path to Forging Your Own Path .69

Theme 2: Vā: Creating Vā (Space) Through Interpersonal Relationships and Social Connections .......87

Theme 3: Tauhi Vā: Taking Care of Relationships Within These Spaces Through Reciprocity..........101

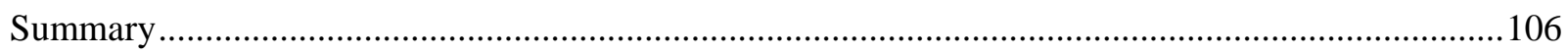

Chapter 5: Discussion, Reflections, and Recommendations ................................................................. 109

Navigation and Wayfinding: Following a Forged Path to Forging Your Own Path ...........................109

Vā: Creating Vā (Space) Through Interpersonal Relationships and Social Connections ....................114

Tauhi Vā: Taking Care of Relationships Within These Spaces Through Reciprocity .........................117

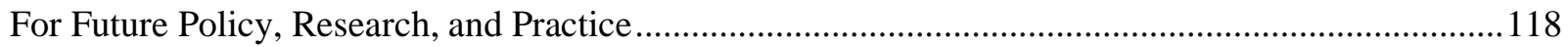

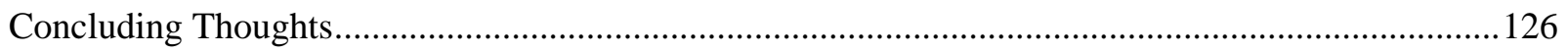

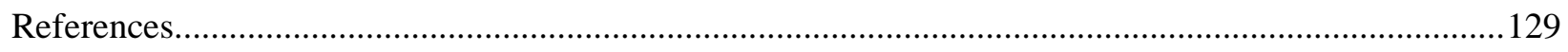

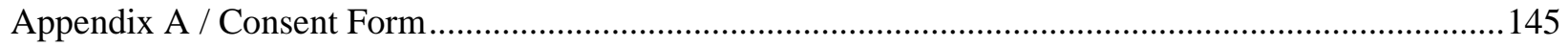

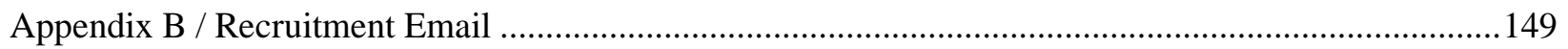

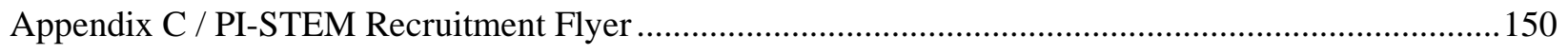

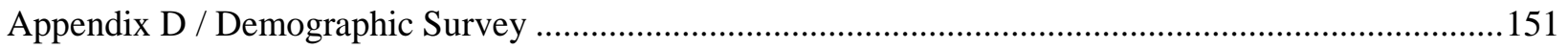

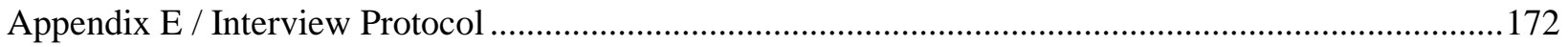




\section{Figures and Tables}

Figure 1. STEM Bachelor's by Postsecondary Institutions and Race/Ethnicity ......................... 1

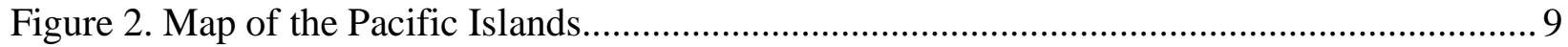

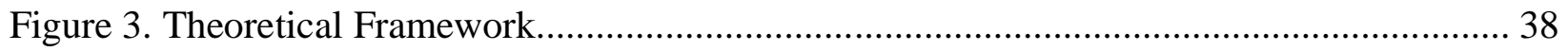

Figure 4. My Educational Trajectory Map.................................................................... 51

Figure 5. Langi’s Educational Trajectory Map................................................................ 72

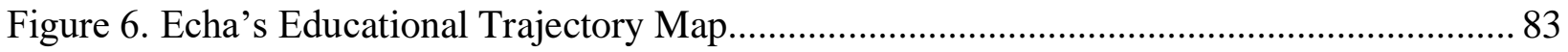

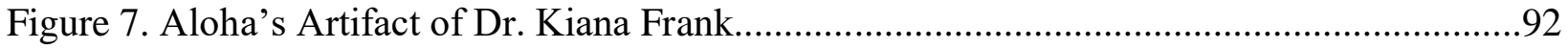

Table 1. Native Hawaiian and Pacific Islander Ethnic Groups.............................................. 8

Table 2. Criteria for Selection......................................................................................4

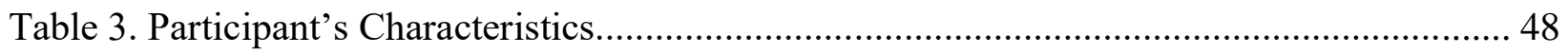

Table 4. Participant Demographics............................................................................5

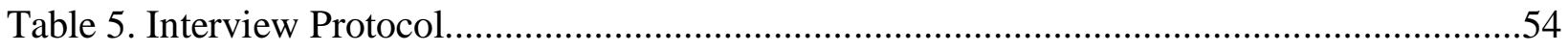

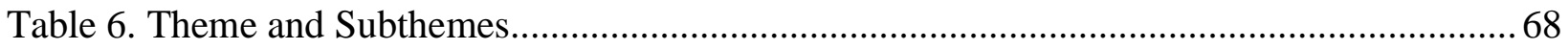

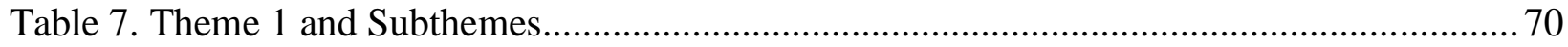

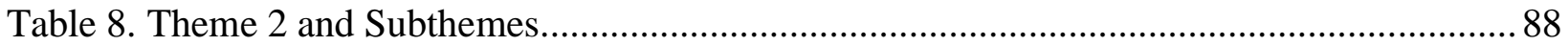

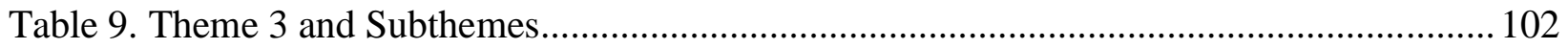


Caminante, no hay puentes, se hace puentes al andar. (Voyager, there are no bridges, one builds them as one walks.)

-Gloria Anzaldúa, Borderlands/La Frontera

\section{Chapter 1: Introduction}

My research highlights the underrepresentation of Pacific Islander (PI) students in science, technology, engineering, and mathematics (STEM) fields, a population often masked under the Asian American Pacific Islander (AAPI) designation. During the 2017-2018 school year, Asians earned 35\% of all STEM bachelor's degrees, followed by Whites with 19\%, Hispanics with 16\%, Pacific Islanders with 16\%, American Indians/Alaska Natives with 15\%, and Blacks with 13\% (National Center Education Statistics [NCES], 2020) (see Figure 1). STEM degree attainment for Asians (35\%) and PIs (16\%) is far from equal, yet the two populations have been designated as one large group, AAPI. The disaggregation of AAPI data regarding STEM degree attainment clearly indicates that PIs are underrepresented in STEM, along with Hispanics, American Indians/Alaska Natives, Blacks, and women, who all have been historically excluded from many fields in STEM (Beede et al., 2011).

\section{Figure 1}

STEM Bachelor's Degrees by Postsecondary Institution and Race/Ethnicity 


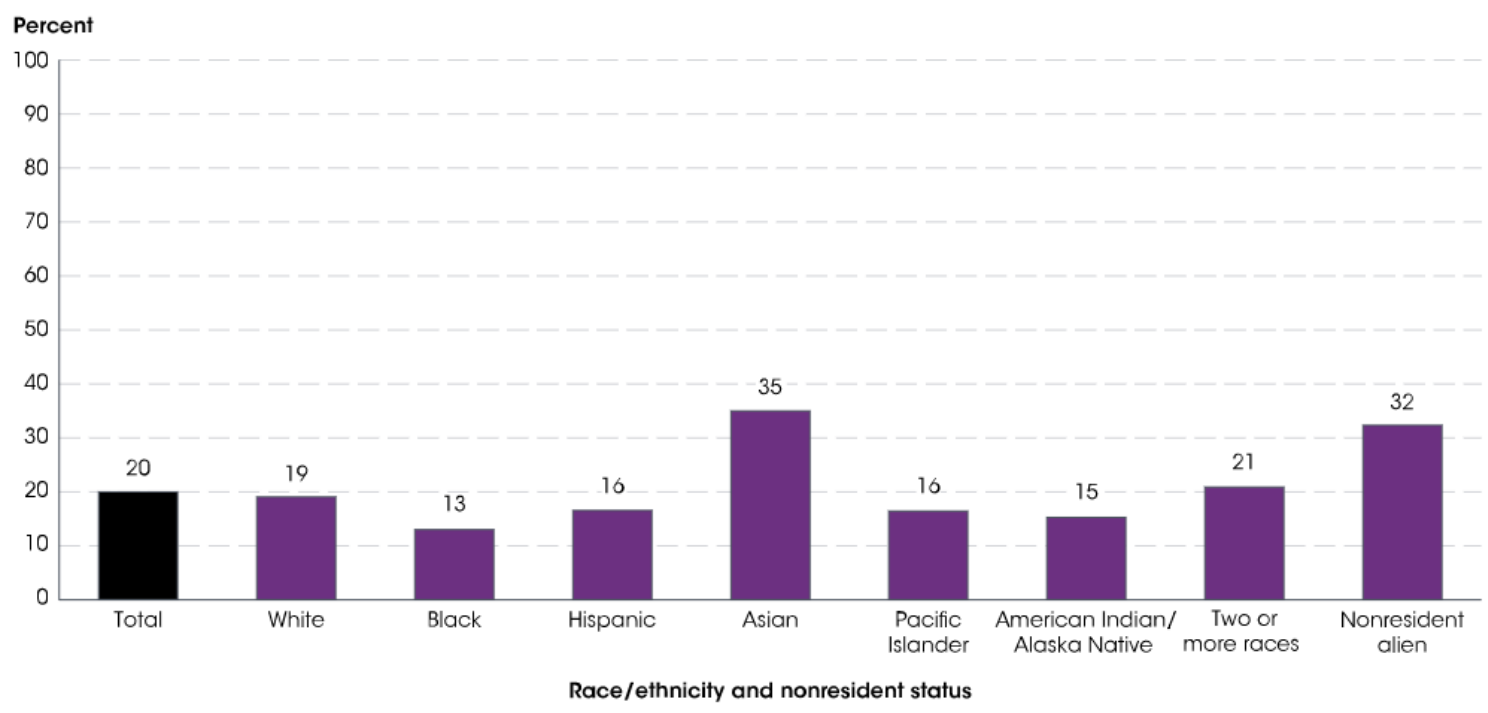

Note: Academic year 2017-2018. Reprinted from U.S. Department of Education. Institute of Education Science, National Center for Education Statistics.

https://nces.ed.gov/programs/coe/indicator cta.asp. In the public domain.

AAPIs comprise over 48 ethnic groups who are vastly diverse in language, culture, and migration history to the United States (Paik et al., 2014; Palmer \& Maramba, 2015). AAPIs have been regarded as the model minority: "hardworking, well-educated, and successful citizens who strongly value educational achievements and economic success compared to other racial minority groups" (Palmer \& Maramba, 2015, p. 45). Policies and programs have relied on the model minority stereotype to rationalize why no funding or programs exist to support Asian Americans or AAPIs, even though most AAPIs are first-generation college students, recent immigrants, and economically challenged (Maramba, 2008; Museus \& Kiang, 2009; Museus et al., 2013; Teranishi et al., 2009, 2012; Teranishi \& Kim, 2017).

The majority of research on AAPIs in higher education and STEM focuses on Asian Americans, with little to no focus on PIs (Allaire, 2017; NCES, 2019; Uehara et al., 2018). For 
the past 40 years, AAPI and NHPI scholars and activists have been advocating to disaggregate AAPI data and encourage more qualitative research to highlight the diverse experiences and challenges of AAPIs (Empowering Pacific Islander Communities \& Asian Americans Advancing Justice, 2014; Hafoka et al., 2020; Museus et al., 2013; Teranishi et al., 2009, 2019). Analysis of disaggregated research has revealed that Southeast Asians and PIs have the highest dropout rates and the lowest rates of college participation and college completion among AAPI students (Palmer \& Maramba, 2015; Teranishi \& Kim, 2017). Over 50\% of PIs enter college but drop out before attaining a degree (Teranishi \& Nguyen, 2011). The AAPI designation has camouflaged these inconsistencies and "completely erased the experiences of NHPIs" (Hafoka et al., 2020, p. 71).

This study centers on the experiences of PIs who are succeeding in STEM in order to examine the assets that PIs use to navigate STEM. Findings from the study can be employed to inform policy, institutions, faculty, and staff on how better to support and increase STEM degree attainment by PIs and add to the research on PIs in higher education.

\section{Statement of the Problem}

PIs are underrepresented in STEM, along with Hispanics, American Indians/Alaska Natives, Blacks, and women, who all have been historically excluded from many fields in STEM (Beede et al., 2011). Dutt (2020) pointed out the lack of diversity in the geosciences and its impact on STEM, stating, "The less diverse a field, the less welcoming it is to minorities, and the more prevalent implicit biases become. Combined with structural and social factors, the relative homogeneity in geoscience reinforces the dominant culture" (p. 2).

STEM has been dominated by White men, who have created a "chilly," individualistic, and competitive culture that is unwelcoming for marginalized populations who value 
community, collectivism, and reciprocity, such as PIs (Cole \& Espinoza, 2008; McGee, 2016).

Researchers working in the STEM fields have produced advancements in medicine, engineering, and technology, including the COVID-19 vaccine and renewable energy. But STEM researchers have also tested nuclear bombs in the Marshall Islands, causing coral bleaching, loss of sea life, and cancer and other diseases in the Marshallese people (Rust, 2019). And STEM researchers conducted the Tuskegee Syphilis Study on Black males, who did not receive the available preferred penicillin treatment, for the purpose of observing unchecked disease progression in a population (Brandt, 1978). Evidently, STEM has been used to privilege others at the expense of disadvantaging marginalized and vulnerable communities of color.

Pasifika scholar Hau'ofa reflected back on how Oceania, the Pacific, and the Pacific Ocean had sustained itself and its inhabitants before the invasion of the Europeans, the White man. Hau'ofa (1998) stated:

In the earliest stage of our interactions with the outside world, we were the South Sea paradise of noble savages living in harmony with a bountiful nature; we were simultaneously the lost and degraded souls to be pacified, Christanised, colonised and civilised. Then we became the South Pacific region of much importance for the security of Western interests in Asia. We were pampered by those whose real interests lay elsewhere, and those who conducted dangerous experiments on our islands. We have passed through that stage into the Pacific Islands Region of naked, neocolonial dependency. Our erstwhile suitors are now creating a new set of relationships along the rim of our ocean that excludes us totally. (p. 34) 
Imperialism and colonization ravaged the land and the ocean, wrecked the livelihood of PIs, and exploited PI ways of knowing to satisfy the greed of illegal and unwanted trespassers. This destruction is paralleled in the negative impacts of STEM.

PIs are a relational people whose connections and interpersonal relationships have been maintained throughout Oceania to "instill a strong sense of belonging for the sake of sustained regional accountability" (Hau 'ofa, 1998, p. 33). PI cultures are communal; the family and the community work and learn together for the benefit of the family and the community (Ka'ili, 2008). The collective culture of PIs contrasts the individualistic and competitive culture of STEM, which can be unwelcoming and challenging for PIs who major in STEM. With the population of PIs projected to increase, STEM has the potential to create advancements to improve sustainability that benefits everyone by changing its culture to be more collective and less individualistic. For the United States to maintain a competitive edge in the global economy, faculty, staff, researchers, and institutions must transform STEM education and culture to be more inclusive for increasing STEM diversity and innovation.

\section{Purpose of the Study}

The purpose of the study is to explore how PIs are navigating in STEM. PIs began migrating to the United States in waves from the 1950s and 1960s because the Mormon Church, better known as the Church of Jesus Christ of Latter-Day Saints, began enrolling students from Hawaii, Samoa, Fiji, Tonga, and New Zealand into the Church College of Hawaii (Olson, 1961; Swain, 2010). As recent immigrants, PIs have a strong cultural identity and connection to their family, community, and ancestors, which I believe has influenced how they are navigating and persisting in STEM. 
For my research, I have interviewed 31 participants who self-identified as Pacific Islander and were a junior, senior, or recent graduate in a STEM major at a 4-year institution. During data collection, I gathered information on my participants' identity, precollege experiences, college experiences as a STEM major, and cultural experiences. Understanding who my participants were, how they were raised, how they prepared for college, and what their college experiences had been, provided insight on how they were navigating in STEM through wayfinding.

Based on my experiences as a PI in STEM and the results of a recent pilot study that I conducted, clear evidence supports that PI children have "thick contexts" (Vélez-Ibáñez \& Greenberg, 1992) because they were raised by their parents, extended family members, and the community. PIs are not raised to be individualistic or selfish but rather to connect with and support one another within the family and the community ( Ka'ili, 2008). PIs may not have the social and cultural capital associated with the dominant culture, that of being White, or possessing upward class mobility and education access (Bourdieu \& Passeron, 1977), but PIs possess values, knowledge, skills, abilities, and resources gained from their family and community that have enabled them to navigate their way to college and in STEM.

The goal of this study is to understand how PIs are navigating in STEM through the examination of the identity, upbringing, and cultural knowledge of PIs; the college trajectories of PIs with STEM majors; and the precollege and college experiences of PIs in STEM.

\section{Significance of the Study}

This study has implications for policy, practice, and theory. In this section, I aim to show how policy must disaggregate AAPI data to understand how PIs are being underserved; to increase college and university awareness of and support for PIs; to inform institutions so that 
they acknowledge and validate PI values and knowledge in the classroom and improve teaching practice through culturally relevant professional development; to support initiatives for PI studies and offer PI ethnic courses; and, last, to create or build on theories that acknowledge and address the impact of colonialism and racism on PIs and apply the asset of their cultural knowledge to overcoming barriers and challenges.

Most PIs are the first in their family to attend college, come from a low socioeconomic background, and are recent immigrants (Teranishi, 2012). Navigating college as a marginalized student of color can be intimidating, especially if there is no one in the family to ask about how to enroll in classes or how to apply for financial aid. This lack of guidance from family is evidenced by the low college degree attainment of PIs (Teranishi \& Kim, 2017). There is little to no research on PIs in STEM or in higher education (Museus \& Kiang, 2009; Teranishi \& Kim, 2017). Based on data from the NCES (2020), an overrepresentation of Asians in STEM exists, but the same is not true for Pacific Islanders. This disparity indicates that inequities are overlooked within a group as large and diverse as AAPIs and that data must be disaggregated to expose which groups need support. Growing the body of research on PIs is important for understanding the challenges and barriers they experience, and the assets PIs bring to college. From this research, we can create policies that inform 2- and 4-year institutions on how to better support PIs.

\section{Background}

The terms "Native Hawaiian and Pacific Islanders (NHPIs)," "Asian American and Pacific Islanders (AAPIs)," "Pasifika peoples," and "Moanans" are used interchangeably to identify Pacific Islanders (Hau'ofa, 1994), even though the requirement to separate "Asian" and "Native Hawaiian or other Pacific Islander" by the Office of Management and Budget occurred 
over two decades ago (Teranishi et al., 2019). Pasifika is commonly used by the Ministry of Education in New Zealand to identify PIs and is widely used all over the Pacific, including Fiji, Samoa, and Tonga (Airini et al., 2010). Moanans refers to the peoples of the Moana, or Pacific Ocean, and is commonly used by Pasifika scholars from Oceania (Hau'ofa, 1994). NHPIs are generally made up of over 20 ethnic groups (Saelua et al., 2016), including Fijians, Marshallese, and Maoris (Indigenous People of Aotearoa, or New Zealand), who were classified into three groups: “Melanesia ('black islands'), Micronesia ('tiny islands'), and Polynesia ('many islands')" (Hafoka et al., 2020, p. 70) by European and American colonizers (Hafoka et al., 2020; Hau'ofa, 1994). In Table 1, NHPI ethnic groups are categorized under their colonized group names, but for my research study, NHPI and PI will be used interchangeably.

\section{Table 1}

Native Hawaiian and Pacific Islander Ethnic Groups

\begin{tabular}{lll}
\hline \multicolumn{1}{c}{ Melanesian } & \multicolumn{1}{c}{ Micronesian } & \multicolumn{1}{c}{ Polynesian } \\
\hline Fijian & Carolinian & Cook Islander \\
New Caledonian & Chamorro Islander & Native Hawaiian \\
New Guinean & Guamanian & Kapingamarangan \\
Papuan & Kiribatese & Maori \\
Solomon Islander & Kosraean & Niuean \\
Vanuatuan & Nauruan & Samoan \\
& Marshallese & Tahitian \\
& Palauan & Tokelauan \\
& Pohnpeian & Tongan \\
\hline
\end{tabular}


Note: Adapted and modified from the United States Census Bureau

https://www.census.gov/newsroom/facts-for-features/2014/cb14-ff13.html. In the public domain.

In Figure 2, I chose to show a map of the Pasifika Region (Pacific-Media.org, n.d.) or Pacific Islands with their colonized names (in parentheses) and indigenous names to respect and acknowledge the ancestors who explored and made the Moana (Pacific) their home.

\section{Figure 2}

Map of the Pasifika Region

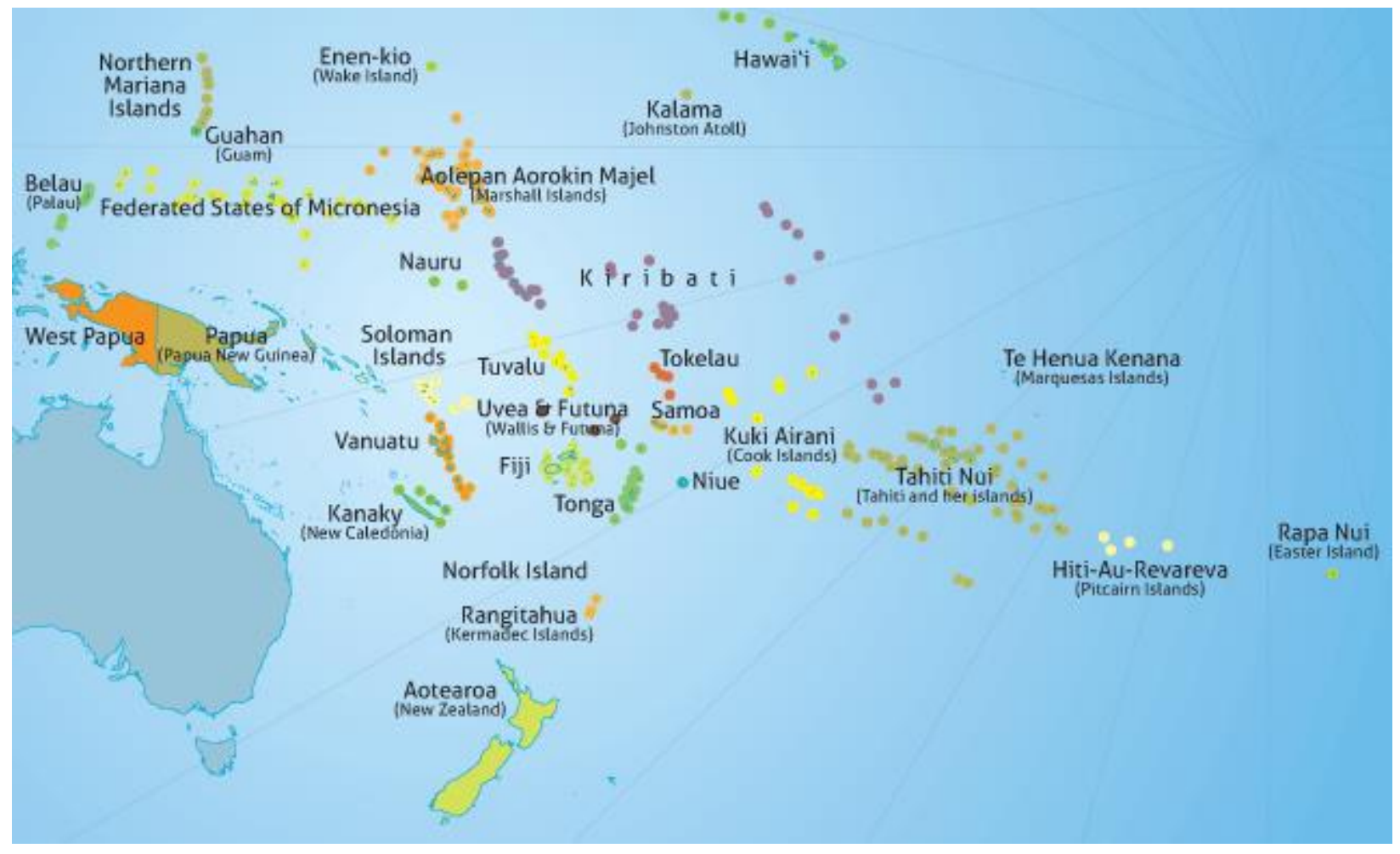

Note: A map of the Pasifika Region or Pacific Islands with their indigenous names (https://www.pinterest.com/pin/15833036167669938/). In the public domain. 
The Pacific Islands have a shared history of navigation, trade, war, and intermarriages between islands, to which many PIs can trace their lineage (Hau'ofa, 1994). In fact, most PIs acknowledge one another in public with a simple greeting, smile, or conversation. I have engaged in several interactions with other PIs and have been able to find some connection even when we had just met. It is part of our cultural DNA as PIs, who have close ties to their family, community, and ancestors, and where cultural knowledge is retained and integral to our identity through practice and representation. For example, during Tongan funerals, engagement between the elders and the younger generation is purposeful in that cultural knowledge is shared and performed to preserve the past in celebrating the present. Pasifika scholar Thaman (1997) stated: Wherever Pacific Islanders live, be it in New Zealand, Australia, U.K. or U.S.A., there exist Pacific cultures with which we, our parents or grandparents identify, be they Samoan, Maori, Tongan, Fijian, I-Kiribati, Ni-Vanuatu or whatever. As Pacific Islanders, we look for, and often engage in, a shared discourse. ... Pacific culture ... is something that is lived and continually demonstrated as a matter of behaviour and performance. (p. 123)

Similar to the funds of knowledge of Mexican families and communities along the U.S.Mexico border (Moll et al., 1992) and drawn upon by Latinx college students (Rios-Aguilar \& Kiyama, 2012), PIs have accumulated funds of knowledge unique to PI culture and experiences. PI knowledge has been shared and taught to benefit the family, the community, and nation, which is contrary to the individualistic and competitive culture in the U.S. classroom, which is often taught, modeled, and emphasized. Ladson-Billings (1995) uses Au's (1980) research about incorporating Hawaiian culture, such as talk-story to teach Hawaiian children, to support her theory of culturally relevant pedagogy to help teachers teach students of color. If this practice of 
acknowledging and valuing marginalized cultures in the classroom were carried into postsecondary education, student engagement and learning would be positively impacted.

\section{Theoretical Rationale}

This study will focus on PIs who, despite the challenges, have successfully navigated STEM through wayfinding, like their ancestors. "Research on Pacific Islanders in higher education should not only create new knowledge, but also empower PI communities to create praxis from this knowledge, thus empowering them to create a future of their own making" (Kukahiko, 2017, p. 22). The educational experiences of PIs are unique because of the strong connection between PIs and their ancestral past, family, and culture, which to date has not been considered in creating changes in policy or increasing support for PIs in postsecondary education. This qualitative research will highlight PI experience through the counternarratives of their educational trajectories in STEM and expand the research regarding PIs to include assetbased frameworks to validate the positive impact of PI cultural knowledge and identity.

\section{Community Cultural Wealth}

Yosso's (2005) theory of community cultural wealth examines funds of knowledge through a critical race theory (CRT) lens. Community cultural wealth highlights the culture of communities of color to explain how underrepresented students are navigating and persisting in spaces usually reserved to those with privilege, such as those in institutions of higher education. The lived experiences of underrepresented students overcoming challenges and barriers in education share one or more of the capitals of community cultural wealth: aspirational, familial, linguistic, navigational, resistant, and social.

\section{Tauhi Vā}


The concept of space is important in the culture of Pacific Islanders, because as a collective culture, space is where learning takes place and where relationships are formed and maintained. $V \bar{a}$, the Moanan notion of space, is the "space between people or things" (Ka'ili, 2005, p. 89). Vā is that space where connections and relationships provide a sense of community and unity (Mila-Schaaf, 2006). Tamaira (2009) elaborated further:

The space between is a prevalent metaphor in the Pacific, including within its scope indigenous concepts such as vā (in Samoan and Tongan culture) and wā (in Māori and Hawaiian culture). It has been referred to as an intermediary site-a liminal zone marked not only by tension and transformation but also by confluences and connections. (p. 1) In Tongan, tauhi means "to take care of and nurture." Therefore, tauhi vā means "to take care of and nurture the space between people or things to maintain a harmonious relationship." In communal and collective cultures that value kinship, unity, and social connections, such as Moanan culture, tauhi vā is the strengthening of those relationships through reciprocity (Ka'ili, 2005). Thaman (2008) stated:

Và requires constant protection, and this is reflected in the notion of tauhi vaha'a (to look after or protect the spaces between two or more persons or groups who are related to each other in some way). Protecting vā is seen as desirable to maintain harmonious relations and minimizing conflicts among those involved. (p. 179)

Tauhi vā is extended to include friends and mentors, such as when fixing a roof for a friend or mentoring younger siblings to prepare them for college. Tauhi vā and reciprocity work together to build strong relationships and community. My mom was instrumental in bringing her younger siblings to America and, today, my aunts and uncles have encouraged and supported me in my doctoral studies. In return, I hope to help their children and grandchildren get into college. 
Tauhi vā is how PIs have been able to move from their countries and thrive. And tauhi vā is how PI students are navigating STEM today.

\section{Positionality}

As a first generation Tongan woman, my parents exemplified tauhi vā, which was then passed down to me. When someone in the community celebrated a wedding, held a church event, or had a funeral, my parents showed up to these events with gifts, desserts to feed the congregation, and monetary gifts to help with funeral expenses. During college, the family and community members that my parents had tauhi vā with would slip me money to buy groceries and pay for books and encourage me to finish college. Although many in my family and community did not complete college, their tauhi vā toward me inspired me to push through the unknown challenges as a first-generation college student and as the only PI in my STEM major. When I graduated, I moved back to Oakland to mentor, tutor, and encourage PIs in high school to go to college, which is tauhi vā. I was reciprocating what was done for me to protect and add knowledge to the vā in my community. Conducting this research is another form of tauhi vā to my PI community to add to the research and highlight how PIs' ways of knowing and culture are helping them to access, navigate, and succeed in STEM.

I hypothesize that PIs have inherited the wayfinding skills of their ancestors and have learned experiences of tauhi vā from their parents. PIs have acquired capitals through the cultural and community wealth from their family and community and the navigating skills of their ancestors, grandparents, and parents who migrated to the United States. PIs use these capitals to navigate the education system in attaining a STEM degree.

\section{Research Questions}


Through this qualitative research, I seek to understand the nuanced experiences of Pacific Islanders persisting and navigating STEM through the strength-based lens of Yosso's (2005) community cultural wealth and tauhi vā. The research questions guiding this study follow:

1. How do community cultural wealth and tauhi vā influence the navigation of Pacific Islanders in STEM?

2. How does tauhi vā create vā specific to Pacific Islanders to wayfind STEM and develop community cultural wealth?

\section{Summary}

The disaggregation of AAPI data to analyze PIs separate from Asians has revealed the underrepresentation of PIs in STEM bachelor's degree attainment. PIs are often first-generation college students having a background of low socioeconomic status, with high dropout rates and low college completion rates. As recent immigrants, PIs are relational people with close ties to their culture and community, who are likely to conflict with the individualistic and competitive culture of STEM fields. PIs are likely to encounter barriers and challenges in STEM, as do other underrepresented groups, such as Blacks, Latinxs, Native Americans/Alaskan Natives, and women. With the focus of this study on the successful navigation of PIs in STEM through an asset-based framework, community cultural wealth, and the PI cultural value of tauhi vā, I aim to highlight the nuances and strengths of PIs in STEM. 


\section{Chapter 2: Review of the Literature}

\section{Introduction}

Earning a degree in STEM has been achievable for some but has eluded many others, specifically students from marginalized populations. Students of color are more likely to be less prepared for college because they are first-generation college students, have low socioeconomic status, and attend low-performing K-12 schools (Morgan et al., 2016). Even with institutionalized STEM initiatives geared toward marginalized populations, such as STEM “pipelines" and STEM academic preparation programs for precollege, community college, and university levels, STEM degree attainment by students of color and women has not significantly increased (Metcalf, 2014). In fact, marginalized students who major in STEM experience microaggressions and stereotype threat from peers, staff, faculty, and institutions, which negatively impacts students' motivation and ability to do well (Bonous-Hammarth, 2000a; Spencer et al., 1999; Steele \& Aronson, 1995). The underrepresentation of students of color in STEM majors and STEM degree attainment is due to many factors, including the academic culture of STEM that mirrors the dominant White male upbringing and conflicts with the warm, rich, and community-like culture of marginalized populations (Carter et al., 2019). Further, STEM associates successful scientists with males who are White, Asian, or Asian American, which may explain the bias that underrepresented students of color and women often experience in STEM (Carter et al., 2019).

The low STEM degree attainment of PIs has recently been made visible through the disaggregation of AAPI data (NCES, 2019). PIs have the same negative experiences and challenges as other students of color in STEM having a low socioeconomic status, having experienced a poor precollege experience, and being the first in their family to go to college (Ah 
Sam \& Robinson, 1998; Allaire, 2017; Benham, 2006; Teranishi et al., 2009; Teranishi et al., 2019). As recent immigrants, PIs have endured a history of colonialism in the Pacific, which has continued as a form of racism in how PIs are experiencing and navigating higher education (Kukahiko, 2017). Pacific Islander culture and history is important in understanding how PIs are approaching obstacles in higher education, which I will explore in this study. The focus of this study is on the navigation of PIs in STEM specifically, therefore factors that promote persistence in STEM are given more importance for this underrepresented group.

In the following section, I will review literature regarding the navigation of underrepresented STEM students and their racialized experiences, which include the leaky STEM pipeline, chilly STEM culture, microaggressions, and stereotype threat. To establish context specific to PIs, I will present a background of PIs and their experiences in higher education and STEM. Students of color in higher education can have positive experiences with means of support and access to safe places, such as academic or social counterspaces, where students feel comfortable to vent and share. Last, I will review the literature that illustrates how underrepresented minoritized populations are navigating, persisting, and succeeding in STEM and STEM programs.

\section{Literature Related to Navigation in STEM}

\section{Navigation in STEM}

Navigation is the mobility of traveling a planned path or following a route that others have used. Navigation in STEM can be a high school student asking a college-educated parent how to apply for college, study, find research opportunities with a professor, or network with graduate students for advice about classes or graduate school. Navigation is figuring out what works and what does not work. Navigation is transformative; it is about a person learning from 
others and from their own experiences, then choosing to follow a path used by others or to create their own path (Page-Reeves et al., 2019). With either choice, navigation requires persistence, a quality that researchers have studied to explore how students are succeeding in STEM.

Research has shown that persistence in STEM is positively impacted by strong precollege experiences, good STEM entry course grades, and research opportunities or hands-on experimenting with faculty. Examples of precollege experiences that predict high persistence in STEM include attending a high school with strong math and science programs, taking Advance Placement (AP) courses, scoring highly on AP and Scholastic Aptitude Test (SAT) exams, and achieving a high grade point average (GPA) (Chang et al., 2011; Ehrenberg, 2010; Shaw \& Barbuti, 2010). Taking rigorous science and math courses in high school can be advantageous, especially when STEM entry courses are used to weed out or "sort" students, a process that often serves as a barrier to students of color who may not have the precollege experiences or access to resources, such as AP courses in high school, to prepare them for the high expectations in college (Bonous-Hammarth, 2000; Solórzano \& Ornelas, 2002). Good high schools where teachers are invested in teaching students college-level biology and guidance counselors are committed to advising students on how to get into top universities are typically associated with socioeconomic status and parent's background (Ross et al., 2012). Students who have college-educated parents and attend private schools or schools in neighborhoods of high socioeconomic status have a greater advantage as a college STEM major than first-generation students from families with low socioeconomic status.

Most research on navigating STEM has been associated with students of color and women. Factors affecting the navigation of underrepresented students in STEM include having supportive parents, having peers or a cohort to network with, and navigating with academic 
advisors and mentors as guides (Allaire, 2017; Charleston et al., 2014; Jones, 2019; Ong et al., 2018).

For underrepresented students, navigating STEM is about making personal sacrifices and creating relationships and spaces of encouragement and belonging. For example, Black women pursuing degrees in computing science who felt isolated and subordinate to their White colleagues made sacrifices to remain disciplined and focused because the benefits associated within their STEM field would afford them an idyllic lifestyle with preferential options (Charleston et al., 2014). The sacrifices that Black women made to succeed included working late hours, which impacted their social life and relationships with loved ones (Charleston et al., 2014). In Allaire's (2017) study, all the Native Hawaiians were first-generation college students who were able to find a sense of belonging in their Native Hawaiian STEM cohort, which provided a space where they were able to network and share their frustrations and resources to navigate STEM.

\section{Underrepresented Students in STEM}

Asians are overrepresented in STEM, but other students of color and women are still underrepresented (Mau, 2016; NCES, 2020). Although women and students of color (with the exception of Asians) are less likely to declare, persist, or complete a STEM degree compared with Asians and Whites, they are persisting and attaining degrees in STEM nonetheless (Mau, 2016). Underrepresented students are more likely to persist in their first year in STEM if they are younger and possess precollege experiences, such as a high GPA and high SAT math or ACT scores (Chang et al., 2014; Crisp et al., 2009; Mau, 2016). Underrepresented students who enroll in gatekeeper introductory STEM courses during their first year, have a high first-semester GPA, take on extra units, and attend a minority-serving institution (MSI) are more likely to graduate 
with a degree in STEM (Crisp et al., 2009; Flower, 2016; Mau, 2016; Palmer et al., 2012; Perna et al., 2010).

MSIs play a critical role in diversifying STEM. Historically Black colleges and universities graduate more underrepresented students in STEM, and Hispanic-serving institutions (HSIs) serve as a main pathway to STEM for Latinx, underrepresented, and racially minoritized students (Flower, 2016; Herrera \& Rodriguez-Operana, 2020). Interactions with a faculty member, advisor, or STEM professional of the same gender or ethnicity positively impacts underrepresented students and influences them to major in STEM (Kricorian et al., 2020). Twoyear colleges are the entry point for college for most underrepresented students who major in STEM. Chang et al. (2014) found that institutions need to do more in providing interventions that "have more positive long-term effects when they are reinforced with activities in college that ensure student success (e.g., bridge programs, supplemental instruction and tutoring, and metacognitive study strategies) and assist students through introductory coursework" (p. 568).

NCES data revealed that a higher percentage of Asian and White students had parents with a bachelor's degree than Black, Latinx, NHPI, and American Indian/Alaskan Native students (Ross et al., 2012). Evidently, there is some correlation between STEM degree attainment, persistence in STEM, and parents' education that indicates why students of colors are underrepresented and racial disparities are multigenerational.

\section{Leaky STEM Pipeline}

Marginalized populations are seen as "untapped resources” (Metcalf, 2010, "Pipeline Predictions and Supply-Side Focus" section) that need to be recruited and retained in STEM. The STEM pipeline model was designed by engineers and the National Research Council's Committee on the Education and Utilization of the Engineer to increase the number of engineers 
and scientists to maintain the competitive edge of the United States with the rest of the world (Metcalf, 2014). The model included "linear steps through various educational stages required to become a scientist or engineer" (Metcalf, 2014, p. 78). This ideal model applies to and benefits students having the perfect environment and support system to follow every step without any disruption. Conversely, students from marginalized populations historically have lower socioeconomic status, attend underfunded schools with fewer resources resulting in a lower quality of education (Morgan et al., 2016), and may not be "flowing along the prescribed sequence" (Metcalf, 2014, p. 78).

Students of color tend to experience "leaks," because the pipeline from high school to college to a career in STEM is not linear (Blickenstaff, 2005; Chang et al., 2011; Metcalf, 2010, 2014). The leaks can be caused by low SAT scores, lack of financial aid, or academic probation, which can interrupt flow and create obstacles (Blickenstaff, 2005; Chang et al., 2011; Metcalf, 2010, 2014). The pipeline model does not take into account that the leaks are systemic and may benefit only a few students. Research has found that the STEM pipeline fails to understand why students are leaving STEM or to recognize alternative paths that students are taking to earn a degree in STEM (Cannady et al., 2014). The pipeline model focuses on producing engineers and scientists and hardly addresses the barriers that exist at the institutional level and in the STEM fields themselves.

\section{Literature Related to STEM Culture}

\section{Chilly STEM Climate}

STEM has not included or been welcoming to women, students of color, and minoritized students. Traditionally, White males have been the majority demographic associated with STEM

(Carter et al., 2019; Ong et al., 2011; Riegle-Crumb \& King, 2010). STEM has been described as 
competitive and meritocratic, qualities that may be contrary to cultures that work together to benefit the community. Specifically, African American, American Indian, and Latinx students tend to leave STEM because of the "chilly academic climate, which is usually in conflict between values within their major and the respective disciplines of their peers" (Cole \& Espinoza, 2008, p. 287). Students of color in STEM have difficulty finding peers who look like them, who share the same values, and can relate to them (Bonous-Hammarth, 2000a).

Research has shown that institutions that are predominately White are characterized as "chilly, alienating, unsupportive, and perpetuators of racial microaggressions" (Palmer et al., 2012). For underrepresented students of color, campus climate and negative racial experiences with peers, staff, and faculty negatively affects academic and social experiences in college and decreases persistence to earn a degree in STEM (Cabrera et al., 1999; Hurtado et al., 1996). Chen (2013) has added that women and underrepresented students are more likely to experience isolation in STEM, inadequate advising and support from their institutions, and discrimination in the STEM workforce because of their gender, race, or ethnicity.

Clearly, multiple factors have enabled the underrepresentation of students of color and women in STEM. With the population of underrepresented students expected to increase in the next decades, institutions have the opportunity to proactively address the negative racial and gender experiences that exist in STEM today to prepare for the future.

\section{Microaggressions}

On college campuses, marginalized students experience microaggressions, which research has suggested impacts their academic and social experiences and degree attainment (Chang et al., 2011; Sue et al., 2007). Microaggressions are "subtle insults (verbal, nonverbal, and/or visual) directed toward people of color, often automatically or unconsciously" (Solórzano 
et al., 2000, p. 60). Pérez Huber and Solóranzo (2015) have aimed attention at racial microaggressions in critical research to identify racism that students of color experience in and outside of the classroom, which includes feeling singled out, insecure, and frustrated with professors and peers with having to prove they are good enough to be in college.

Microaggressions occur through everyday interactions that send messages of superiority through belittling and demeaning language and behavior that have caused students of color to change majors, drop classes, or leave to attend a different school (Solórzano et al., 2000). Sue et al. (2007) identified three forms of microaggressions: microassault, microinsult, and microinvalidation. A microassault is a verbal or nonverbal racial attack, which is meant to be hurtful through name-calling or ignoring. A microinsult is a verbal attack that is meant to humiliate a person because of their racial identity. A microinvalidation denies and refuses to validate the negative experiences of people of color. Microaggressions are a form of racism used to generate fear and assert dominance (Sue et al., 2007). A student receiving consistent reminders of not belonging or not being good enough to be in college or in STEM can ultimately lead to stereotype threat for that student (Spencer et al., 1999, 2016; Steele \& Aronson, 1995).

\section{Stereotype Threat}

Marginalized populations, including students of color and women, are susceptible to stereotype threat, where an individual is judged based on societal stereotyping about an individual's group and gives into the stereotype (Spencer et al., 1999; Steele \& Aronson, 1995). The danger of stereotype threat is realized in individuals who live up to the stereotype and validate that majority populations intend them to be inferior. For example, Black students performed lower on a test than White students, even though the two groups received the same preparation (Steele \& Aronson, 1995). According to Solóranzo et al. (2000), interviews with 
African American students who experienced constant negative racial exchanges with faculty and students revealed that they began to doubt themselves and their abilities.

Race and gender disparities in STEM may be partly due to stereotype threat (Spencer et al., 2016). Underrepresented students in STEM who have had negative racial experiences or have experienced microaggressions are prone to stereotype threat and have actually left STEM because they believed they did not belong (Bonous-Hammarth, 2000; Spencer et al., 1999, 2016;

Steele \& Aronson, 1995). Further, Bonous-Hammarth's (2000) research on the factors that impact the retainment and attrition of science, mathematics, and engineering (SME) majors in a specific group of students found that African Americans, Native Americans, and Latinx students were expected to be unsuccessful and consequently left SME.

\section{Literature Related to Pacific Islanders}

\section{Pacific Islanders}

Pacific Islanders (PIs) have been categorized under the Asian American and Pacific Islander (AAPI) group, which represents over 48 different ethnic groups with varied cultures and lived experiences. The lack of research on AAPIs and PIs is problematic because Asians are earning more degrees in STEM than the White population, which supports the model minority myth (MMM) that AAPIs are doing well and do not need support (Teranishi \& Kim, 2017). As a minoritized group within a larger overrepresented group, PIs are not as successful as Asians because PIs have high college enrollment and low college degree attainment (Teranishi et al., 2019; Teranishi, 2012). Through a CRT lens (Solórzano, 1998), use of the MMM stereotype is a social justice issue because the stereotype could help explain why institutions fail to recognize or support PIs in higher education and particularly in STEM. 
Most research on retention in students of color in STEM is based on the United States' need to innovate, diversify, and increase workers in the STEM workforce to keep up with the global economy (Amelink et al., 2015; Bahr et al., 2017; Palmer, Maramba, \& Dancy, 2011; Wang, 2015). This need is significant, as it is projected that underrepresented populations will become the majority by 2050 in the United States (Teranishi, 2012). In the past and even now, the responsibility of earning a degree in STEM has been on the student, with little to no support from the institution. Precollege experiences and choice of a major in STEM as first-year students are major factors for persistence in STEM, but studies have shown that institutions must do more to support and retain students in STEM, specifically first-generation underrepresented students of color (Bonous-Hammarth, 2000c; Cole \& Espinoza, 2008; Hurtado et al., 2007; Palmer, Maramba, et al., 2011b).

PIs are persisting in STEM, but there is little to no published or peer-reviewed research on PIs in higher education because it is usually found in unpublished master's theses and doctoral dissertations (Allaire, 2017; Hall, 2015; Uehara et al., 2018). PIs are placed under the group NHPI, which is made up of over 20 cultural groups, including Native Hawaiians, Samoans, Marshallese, Chuuk, and Fijians who "share similar cultural features and practices. Because many Pacific Islander communities live within a clan system, gender roles and hierarchy are embedded and respected in daily interactions" (Uehara et al., 2018, p. 183).

NHPIs are often referred to as a collective culture because of the required participation and contribution to events such as weddings, funerals, or community celebrations. Reciprocity is integral in maintaining harmony and taking care of one another (Ka'ili, 2008). There is a strong sense of obligation to give back when one has found success, such as the opportunity to attend college (Uehara et al., 2018). The community will support college-bound individuals with the 
intent that they will return to help others succeed. To return home with no degree can bring shame to the family, so the aspiration to persist is great.

Most NHPIs are the first in their family to attend college (Allaire, 2017) and are supported by their parents and the community, who have no idea how to navigate higher education. NHPIs who are raised in a close-knit family and community have accumulated funds of knowledge (Rios-Aguilar \& Kiyama, 2012). PI culture among the different groups is overwhelmingly similar because it has been practiced and performed over millennia, which translates into a body of ways of learning and knowing (Vakalahi et al., 2008). Vakalahi et al. (2007) examined the model called Ho 'okele, which means "to navigate" in the Hawaiian language, to explain how grandparents have the responsibility to uphold cultural traditions and customs to preserve the connection between the younger generation and the older generations. As the Ho'okele, or navigators, grandparents play a key role in passing on their knowledge to the next generation of Ho'okele. It comes as no surprise that in Uehara et al.'s (2018) research, PI students demonstrated respect of others, especially elders; viewed their education as a responsibility to their family and community to graduate; felt obligated to set an example for their younger siblings and family members to succeed; and were supported by their family and community.

At the University of Hawaii (UH), NHPIs are underrepresented (Ah Sam \& Robinson, 1998; Cintina \& Kana'iaupuni, 2019; Uehara et al., 2018). Ah Sam and Robinson (1998) listed the barriers that NHPIs face at UH:

- lack of PI-focused programs that provide and coordinate social, academic, or financial advice, aid, and support to PI students;

- inadequate academic advising and counseling due to cultural barriers or lack of knowledge; 
- lack of a specific orientation program to address their unique concerns and issues and to prepare them for what to expect in college;

- paucity of PIs in leadership or professional staff positions in the UH system who could serve as mentors to new or continuing students;

- inadequate college preparation and little encouragement to pursue higher education while in primary and secondary school;

- frequent prioritization of cultural, kinship, and family obligations before higher education;

- lack of communication, information dissemination, and outreach relating to educational opportunities and programs; and

- financial constraints (1998, p. 44).

Allaire's (2017) research on Native Hawaiians in STEM showed how participants who were first-generation college students felt unprepared for college and how their families did not have the collegial experiences to help them navigate the registration or financial aid process or cope with the emotional and mental challenges of college. Despite being tokenized as Hawaiians to be poster children for diversity in STEM, these students found a support system that allowed them to persist and achieve their goals. Programs that target Native Hawaiians for STEM degrees were created to help them overcome barriers in STEM and appreciate their cultural identity. The cohorts were especially helpful because the students had much in common culturally and ethnically, which eliminated the isolation often experienced in STEM. In addition, their parents continued to support them unconditionally. Their Hawaiian culture and values played a vital role in these students' persistence.

The peoples of the Pacific welcomed strangers onto their lands, only to be inundated with the strangers' greed, diseases, and lack of acknowledgement or respect for the land, culture, and 
knowledge. By the late 1800s and into the 1900s, Native Hawaiians were not allowed to speak or write in their native tongue, but they retained the traditional oral history of their kupunas (elders, ancestors) by passing their 'ike (knowledge) to the next generation (Ho'omanawanui, 2004). "This 'ike inspires us to kū' $\bar{e}$, to resist, and to stand in opposition against colonization, and against foreign domination, suppression, and appropriation of who we are and what our culture is and means to us" (Ho'omanawanui, 2004, pp. 88-89). Navigating the Pacific Ocean and exploring and cultivating new islands was no easy task, but NHPIs have a saying that goes, "Look forward to drinking the bitter saltwater." Like many underrepresented students in higher education, PIs are persisting because of the cultural knowledge that was passed down to them and the responsibility they hold to give back.

\section{Pacific Islander Cultural Racism Theory}

As a marginalized group, PIs have had similar negative racial experiences to Latinxs and African Americans (Cole \& Espinoza, 2008; Spencer et al., 1999; Steele \& Aronson, 1995). The Pacific Islander cultural racism theory (PI-CRiT) was introduced by Kukahiko (2017) as a framework that "1) connects the history of U.S. colonialism in the Pacific to the contemporary circumstances of PI communities, [and] 2) identifies forms of cultural racism that operate within institutions of higher education" (p. 21). To control the Pacific, the United States used methods on the Indigenous Peoples of the Pacific Islands comparable to those used on Native Americans: spreading diseases, stealing their land, and imposing their educational system and capitalistic culture on a group of people that were culturally established centuries before the United States had become a country (Kukahiko, 2017).

Racism is built on and is a result of colonization (Smith, 2013), which is perpetuated in the educational system to eliminate Indigenous cultures through assimilation to the dominant 
culture and has encouraged Native resistance and dissimilation by living Indigenous cultures (Kukahiko, 2017). PI-CRiT, based on critical race theory (CRT), was developed after the Civil Rights Act of 1968 through critical legal studies to examine why the legal system continues to privilege Whites and oppress Blacks. Ladson-Billings and Tate (1995) then applied CRT to education, which focuses on the Black and White binary. However, PI-CRiT focuses on the experiences of PIs. It is disinformation that a college education is an equal opportunity. Cultural racism continues to exist within institutions of higher education where PIs often navigate obstacles of negative racial experiences, exploitation, and deficit.

\section{Literature on the Persistence of Underrepresented Students in STEM}

\section{Persistence in STEM}

With the focus of this study on the successful navigation of PIs in STEM, it is important to understand how underrepresented students are persisting in STEM. The factors that promote persistence and retention in STEM for students of color are supportive educational environments; role models of color; knowledge and lesson sharing from advanced students, mentors, and faculty of similar ethnic groups; summer precollege programs; and research experiences (Palmer, Maramba, \& Dancy, 2011). For example, the Pre-Freshman Academic Enrichment Program at the University of Maryland, College Park, observed an increase in retention and graduation rates of students of color who majored in STEM versus students who did not participate (Maton et al., 2000). Black students tend to fare better in STEM if the faculty is Black (Ehrenberg, 2010). For Latinx students in science, family support and faculty mentors are key to their success and high academic self-efficacy (Anaya \& Cole, 2001; Cole \& Espinoza, 2008; Torres \& Solberg, 2001).

Researchers have found that underrepresented students persisted in STEM if they were involved in STEM-related activities, clubs, or organizations, such as the National Society of 
Black Engineers (NSBE) and the Society of Women Engineers (SWE) (Chang et al., 2014;

Palmer, Maramba, \& Dancy, 2011). Being part of a supportive group provides opportunities for networking and social engagement. As meaningful relationships increase, confidence and motivation to succeed in STEM increase (Chang et al., 2014).

\section{Persistence Framework}

The persistence framework to retain STEM majors, especially underrepresented students, highlights three important interventions for success: opportunities for early research, active learning in the classroom, and learning communities (Graham et al., 2013). Undergraduate programs that target underrepresented students to diversify STEM and historically Black colleges and universities that have included the three interventions proposed in the persistence framework have higher retention and graduation rates in STEM (Graham et al., 2013). Small liberal colleges have a higher success rate of graduating underrepresented students in STEM because smaller class size, prioritized teaching, active student engagement, and positive learning environments are encouraged in the classroom and in laboratory experience (Museus, 2014). Most large institutions have a majority of White students and may offer little to no opportunity for research, small interactive classrooms, or programs that support underrepresented students in STEM.

\section{Counterspaces}

At predominately White institutions (PWIs), counterspaces have been created in STEM because of the unwelcoming, individualistic, and competitive culture that is associated with White male scientists (Ong et al., 2018). Finding support to overcome the stereotype threat brought on by constant microaggressions and negative racial expressions in and out of the classroom, African American students have formed academic and social counterspaces on and 
off campus (Solórzano et al., 2000). Counterspaces are safe spaces that allow students to learn in a supportive environment, where they can share their frustrations and seek validation from other students who have had similar experiences (Solórzano et al., 2000). Student organizations such as fraternities, sororities, and ethnic-specific peer and study groups are examples of spaces where underrepresented students have found and developed the necessary refuge, reassurance, and strength to persist.

Ong et al. (2018) found that women of color in STEM experienced isolation and microaggressions from peers, faculty, and the institution and sought out a supportive community by creating counterspaces. According to Ong et al. (2018), participants described various types of counterspaces that helped them to persist in STEM, which include "peer-to-peer relationships; mentoring relationships; national STEM diversity conferences; STEM and non-STEM campus student groups; and finally, STEM departments as counterspaces” (p. 219).

For first-generation Latinx students, Chicano studies is a space for students to interact with other Latinx students with similar cultural backgrounds who have felt isolated and out of place because their university lacked the diversity of their home communities (Nuñez, 2011). Similarly, the African American Student Network has been a counterspace for Black students at PWIs to help with the challenges of stereotype threat, microaggressions, and isolation that can lead to "race-related stress" (Grier-Reed, 2010, p. 183). Although counterspaces vary, they have all served the same purpose of creating a space for marginalized students on campus and in STEM who need to be supported, to vent out negative experiences, and to network with peers and faculty for validation that they belong.

\section{STEM Programs}


Campus-based intervention programs such as the Meyerhoff Scholars Program were initially created to increase representation of African Americans in science, mathematics, and engineering but now include underrepresented minoritized populations (Maton et al., 2000). The Meyerhoff Scholars Program offers opportunities for undergraduate research and mentoring from faculty and peers, which has created a sense of belonging and inclusion that goes beyond the classroom and is critical in the persistence of students of color in STEM.

Asian American and Native American Pacific Islander-serving institutions (AANAPISIs) are minority-serving institutions (MSIs) that are federally funded and created to increase access to college for low income and underserved Asian American Pacific Islanders (AAPI) students (Maramba, 2013). As a designated AANAPISI, the City College of San Francisco recognized that the degree attainment and transfer rates of Filipino and Pacific Islanders were much lower than other Asian American subgroups and White students (Maramba, 2013). To address these disparities, the community college used AANAPISI funding to create the STEM Achievement Project (ASAP) and the ASAP center, which included a space for studying, a computer lab, and counseling (Maramba, 2013). Thanks to outreach and recruitment, AAPI students who participated in ASAP had a transfer rate of $42 \%$ compared to the transfer rate of $15 \%-20 \%$ of nonparticipants (Maramba, 2013).

Institutions that are intentional in serving and supporting underrepresented students of color in STEM and changing the culture of STEM into a positive experience have contributed to an increase in STEM degree attainment and interest in pursuing graduate degrees (Carter et al., 2019). However, students of color, including Pacific Islanders, are greatly underrepresented in STEM degree programs and STEM degree attainment.

\section{Theoretical Framework}


I will be using Yosso's (2005) theory of community cultural wealth and tauhi vā (Ka'ili, 2008) to understand how the role of PI cultural knowledge is maintained and shared in their navigation in STEM.

\section{Community Cultural Wealth}

The United States has a long history of racism that is perpetuated in how underrepresented students are taught, advised, and researched, with the assumption that they lack the capital or skills to succeed in college. Cultural capital theory states that privileged groups, namely those who are White and middle-class, have access to opportunities, knowledge, and people to increase their social mobility (Bourdieu \& Passeron, 1977). Conversely, communities of color lack the cultural capital to improve their class status and are further stereotyped as culturally poor (Yosso, 2005). Bourdieu's theory on social and cultural capital was used to explain why the educational and social outcome of Whites has been higher than those of people of color, a concept often perpetuated in academia to maintain the hierarchy or status quo of Whites (Yosso, 2005).

Applying a critical lens means challenging deficit frameworks and theories that devalue the cultural knowledge and skills of communities of color, which is a form of racism. For example, Native American children forced to leave their families and homes to attend boarding schools to properly assimilate them to be more White by making them speak only English learned White history and behaviors (Brayboy, 2005). Deficit thinking assumes that the children of marginalized populations are doing poorly in school because they do not have the "normative" upbringing or knowledge of White families and that their parents do not value education or support their children, like White families do (Yosso, 2005). 
Often, Latinx students attended schools taught predominately by White teachers with different learning experiences and culture that may have been counterintuitive to Latinx children's culture, cultural knowledge, and ways of learning (Moll et al., 1992). For instance, when students of color did not look teachers in the eyes or speak up because they were taught to speak only when spoken to, White teachers assumed the students did not understand English and were not capable of learning. Or the teachers presumed that Latinx parents did not care about their children's education, when in fact the parents did care. According to the results of Kiyama's (2010) study, Mexican parents placed a high value on education and were able to support their children through personal and social networks. For example, parents would reach out to family members or someone in the community who had gone to college to learn about applying for college and financial aid (Kiyama, 2010).

Research on Latinx families (Moll et al., 1992; Olmedo, 1997; Vélez-Ibáñez \& Greenberg, 1992) showed how cultural knowledge and skills had been passed down from family and community members to their children as funds of knowledge (Gonzalez et al., 1995). A more recent study showed how Latinx students built their funds of knowledge from observing and learning from their parents and then applied these funds to a community-based engineering project (Mejia et al., 2014). 'By drawing from students' at-home experiences, bodies of knowledge, skills, and interests, engineering can be more culturally responsive for Latinx students" (Mejia et al., 2014, p. 18).

Community cultural wealth builds on funds of knowledge and identifies those resources of knowledge and skills that students bring into higher education (Yosso, 2005). Yosso uses critical race theory and funds of knowledge to challenge Bourdieu's (Bourdieu \& Passeron, 1977) cultural capital theory through the community cultural wealth framework to illustrate how 
communities of color are utilizing their cultural background, upbringing, and lived experiences to access and challenge an education system that was not made for them. Community cultural wealth consists of six capitals: aspirational, navigational, social, linguistic, familial, and resistant capital (Yosso, 2005).

Aspiration Capital. Aspirational capital refers to the dreams and hopes that can be oppressed by barriers set up by inequitable systems. For example, parents who were not able to get an education or finish school often want their children to have the opportunity to go to college. These parents may not have the experience of applying to college or registering for classes but do support their children in other ways (Auerbach, 2004; Pascarella et al., 2004).

Navigational Capital. Navigational capital is understanding how to move and persist beyond these barriers and systems. College can be intimidating for first-generation college students of color who have no one at home to ask for help. Students who are successful are very resourceful in asking peers or counselors for help, attending orientations, or joining a support program on campus to navigate their way through college.

Social Capital. Social capital is having a network of friends, family, colleagues, and community that provide support and resources. Chemistry students who need research experience for admittance to graduate school, for instance, may ask their friends and professors about research opportunities.

Linguistic Capital. Linguistic capital is knowing how to speak or communicate in more than one language. Students who speak a second language at home usually interpret for their parents and peers who speak the same native language and need help with English.

Familial Capital. Familial capital is the cultural knowledge passed down through the family. Familial capital also has to do with kinship and maintaining relationships within the 
family and community. For example, when a grandmother watches her grandchildren, she can speak Hawaiian, so they learn the language, teach them how to hula, or have them help while she cooks. A grandparent has the opportunity to pass down cultural knowledge, traditions, and skills to children and grandchildren. Capitals can overlap, such as in this example of both linguistic and familial capital.

Resistant Capital. Resistant capital is the skills and capability created from experiences that hinder one's access to opportunity or progression. Resistant capital can be transformative in that a person may use barriers as motivation to overcome them.

These capitals can be relational in that more than one can be acquired or used simultaneously and successively. For instance, a person may use linguistic capital to communicate aspirations of becoming a lawyer to advisors or professors in seeking out opportunities for an internship at a law firm. A mentor attorney at the law firm then may introduce the intern to a program that helps undergraduates get into law school. In this scenario, the person uses linguistic and aspirational capital to get an internship, which leads to acquiring social and navigational capital.

The privileged or dominant population monopolizes culture to disenfranchise and disempower communities of color. Community cultural wealth exposes the flaws in Bourdieu's cultural capital theory by focusing on the experiences of people of color and highlighting their rich history and contributions of knowledge. Yosso (2005) uses critical race theory to challenge Bourdieu's cultural capital theory through the community cultural wealth framework to illustrate how communities of color are utilizing their cultural background, upbringing, and lived experiences to access and challenge the education system.

\section{Pacific Islander Community Cultural Wealth}


The people of Oceania traveled often between Samoa, Tonga, and Fiji to visit family or attend events such as weddings (Hau'ofa, 1994). These voyages would take days or weeks, depending on the destination and sailing conditions. PIs did not become expert way finders overnight. It took years of experience to observe and read the stars, to steer or paddle with the wind and waves, and recognize signs of land. Navigational capital requires similar skills to traverse educational and social institutions (Yosso, 2005), especially for first-generation college students of color. This could be relevant for learning how to register for classes, apply for financial aid, or determine which classes to take.

Resistant capital refers to knowledge acquired through challenging the inequalities of an oppressive experience. For PIs, oppression came with the European and American colonists who imposed their own language, beliefs, and schooling on the established group. For instance, Hawaii was illegally annexed by the United States, but there is a surge to reclaim Hawaii's language, culture, and land. As a Native Hawaiian, Reyes (2018) stated,

I am the first on my father's side of the family ever to earn any college degree, let alone a doctorate. This latter experience perhaps of all has motivated me to enter the field of higher education so that I could play a role in empowering minoritized and especially, Indigenous people to access and harness higher education to meet their own needs and objectives. (p. 740)

This is an example of the resistant capital held by most PIs in higher education and the importance of passing down this knowledge to others, like our ancestors before us.

Counternarratives are critical in validating what students bring to the classroom and exposing how institutions are not doing enough to be inclusive of the culture, history, and knowledge of communities of color. Before the invasion and imposition of opportunistic foreign 
colonists, the people of Oceania were well advanced in seafaring, canoe building, fishing, land cultivation, and medicine. As recent immigrants to the United States, PIs utilized these same skills and knowledge from their ancestors to survive in a new country, which they passed on to their children. This exemplifies most that the capitals are defined as community cultural wealth, which PIs have used to navigate higher education, specifically PIs who major in STEM.

\section{Tauhi Vā}

Pacific Islanders are communal in that sharing of resources and nurturing kin-like relationships have been essential for survival and cultural identity. Ka'ili (2005) states, "For Tongans and other Moanans, nurturing ties between individuals and kainga (kin, extended family) generally involves reciprocal exchanges of economic and social goods” (p. 92). Tauhi vā, introduced by Ka'ili $(2005,2008)$, is one of the Tongan values common to all PIs. The word tauhi means "to take care of and protect," and $v \bar{a}$ is the "space that connects and relates people to one another" (Ka'ili, 2008, p. 26). Pacific scholars connect vā to tauhi vā to tauhi vaha'a, where $h a^{\prime} a$ are clans or cultural groups. These terms define the community principals that embody tauhi vā, which is to nurture and protect the human spaces and relationships between persons or groups who are related or in different cultural groups in society (Halapua, 2000; Ka'ili, 2008).

As recent immigrants, PIs use tauhi vā by networking with other PIs to secure a job and a place to live. PIs understand that whatever goods or services they receive must be reciprocated and paid forward to another PI. Attending life events, such as weddings and funerals, is an opportunity to nurture and protect those communal ties and maintain cultural traditions and knowledge. In my pilot study, there was evidence of tauhi vā shared by the participants, who felt it their responsibility to talk about their college experiences at high school conferences for PIs, mentor and tutor other PIs in college, and participate in my research to increase scholarship on 
PIs in STEM. As a PI, I have a responsibility to my participants and PI community to relay their stories in order to inform institutions on how to better serve PIs in STEM and to inform the research community that PIs have the skills and knowledge to major in STEM. I believe tauhi vā has the potential to impact STEM positively, transforming STEM from a chilly, individualistic, and competitive culture to a warm, sharing, and communal culture.

My theoretical framework is based on the community cultural wealth that PIs in STEM have experienced, learned, and attained, and then interpreted as one of the capitals: aspirational, familial, linguistic, navigational, resistant, and social. PIs in STEM are supporting one another through tauhi vā, which is then reciprocated to inform future PIs in STEM (see Figure 3).

\section{Figure 3}

\section{Theoretical Framework}

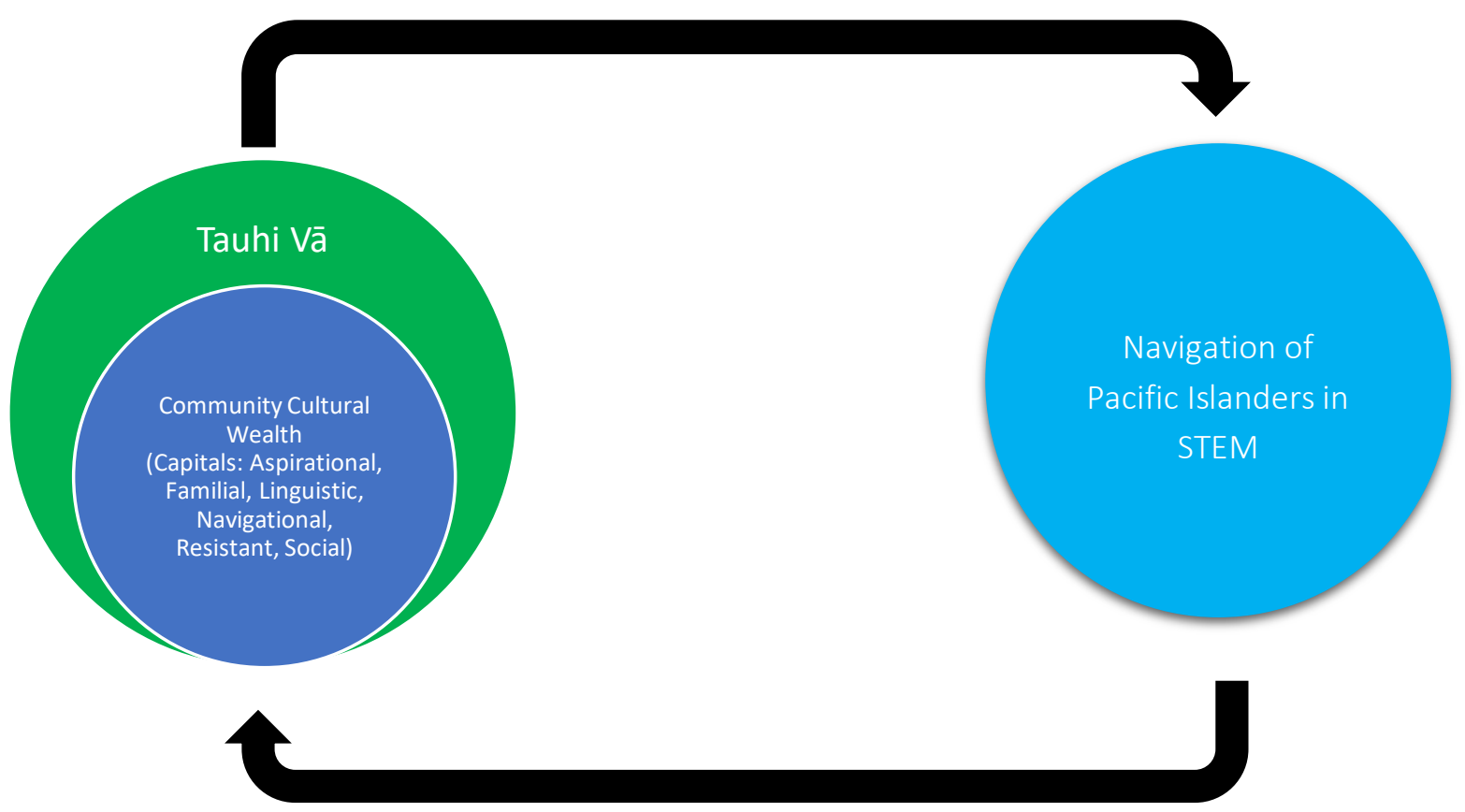


I hypothesize that PIs have inherited and transformed the wayfinding skills of their ancestors and learned experiences from their immigrant parents into capitals to navigate the education system in attaining a degree in STEM. PIs have acquired capitals through the cultural wealth from their families and community and the navigating skills of their ancestors, parents, and grandparents who migrated to the United States. PIs also acquire capitals in their precollege and collegiate experiences and use tauhi vā to persist and navigate STEM.

\section{Research Questions}

Using Yosso's (2005) theory on community cultural wealth, PIs are utilizing their acquired aspirational capital, linguistic capital, social capital, familial capital, resistant capital, navigational capital and tauhi vā, to navigate STEM. Two research questions guide this research study:

1. How do community cultural wealth and tauhi vā influence the navigation of Pacific Islanders in STEM?

2. How does tauhi vā create vā specific to Pacific Islanders to wayfind STEM and develop community cultural wealth?

\section{Summary}

Pacific Islanders are attaining degrees in an unwelcoming discipline at institutions that do little to transform the culture or support underrepresented students in STEM. With a dearth of research regarding PIs in STEM and higher education, the literature review included research on the barriers and challenges that those underrepresented in STEM are experiencing and have had to overcome to succeed in STEM. The STEM culture does not complement or align with PI cultural values and is a continuation of the negative impact of European and American colonizers of the Pacific, which is affecting PIs in higher education and STEM. Similar to many other 
communities of color, PIs bring a wealth of knowledge that has allowed them to thrive in the United States. Through this qualitative research, I seek to understand the nuanced experiences of Pacific Islanders navigating in STEM through the strength-based lens of community cultural wealth and tauhi vā. 


\section{Chapter 3: Methodology}

This chapter describes the qualitative research approach used to examine the experiences of Pacific Islanders who majored in STEM. The pilot study I conducted in March of 2019 showed that the experiences of my participants mirrored my own experience in STEM, which have informed the theoretical framework and methodology for my research. Drawing from an asset-based framework, the study validates the knowledge and experiences of a highly marginalized population in STEM. In this chapter, I discuss my positionality and relationship to the research. Second, I explain how I designed my research and the methodologies used. Third, I describe the participants in this study and how I analyzed the data. I end the chapter with a discussion on the limitations of this study, focusing on the importance of counternarratives as transformative resistance to validate PI experiences and culture as knowledge.

\section{Research Questions}

To examine the experiences of Pacific Islanders in STEM, this study addresses the following research questions:

1. How do community cultural wealth and tauhi vā influence the navigation of Pacific Islanders in STEM?

2. How does tauhi vā create vā specific to Pacific Islanders to wayfind STEM and develop community cultural wealth?

\section{Positionality}

During introductions following Pacific Islander protocol, it is a sign of respect to include your genealogy and homeland or village so that others can try to connect with you. This connection is important because it assures trustworthiness and responsibility to the community. It 
also affirms that my research was done to the best of my ability and held with great importance for the benefit of the larger community and future generations.

My name is Marlena Milika Vi Wolfgramm. My mother is Lisia Finau Vi, whose mother, Tohuia Mailau, is from Kolonga and whose father, Vitolio Vi, is from Afa and Eueiki. My father is Walter Phillip Wolfgramm, whose mother is Salote Fakatou from Feleme'a and whose father is Iohani Wolfgramm from Ha'alaufuli. I represent each family member and the villages they hail from.

The goal of both of my grandfathers was that their children and future posterity would live, get an education, and prosper in the United States. My mother would often remind me that Grandpa Vito wanted his grandchildren to go to college, which was ingrained in me as a young child. The only problem was that I did not know how to get into college, except to get good grades and take the SAT. In high school, I did exactly what my friends did and applied for college because my counselor, Mrs. Daskorolis, would not help me. She is the only faculty or staff member whose name I remember from high school because of how dismissive she was when I asked about college.

I did well in high school and my first two years in community college, but when I transferred to University of California, Santa Cruz, I found out how unprepared I was. Despite having classes with over 300 other students, managing in a competitive and unfriendly culture, dealing with discouraging advisors, and feeling completely alone, I graduated with a degree in STEM. I forgot that part of my life because it was quite traumatic, which I did not realize until I began collecting data for my professor's research.

As a research analyst for the Research and Equity Scholarship Institute on Student Trajectories in Education (RESISTE), I had the opportunity to work on the Educational Settings 
Yielding Science, Technology, Engineering, and Math Success (ED-SYSTEMS) Project (Research \& Equity Scholarship Institute, 2021), where I collected data and analyzed data by verifying and coding interview transcripts. Data collection for the project's study design included interviews, educational journey maps, and artifact elicitation from the participants. The demographic survey and the interview protocol that I used in my study were adapted from a larger study in the ED-SYSTEMS Project. My experience as a research analyst for RESISTE was helpful in designing the research for this study.

During the interview process for the ED-SYSTEMS Project (Research \& Equity Scholarship Institute, 2021), my eyes would tear up as participants, who were students of color and transfer students majoring in STEM, shared their stories. Their experiences were my experiences, and they validated what I had been through. I asked my professor if there was any research on PIs in STEM. She advised me to investigate, and I found nothing current or relevant. This was a monumental moment, because I knew then exactly the research topic for my doctorate and how I would contribute to academia. I knew I was where I was supposed to be, researching the experiences of PIs in STEM. I confirmed my research interest during my pilot study, in which I interviewed PIs who majored in STEM, and reinforced my responsibility as a PI to tell their stories. Findings from the results of my work will inform institutions and academia and, most importantly, prepare the next generation of PIs in STEM.

When Indigenous peoples become the researchers and not merely the researched, the activity of research is transformed. Questions are framed differently, priorities are ranked differently, problems are defined differently, and people participate on different terms. (Smith, 2013, p. 196)

\section{Research Design}


As a Pacific Islander and a Tongan woman of the diaspora, I conducted a qualitative research study using talanoa to address the research questions examining the experiences of PIs who have navigated STEM. Talanoa is similar to a narrative research study (Fa'avae et al., 2016) but belongs to the phenomenological research family (Vaioleti, 2006). The focus of this phenomenological study was to explore through a critical lens the phenomenon of how PIs are navigating STEM from the secondary to postsecondary educational level. As such, this research study examined and documented the influence of community cultural wealth and tauhi vā in navigating STEM. Because there is a dearth of research highlighting the voices of this particular participant population, a qualitative research study with a demographic survey, an educational journey map, a virtual artifact elicitation interview, and memo notes are my sources of data. I considered these qualitative approaches because I used them as a research analyst for RESISTE and for my pilot study, which focused on understanding the educational trajectories and experiences of underrepresented students in STEM (Research \& Equity Scholarship Institute, 2021).

\section{Phenomenological Study}

My research focuses on a phenomenon that is common among Black, Latinx, women, and other underrepresented and highly marginalized populations who navigate STEM (Beede et al., 2011; Bonous-Hammarth, 2000; Carter et al; 2019; Chang et al., 2011). The phenomenon is

often masked and hidden for Pacific Islanders, who have been grouped with Asian Americans as AAPI (Hafoka et al., 2020; Maramba, 2013; Museus et al., 2013; Palmer \& Maramba, 2015; Teranishi et al., 2009, 2019). Phenomenological research is an approach that focuses on how the "researcher describes the lived experiences of individuals about a phenomenon as described by participants" (Creswell \& Creswell, 2018, p. 13). The lived experiences of the participants are 
the data of phenomenological research, and the examples are described as "anecdotes, stories, narratives, or concrete accounts" (Manen, 2017, p. 814). As a phenomenological researcher, I intended to uncover the factors that impact the navigation of PIs in STEM and to examine the underrepresentation of PIs in STEM degree attainment (NCES, 2020) as participants reflected on and shared their journey during the interview.

\section{Talanoa}

Talanoa is a cultural practice of the Pacific, "a personal encounter where people story their issues, their realities, and aspirations. It allows for more mo'oni (pure, real, authentic) information to be available for Pacific research than data derived from other research methods" (Vaioleti, 2006, p. 1). Talanoa was first introduced by Halapua (Tecun et al., 2018) and then developed by Vaioleti (2006) as a research methodology defined by Halapua (2013) as “unconcealed storytelling by Kēpa and Manu'atu (2006) as a curious dialogue that is a social rather than individual phenomenon, and by O. Māhina (2007) as talking critically yet harmoniously” (Tecun et al., 2018, p. 157). Ka'ili (2014) added that talanoa is a communal learning, where participants cocreate and coproduce knowledge through critical dialogue.

As a Tongan woman who was raised with strong cultural values that are universal in Oceania (Hau'ofa, 1998; Prescott, 2008; Uehara et al., 2018) and researching her own PI community, I felt it was important to incorporate talanoa to decolonize Western methodologies and provide a familiar vā (space) to share, connect, and learn. At the beginning of each interview, I introduced myself and shared where I come from in the Pacific, my personal educational journey, and my intentions. I did this to follow the protocols for talanoa in showing my respect, trust, and responsibility that our talanoa will be used to uplift and benefit our community. 


\title{
Participant Selection
}

Institutional Review Board approval was obtained prior to starting the study and establishing contact with potential participants (see Appendices A and B for the informed consent form and recruitment email flyer, respectively). The three criteria for my research study were that participants self-identify as Pacific Islander, Pasifika, or Oceania; be at least in their junior year as a STEM major or be a recent graduate in STEM; and be at least 18 years old (see Table 2). I recruited 31 participants through purposive and snowball sampling. I contacted colleagues and personal references, and I emailed faculty, staff, and students associated with PI clubs and organizations in several institutions that were designated AANAPISIs in California and Hawaii.

\section{Table 2}

Criteria for Study Participant Selection

\author{
Characteristics
}

Self-identify as Pacific Islander, Pasifika, or Oceania

Be at least in their junior year as a STEM major or recent graduate in STEM Be at least 18 years old

Participants for this study identified as Pacific Islander, Pasifika, or Oceania. I prefer the term Oceania because as Hau'ofa (1994) explained, "Pacific Islands . . . connotes small areas of lands sitting atop submerged reefs or seamounts. ... Oceania connotes sea of islands with their inhabitants" (p. 8). Oceania includes Fiji, Samoa, Tonga, Niue, Hawaii, Aotearoa (New Zealand), Kiribati, the Solomon Islands, Vanuatu, Tuvalu, Tahiti, and the Cook Islands, and have a history of trading goods, sharing wealth, intermarriages, and wars (Hau'ofa, 1994). 
Additionally, these islands have had a lot in common, such as similarities in language, cultural traditions, and stories of origin that are distinct from their Asian counterparts. In my study, I will not use the terms Melanesia, Polynesia, and Micronesia, which were made up by White colonists to divide Oceania with imaginary lines and isolate inhabitants for imperialistic and colonial benefits (Hau'ofa, 1994).

Participants were in their junior year or higher or were a recent graduate as a STEM major at a not-for-profit, 4-year college or university. To provide a rich description of the experience of a Pacific Islander in STEM, participants were enrolled in or had taken multiple courses, including introductory and upper-division courses in STEM. This requirement ensured that participants had experienced the challenges and supports of being an undergraduate student in STEM.

Table 3 summarizes the characteristics of the participants, including their Pacific Islander identity, STEM major, and year in college. The Pacific Islander identities are Chamorro, Native Hawaiian, Palauan, Samoan, Tahitian, Tongan, Chamorro and Samoan, Chuukese and Yapese, Samoan and Tongan, and Samoan and Native Hawaiian. The majors listed in Table 3 include those that students were completing as an undergraduate or graduate student or had completed as a student who had graduated. The STEM majors of the participants include the biological sciences, engineering, technology, environmental science, chemistry, physiology, oceanography, and medical laboratory science. Of the 31 participants, 13 had graduated, 7 were undergraduates, and 11 were graduate students in a master's or doctoral program, or in medical school.

Using the demographic survey and the interview, I was able to gather rich descriptions of the participants that included their precollege and college experiences. For precollege experiences for the PIs in this study, 20 were first-generation college students, 26 had earned a 
GPA of 3.5 or above, 27 had taken calculus or precalculus in high school, and 20 had a socioeconomic status (SES) of $\$ 50,000$ or above. For college experiences, 28 participants enrolled in college immediately after high school, 25 attended a 4-year college or university, 24 lived on campus, 14 earned a bachelor's degree, 9 earned a graduate degree, and 7 were still enrolled in college.

\section{Table 3}

Characteristics of Participants

\begin{tabular}{|c|c|c|}
\hline Pacific Islander identity & STEM major & Year in college \\
\hline Chamorro (1) & Biochemistry $(2)^{*}$ & Undergraduate (7) \\
\hline Native Hawaiian (5) & Bioengineering (1) & Grad student (11) \\
\hline Palauan (1) & Biology (11) & Graduated (13) \\
\hline Samoan (7) & Cellular \& molecular medicine $(1)^{*}$ & \\
\hline Tahitian (2) & Chemistry $(2)^{*}$ & Degrees earned \\
\hline Tongan (11) & Computer systems information (1) & Still enrolled (7) \\
\hline Chamorro/Samoan (1) & Ecology, Evolutionary biology (1)* & AA (1) \\
\hline Chuukese/Yapese (1) & Environmental science (4) & BA/BS (14) \\
\hline Samoan/Tongan (1) & Medical laboratory science (1) & MA (7) \\
\hline Samoan/Native Hawaiian (1) & Microbiology (1) & $\mathrm{PhD} / \mathrm{MD}(2)$ \\
\hline High school GPA & Physiology (2) & \\
\hline $\begin{array}{l}4.0 \text { and above }(11) \\
3.5-3.9(15)\end{array}$ & $\begin{array}{l}\text { Science, technology, and society focused in } \\
\text { environment \& sustainability (1) }\end{array}$ & \\
\hline $3.0-3.4(2)$ & Technology, innovation, education $(1)^{*}$ & \\
\hline $2.5-2.9(3)$ & $\begin{array}{l}\text { Engineering (7) - Biomedical (1), } \\
\quad \text { Chemical (2), Civil (1), Electrical (2), }\end{array}$ & \\
\hline $\begin{array}{l}\text { Highest high school math level } \\
\text { completed }\end{array}$ & Electrical and computer (1) & $\frac{\text { First-generation }}{\text { college student }}$ \\
\hline Calculus (21) & Timing of college attendance & Yes $(20)$ \\
\hline Pre-Calculus (6) & 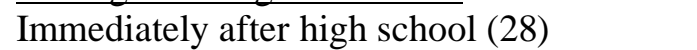 & No (11) \\
\hline Algebra/Trigonometry (3) & Delayed $1-2$ years $(3)$ & \\
\hline \multicolumn{3}{|l|}{ Other math (1) } \\
\hline Socioeconomic status & 4-year college/university (25) & Yes (24) \\
\hline$\$ 75,000$ and above (11) & Community college transfer (6) & No $(7)$ \\
\hline \multicolumn{3}{|l|}{$\$ 50,000-\$ 74,999(9)$} \\
\hline$\$ 49,999$ to less than $\$ 20,000$ (11) & & \\
\hline
\end{tabular}

Note. $*$ = graduate degree program 


\section{Data Collection}

The data collection tools in this phenomenological study included a demographic survey, an educational journey map, a virtual artifact elicitation interview, and memo notes during and after each interview. Multiple data-gathering collection methods "enhance the credibility and trustworthiness of a study through what is known as triangulation" (Saldaña, 2011, p. 76) and provided a greater understanding of how PIs are navigating STEM.

\section{Data Sources}

Demographic Survey. Data collection began with participants taking a brief demographic survey on Qualtrics (see Appendix D) prior to the interview. The demographic survey (adapted from Research \& Equity Scholarship Institute, 2021) was modified to screen participants who self-identified as Pacific Islander and were at least in their junior year as a STEM major. The survey requested of the participants their specific Pacific Island region of heritage, such as which islands they come from; whether they spoke any Pacific Islander language; and what factors impacted their success in STEM. I wanted to obtain a precise picture of my participants' various identities, educational trajectory, and precollege and college experiences prior to the interview. The interview questions were the same for all participants but seeing the participants' responses from the demographic survey before the interview allowed me to modify my prompts and follow-up questions. Some of the basic demographic questions that I asked on the survey included gender, birth year, race/ethnicity, primary language, and parental education level. Participants were also asked to list the institutions they attended, major(s), and degree(s) earned or working toward. Some of the more basic demographics, such as PI identity, gender, STEM major, and highest degree attained are summarized in Table 4. 


\section{Table 4}

Demographics of Study Participants

\begin{tabular}{|c|c|c|c|c|}
\hline Name & $\begin{array}{l}\text { Pacific Islander } \\
\text { identity }\end{array}$ & Gender & STEM major & $\begin{array}{c}\text { Highest } \\
\text { degree } \\
\text { attained }\end{array}$ \\
\hline Leihana & Chamorro & $\mathrm{F}$ & Microbiology & $\mathrm{BS}^{* *}$ \\
\hline Echa & Chamorro/Samoan & $\mathrm{F}$ & Biology & $\mathrm{BS}$ \\
\hline Holu & $\begin{array}{l}\text { Native Hawaiian/ } \\
\text { Samoan }\end{array}$ & $\mathrm{F}$ & Environmental science; Oceanography & $\mathrm{BS} * *$ \\
\hline Makana & Native Hawaiian & M & Biology & MD \\
\hline Tiare & Native Hawaiian & $\mathrm{F}$ & Environmental science & $\mathrm{BS}$ \\
\hline Mareva & Native Hawaiian & $\mathrm{F}$ & Environmental science & BA \\
\hline Aloha & Native Hawaiian & N/A & Biology & $\mathrm{MA}^{* *}$ \\
\hline Noa & Native Hawaiian & $\mathrm{M}$ & Chemical engineering; Chemistry & $\mathrm{BS} * *$ \\
\hline Kiaria & Palauan & N/A & Electrical and computer engineering & UG \\
\hline Teuila & Samoan & $\mathrm{F}$ & Technology, innovation, education & MA \\
\hline Fetu & Samoan & M & Biology; Biochemistry & $\mathrm{PhD}$ \\
\hline Penina & Samoan & $\mathrm{F}$ & Biomedical engineering & $\mathrm{BS}$ \\
\hline Bob & Samoan & $\mathrm{F}$ & Biology & $\mathrm{UG}$ \\
\hline Manu & Samoan & M & Biology & $\mathrm{UG}$ \\
\hline Talia & Samoan & $\mathrm{F}$ & Biology & MA \\
\hline Aleki & Samoan & M & Electrical engineering & $\mathrm{UG}$ \\
\hline Taina & Tahitian & $\mathrm{F}$ & Science, technology, and environment & BS \\
\hline Ta'ata & Tahitian & $\mathrm{M}$ & Environmental science & $\mathrm{UG}$ \\
\hline Toakase & Tongan & $\mathrm{F}$ & Chemical engineering & MA** \\
\hline Hina & Tongan & $\mathrm{F}$ & Physiology & $\mathrm{BS}^{* *}$ \\
\hline Latai & Tongan & $\mathrm{F}$ & $\begin{array}{l}\text { Physiology; Cellular and molecular } \\
\text { medicine }\end{array}$ & MA** \\
\hline Tuitavuki & Tongan & $\mathrm{M}$ & Medical laboratory science; Chemistry & $\mathrm{UG}$ \\
\hline Fipe & Tongan & $\mathrm{F}$ & Computer systems information & $\mathrm{UG}$ \\
\hline Elisiva & Tongan & $\mathrm{F}$ & Biology & $\mathrm{BA}^{* *}$ \\
\hline Hamani & Tongan & $\mathrm{M}$ & Biology & $\mathrm{BS} * *$ \\
\hline Langi & Tongan & $\mathrm{F}$ & Bioengineering & BS \\
\hline Heilala & Tongan & $\mathrm{F}$ & Biochemistry; Biology & MA \\
\hline Inoke & Tongan & M & Civil engineering & BA \\
\hline Kiteau & Tongan & M & Electrical engineering & BA \\
\hline Toahola & Tongan/Samoan & $\mathrm{F}$ & Biology & $\mathrm{BA}^{* *}$ \\
\hline Nienkapi & Yapese/Chuukese & $\mathrm{F}$ & $\begin{array}{l}\text { Environmental science; Ecology; } \\
\text { Evolutionary biology }\end{array}$ & $\mathrm{BA}^{* *}$ \\
\hline
\end{tabular}

Note. ${ }^{* *}=$ graduate student; $\mathrm{N} / \mathrm{A}=$ preferred not to answer; $\mathrm{UG}=$ undergraduate student 
Educational Journey Map. The purpose of the educational journey map was for the participants to remember and reflect on their experiences in STEM, such as their first science experiment or participation in a STEM program during college, to trace back to the reasons they became interested and persisted in STEM. I believed that in order for the participants to identify the factors that had led them to their current position in STEM, they had to retrace their steps to validate their experiences. In addition, it would be powerful to observe the participants as they remembered and reflected on their educational journey.

At the beginning of the interview and prior to the participants' creating their educational journey map, I shared my own journey map depicting my navigation as a STEM major (see Figure 4). In my map I listed the schools I attended, the years I attended them, the degrees attained, any factors related to STEM (i.e., math courses, STEM-related research), important life events, and future goals, with arrows to show forward or backward mobility. Sharing my personal journey allowed me not only to model how an educational trajectory map could look but also to build rapport, trust, and connection with each participant.

Following the interview procedures from my previous research examining student STEM pathways (Research \& Equity Scholarship Institute, 2021), each participant was then asked to draw their personal educational trajectory map. Using a phenomenological approach, I sought out any commonalities among the participants' STEM journey, such as activities that influenced interest in STEM before college, STEM-related research or internships during college, and linear or slightly deviated paths.

\section{Figure 4}

Educational Trajectory Map of Researcher 


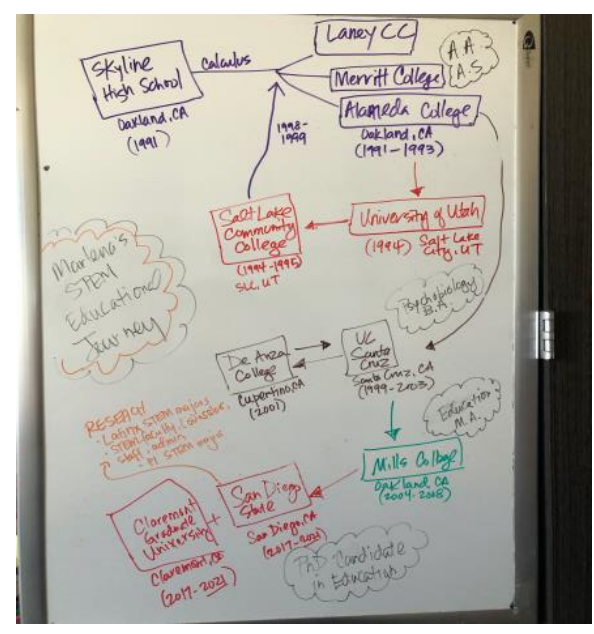

Artifact Elicitation Interview. As recent immigrants to the United States, most PIs have a great appreciation for and knowledge of their culture and ancestors. I was interested in discovering whether cultural identity, knowledge, and traditions had played a role in how the participants were navigating and persisting in STEM. In my previous research with EDSYSTEMS (Research \& Equity Scholarship Institute, 2021) and in my pilot study, the use of artifacts in the interview process had been powerful, because participants controlled the interview by bringing actual items or photos as artifacts to connect to their underrepresented cultural identity. My experience with using artifacts influenced me to focus on artifact elicitation for this section of the interview to experience deeper conversations centered on the role of racial/ethnic identity within STEM pathways. I asked participants to provide artifacts, such as photos or objects, that represented their underrepresentation in STEM as a PI. In phenomenological research, artifacts allow participants the agency to provide profound insight on factors that impacted their navigation in STEM. I had learned from my pilot study that this was an effective method, because participants easily shared how their journey in STEM was connected to their cultural and personal identity. The focus was taken off them and placed on the artifact they chose to bring to the interview. Inserting an artifact into the interview process is 
called artifact elicitation, which is an extension of photo elicitation and can include inanimate objects, drawings, or photos (Douglas, 2015).

In Cappello's (2005) study of eliciting data through conversations with children, photographs taken by participants allowed them to easily recall and share their experiences during the interview. The photo elicitation method helped to engage participants into a richer and more in-depth interview (Clark-Ibanez, 2004; Harper, 2002). "Thus images evoke deeper elements of human consciousness ... that evokes a different kind of information" (Harper, 2002, p. 13). Artifact elicitation is similar to photo elicitation and includes physical or virtual objects that represent the knowledge or experience of the participants. Douglas (2015) added that using artifact elicitation helped his participants to be reflective of their experiences in engineering, their engineering identity, and their adaptive experiences, which aligns with my research on PIs in STEM. Artifact elicitation adds a unique perspective not found in a conventional interview and helped to build rapport and connection, which I found in my pilot study is essential in PI culture.

Virtual One-on-One Interview via Zoom. The interview was important for this phenomenological research study because it provided a voice for a highly marginalized population for whom there is a dearth of research, especially qualitative research. The interviews were virtual, one-on-one, via Zoom, and lasted between 60 and 90 minutes. Before each interview, I emailed each participant an interview protocol (see Appendix E) so that they could prepare by knowing what questions to expect. The interview protocol (adapted from Research \& Equity Scholarship Institute, 2021) was aligned to my theoretical framework and the ethnic/racial identity of the participants in this study. The sections of the interview protocol were Introduction/STEM Trajectory, Precollege Experiences, College Experiences, Pacific Islander 
Identity, and Underrepresented Identity Experiences with STEM. Table 5 lists the interview protocol and some of the interview questions.

In the first section of the interview protocol, Introduction/STEM Trajectory, the participants identified themselves, their racial/ethnic identity, their major, and the colleges they had attended. For the Precollege Experiences section, I asked what type of student my participants were in high school, how they prepared to major in STEM, and how they prepared to apply for college. In the College Experiences section, participants answered questions about how well they integrated into college, their relationship with their professors and peers, their major supports in STEM, and challenges and barriers they faced as a STEM major. For the Pacific Islander Identity section, I queried how participants had been actively engaged in their PI culture and community. Last, the section Underrepresented Identity Experience with STEM Discipline was an opportunity for the participants to reflect on how they saw themselves in STEM. The questions were framed to explore which capitals from community cultural wealth were utilized and at what point of their navigation and in what role did tauhi vā play in how PIs were navigating using wayfinding in STEM.

\section{Table 5}

Interview Protocol

Section heading of interview protocol

Types of questions

Introduction/STEM

Trajectory
Ask about major/program of study.

Ask about year in school.

Ask about previous community colleges or universities.

Please describe your racial/ethnic identity.

Do you identify as a Pacific Islander? If yes, what does being a Pacific Islander mean to you? 


\begin{tabular}{|c|c|}
\hline Precollege Experiences & $\begin{array}{l}\text { What type of student were you in high school? } \\
\text { Were you involved in a STEM or college bridge program (e.g., } \\
\text { summer program, club, internship), or did you attend a STEM- } \\
\text { specific high school? } \\
\text { Did you take any AP courses? } \\
\text { When and why did you decide to go to college? } \\
\text { Did your family support your decision to go to college? }\end{array}$ \\
\hline College Experiences & $\begin{array}{l}\text { What type of college student are/were you? } \\
\text { Did you meet with professors outside of class for office hours, do } \\
\text { internships, or work on research with your professor? } \\
\text { Do you have the opportunity to work in a lab or do research in } \\
\text { STEM? } \\
\text { How would you describe the culture within your STEM } \\
\text { major/classes? } \\
\text { What sparked your interest in STEM? } \\
\text { What were the major supports for you as a STEM major? } \\
\text { What are the challenges or barriers that you experienced as a } \\
\text { STEM major? }\end{array}$ \\
\hline Pacific Islander Identity & $\begin{array}{l}\text { What do you feel is the most important thing about your culture? } \\
\text { As a Pacific Islander, have your cultural identity, values, or } \\
\text { traditions impacted your educational experiences? }\end{array}$ \\
\hline $\begin{array}{l}\text { Underrepresented Identity } \\
\text { Experience with STEM } \\
\text { Discipline }\end{array}$ & $\begin{array}{l}\text { Describe your artifact. } \\
\text { Why did you choose your artifact to represent your experience as } \\
\text { someone whose identity is underrepresented in STEM? } \\
\text { How important is it to be a Pacific Islander in STEM? }\end{array}$ \\
\hline
\end{tabular}

Note. This is a brief excerpt of the interview protocol taken from Appendix E, which includes these headings and all the sample questions used in the interview.

During the interview, I asked semistructured questions about the participants' collegial experiences as a STEM major to find out whether the institution, faculty, staff, or support had had any impact in the students' navigation in STEM as a PI. Some of the participants reviewed the questions and began by storytelling and sharing personal stories of barriers and triumphs. “Halapua (2007) describes talanoa as 'talking from the heart' that involves storytelling 'without 
concealment"' (as cited in Fa'avae et al., 2016, p. 147). The interview or talanoa included laughter and tears and became more of a genuine conversation between friends who had found some connection through a shared common experience as PIs in STEM.

Memo Notes. To incorporate my reflexive thoughts in the study, I took notes during the interview and typed up memo notes after each interview. "Memos can trigger thinking process and ... capture new descriptors ... to inform your coding scheme and become the basis for a coding scheme development chart” (Bloomberg \& Volpe, 2019, p. 244). The memo notes included things that stood out in each interview, such as repeating themes of inadequate advising and finding vā (space) of support and belongingness. I also took note of things that were significant about each participant to highlight diverse challenges and experiences. As a phenomenological researcher, I believed that each participant was an individual first to avoid putting a group of people into one box. "Sufficient reflexivity occurs when researchers record notes during the process of research, reflect on their own personal experiences, and consider how their personal experiences may shape their interpretation of results" (Creswell \& Creswell, 2018, p. 184). Being a Pacific Islander who majored in STEM, I was able to relate to the experiences of my participants, which helped me to develop possible codes for the coding process and themes for my findings and to analyze the data to identify similar lived experiences.

\section{Procedures}

Participants were contacted through email with a link to complete an online demographic survey (see Appendix D) on Qualtrics, a professional survey software. Once completed surveys were collected, the data was exported to a Microsoft Excel spreadsheet. Pseudonyms were assigned to ensure anonymity. Prior to the interview, participants were asked to digitally sign the consent form (see Appendix A) on Qualtrics. Participants were advised to find a private and 
quiet room because the interview was to be recorded using the Voice Memos application for iOS on my cellular phone.

Before recording each interview, I introduced myself and shared my educational trajectory map. I also informed the interviewees that I was recording and asked whether they had questions or concerns. During the interview, each participant shared an artifact that represented their underrepresented identity in STEM. I shared an example of my artifact for participants who were unsure of what type of artifact to use. The participants were also asked to provide an educational journey map by taking pictures of their drawings or by creating a digital drawing and emailing it to me. After each interview, I wrote a memo about elements that stood out, nuances, possible themes, and questions, which helped me develop codes and themes for the study.

The audio recordings were sent to TranscribeMe, an online transcription service. Before importing the transcribed interviews to QSR International's Nvivo 12, a software that organizes and manages data for analysis, I listened to and verified each interview, making any corrections and adding pseudonyms to protect the interviewees' identity.

\section{Data Analysis}

While this phenomenological study was rooted in talanoa, the theoretical framework of community cultural wealth (Yosso, 2005) and tauhi vā (Ka'ili, 2005) were integral to the data analysis. Community cultural wealth provided a lens that demonstrates the assets that communities of colors are using to navigate and thrive in spaces that they may find contrary to their background and value system. As an underrepresented population, PIs are often viewed from a deficit, so questions were framed to highlight their successes as well as the challenges and barriers. Based on my pilot study, I knew PIs were taking rigorous math courses in high school, spoke more than one language, and were attaining graduate degrees, so I modified the questions 
in the demographic survey and interview protocol to fit my theoretical framework in order to emphasize their assets and expose how PIs were being stereotyped and underserved.

The interview protocol included questions aligned with how one or more of the capitals under community cultural wealth influenced the navigation of PIs in STEM. For example, I asked questions about family support to show evidence of familial capital and questions about how they knew how to apply for college to indicate evidence of navigational capital, social capital, and familial capital. To show evidence of tauhi vā and how it influenced the navigation of PIs in STEM, I asked participants about the importance of their culture and how their PI cultural identity had impacted their educational experiences. By using community cultural wealth and tauhi vā to frame my questions for the demographic survey and interview protocol, I was able to analyze how PIs were navigating STEM. With 31 participants submitting demographic surveys, educational journey maps, artifact elicitation interviews, and 1,837 minutes-or 31 hours - of interviews, I conducted data analysis at the same time as data collection to maintain organization of an overwhelming amount of data and to avoid repetitious data.

\section{Demographic Survey}

Before each interview, participants were asked to complete the demographic survey, the results of which were uploaded and organized into a spreadsheet. The responses of the survey helped to identify the participants by their Pacific Islander identity, socioeconomic level, number of schools they attended, years in school, and major to examine whether their data fit with current research and statistics on PIs in higher education and STEM. Descriptive statistics were used to summarize the data to create an overall picture of who the participants were. I was able to learn what Pacific Islands were represented in the study, types of STEM majors, degrees 
earned, and precollege experiences (e.g., grade point average, highest math course completed before college).

\section{Educational Trajectory Map Analysis}

Participants were asked to submit a map of their educational trajectory to help them remember and reflect on their navigation to and in STEM. I observed and took notes on each participant's navigational path, linearity or nonlinearity of the path, gaps that may have occurred if college was put on hold, and any deviations. I took memo notes on how many institutions the participants attended, the number of years they attended, and the degrees attained. I compared the data from the survey for consistency and to fill any holes in the interview to add to the description of the participants' background and experience.

\section{Interview Data Analysis}

I began data analysis during the interview by writing down notes and memos of my thoughts and reactions, as well as similar experiences I had heard during previous interviews (e.g., strong familial aspirations, self-navigation). I took notes when I heard a change in a participant's tone or demeanor or when they shared personal life-changing or traumatic experiences (e.g., experienced microaggressions, were advised to leave STEM). I wanted to ensure that during the coding process I would take the time to dwell for the "phenomenon to reveal itself and speak its story into our understanding” (Finlay, 2014, p. 125).

After each interview, I labeled and organized the picture of the artifact and reviewed my memo notes to see if I could add anything else I remembered from the interview. I compared my memo notes about each participant's description of the artifact to get a sense of how it connected to their underrepresented identity in STEM and any nuances to help me develop codes and themes around PIs as an underrepresented identity in STEM. 
Taking memo notes was important because I had collected data from 31 participants, and I needed a method for tracking similar experiences and nuances. After each interview, I took memo notes of items that stood out to me, significant details about each participant, and any reflection. My memo notes were sectioned by each participant's pseudonym. At the top of the notes I kept a growing list of common experiences I heard during the interview, with possible codes and themes.

Once the interviews were transcribed and verified, I uploaded the annotated transcripts into Nvivo 12, a computer software program for qualitative data analysis, for initial coding. I used Creswell and Creswell's (2018) work as a reference to analyze the data, which I organized and prepared for analysis by verifying and changing the pseudonyms. I read transcripts and listened to the interviews more than once to familiarize myself with the data. I also took memo notes on any details that were interesting or repetitive. I compiled a list of topics from the memo notes and generated codes and themes that arose in the interviews. From my memos and notes, I created nodes to store and categorize data, based on recurring themes or patterns that emerged during the interviews. During initial coding, several common topics were addressed by the participants in the interview (e.g., "STEM major culture," "Gatekeepers," "Social Connections"), as well as Nvivo nodes using the participants' statements from the interview (e.g., "Imposter Syndrome," "Giving Back").

As a phenomenological researcher, I read and listened to each interview several times to capture the essence of each participant's lived experience and to search for nuances rather than observe only what was already known. In Nvivo 12, I ran several queries of themes or words (e.g., "family," "support") that came up frequently in the transcripts, which helped me to determine what factors were significant and relative among my participants. At the point of 
saturation, I reviewed the nodes that had been coded to merge, modify, and add new codes. I defined each node with short, descriptive words to give it meaning and to identify differences and similarities.

I coded the transcripts a second time and identified 10 categories: Precollege Experiences, College Experiences, Resilience and Self-Efficacy, STEM Trajectory, Sense of Belonging, Navigation, Wayfinding, Pacific Islander Identity, Support System, and Tauhi Vā. After the second round of coding, I drew a mind map on Microsoft's digital Whiteboard, using all the codes to identify themes. The mind mapping process was informed by the capitals in community cultural wealth and tauhi vā. For instance, evidence of familial, aspirational, social, and navigational capital was strongly influenced in the precollege experiences of the participants. And tauhi vā was pronounced when participants encountered barriers and had to create their path and vā (space) to find support. I identified the main themes and showed how they were related by branching the codes that supported each theme. Based on the meanings that I developed for each code, I was able to see patterns emerge between related meanings. I then drew a flowchart showing each code and theme relative to each other.

"The goal of the thematic analysis is to achieve an understanding of patterns of meanings from data on lived experiences (i.e., informants' descriptions of experiences related to the research question in, e.g., interviews or narratives)" (Sundler et al., 2019, p. 736). Finally, I conducted several cycles of coding by lumping the data with larger themes based on my theoretical framework and then splitting the data to capture nuances and to ensure that the data was consistent with each participant (Saldaña, 2009).

\section{Protection of Human Subjects}


San Diego State University granted institutional review board permission for this study. Due to the sensitive questions about collegiate experiences, I did not identify or record and kept confidential the names of the participants and the names of the specific universities that they attended. I collected survey data via a password-protected Qualtrics account and downloaded data onto my password-protected file storage system. The Zoom interview was passwordprotected to ensure that only the interviewer and interviewee were attending the Zoom session. Participants were asked to sign a consent form detailing the participants' rights for protection during data collection.

\section{Trustworthiness}

Creswell and Creswell (2018) recommend using multiple methods to "enhance the researcher's ability to assess the accuracy of findings as well as convince readers of that accuracy" (p. 200). In this study, I used three primary methods to establish credibility and trustworthiness: triangulation, peer debriefing, and member checking.

Triangulation. Triangulation refers to examining data sources from several methods to develop a thorough understanding of the phenomenon (Patton, 1999). In this study, data were triangulated from demographic surveys, interviews, educational journey maps, and memos to justify themes. I compared data from the demographic survey, interview, educational journey map, and memo notes to check for consistency and determine whether any new items had appeared. For instance, for each participant, I was able to confirm the schools attended, degrees

attained, and precollege experiences (e.g., high school grade point average, highest math course taken in high school, attendance at private or public high school). By converging these data sources and perspectives from participants, I was able to develop themes and claim the validity of this study. 
Peer Debriefing. As a senior research analyst, I was fortunate to work with several experienced postdoctoral fellows and colleagues who had recently defended or were working on their dissertation to consult with about my research. With my postdoctoral colleagues, I shared the interview questions, typical responses, and coding structure to confirm their alignment. The other colleagues I debriefed were familiar with my population and the theories I was using in my study, so I shared a brief presentation of the themes and a flowchart of how the themes and findings fit my theoretical framework. I received valuable feedback and confirmation from the postdoctoral fellows and my colleagues.

Member Checking. Last, to determine the accuracy of my findings, I contacted the participants through email and text messaging to justify what I had found. After each interview, I emailed and texted participants with some of my data analysis, interpretations, and conclusions to get their views on the credibility of the findings. Participants replied through text and email and were able to provide missing data, correct data that I had misinterpreted, and confirm my findings and themes. The participants' feedback confirmed my conclusions and interpretations, making this study trustworthy.

\section{Limitations}

Potential limitations of this study are the sensitive nature of the study and the participants' willingness to be open, as I asked questions about identity, upbringing, family, and collegiate experience, subjects that could be positive or negative. The interview was conducted through Zoom, so there could have been instances of someone listening to the interview, causing the participant to hold back pertinent information. The participants ultimately had the right to decline answering any questions and to stop the interview at any time. The following section 
focuses on three main limitations related to this study: (a) sample population, (b) collection techniques, and (c) research design and researcher bias.

Sample Population. The sample population was 31 participants who self-identified as Pacific Islander and majored in STEM. A majority of the participants attended institutions in the Pacific West region of the United States. I recruited participants through purposive and snowball sampling by sharing my recruitment flyers on social media, contacting NHPI and STEM clubs and organizations on college campuses, and following up with personal referrals. I wanted to recruit participants who self-identified as PIs, were at least in their junior as a STEM major, and were over 18 years old, so I used purposive sampling. I shared the recruitment flyers with institutions in California and Hawaii because these two states have the largest populations of PIs.

To increase the potential pool of participants for the study, I used snowball sampling, a “common form of purposive sampling" (Merriam \& Tisdell, 2015, p. 6). Participants shared the flyers and referred friends and peers who also fit the study's criteria. Purposive and snowball sampling was the best method for the population because, as a communal culture, somebody knows somebody, especially if they majored in STEM. Participants wanted to help me as a fellow PI, and so they spread the message in order for me to recruit the required number of participants. Despite my efforts to represent every Pacific Islander through heavy recruitment, several PI groups (e.g., Fijians, Maori, Papua New Guineans) are not represented. This may seem like a limitation, but I believe I have a fair representation of PIs in STEM, and I exceeded the number of participants required by my dissertation committee.

Data Collection. My data collection tools included a brief demographic survey, a oneon-one virtual interview through Zoom, an artifact, and a STEM educational journey map. Because of the COVID-19 pandemic lockdown measures, interviews were conducted virtually 
through Zoom, which may seem like a limitation, but participants were able to speak freely and honestly about their experiences. Before the interview, I made sure that Zoom was secure by setting up a waiting room and a password for each participant. I emailed each participant an interview protocol, so they would understand the personal nature of the questions. During the interview, I made sure that my space was isolated and free of disruptions so that the participants felt safe and secure to share their experiences, which they did.

Researcher Bias. The research was designed to be NHPI-culturally relevant at a scholarly research level. The brief demographic survey provided basic information (e.g., gender, college major) for an overview of my participants. The interview was designed to be face-to-face in a controlled space but could have been compromised on the interviewees' side if they could not share some information freely because family members were present in the background or if there were other interruptions. As a PI in STEM, I have had similar experiences as those of my participants and have a common understanding of Pacific Islander culture, which could have made it easier for participants to share their stories. Each interview was more like a talanoa, a conversation between colleagues, and took some of the pressure off the participants.

\section{Summary}

In summary, Chapter 3 provided a detailed description of my study's research methodology. I used phenomenology as a methodology to examine how community cultural wealth and tauhi vā influence the navigation of PIs in STEM. The participant sample included 31 individuals recruited through purposive and snowball sampling. Five methods of data collection were employed: a demographic survey, an educational journey map, artifacts, a virtual one-onone interview via Zoom, and memo notes. The data were reviewed against literature as well as 
emergent themes. Credibility and trustworthiness were accounted for through triangulation, member checking, and peer debriefing.

I conducted a review of the literature to develop a theoretical framework for the design and analysis of the study. After I completed several processes of data analysis, key themes from the findings emerged. The goal of this study was to make a contribution to understanding the navigation of PI students in higher education and in STEM. In addition, with the findings from this study, I hope to inform students, advisors, and faculty in STEM that their actions and behavior can serve as barriers for students and that institutions must do better to acknowledge and support underrepresented students in STEM. 


\section{Chapter 4: Findings}

\section{Introduction}

The purpose of this research was to examine how Pacific Islanders are navigating their way to attain a degree in STEM. Meritocracy and individualism are prevalent in STEM and are contrary to the collective and communal culture of PIs. This research highlights how PIs have learned to adapt to a culture not conducive to their own. PIs transform their cultural knowledge and educational experiences to create vā (space), which stresses the importance of interpersonal relationships and reciprocity and is favorable to and more aligned with their PI cultural identity of community. This chapter presents the key findings from the 31 participants who took part in a one-on-one, in-depth virtual interview; completed a demographic survey; shared an artifact; and illustrated an educational journey map. This study produced several themes describing the experiences of PIs who majored in STEM. The three major themes that emerged from this research follow:

- Navigation and Wayfinding: Following a Forged Path to Forging Your Own Path

- Vā: Creating Vā (Space) Through Interpersonal Relationships and Social Connections

- Tauhi Vā: Taking Care of Relationships Within These Spaces Through Reciprocity

The findings of this qualitative research address two research questions: How do community cultural wealth and tauhi vā influence the navigation and wayfinding of Pacific Islanders? How does tauhi vā create vā specific to Pacific Islanders to wayfind STEM and develop community cultural wealth?

\section{Summary of Themes}

The first theme, Navigation and Wayfinding: Following a Forged Path to Forging Your Own Path, explores how PIs are doing exactly what they need to do to be admitted to college, but 
obstacles in college force them to begin moving forward in STEM by wayfinding. The subthemes are Navigation: Following a Forged Path; Barriers in STEM as a Pacific Islander; and Wayfinding: Pacific Islanders Forging Their Own Path. Each subtheme addresses the role of precollege experiences and navigational agents, and the necessity of wayfinding to attain a degree in STEM.

The second theme, Vā: Creating Vā (Space) Through Interpersonal Relationships and Social Connections, reveals how Pacific Islanders utilize their collective values of community and tauhi vā to thrive and succeed in STEM. The subthemes are Finding Vā (Space) to Connect and Nurture Relationships and Well-Being, Pacific Islanders' Experiences in STEM, and Pacific Islander Cultural Capital: Creating Vā (Space \& Relationships). The subthemes encompass Pacific Islander experiences in college and in STEM.

The third theme is Tauhi Vā: Taking Care of Relationships Within These Spaces Through Reciprocity. It addresses the influence of tauhi vā and how PIs are creating vā (space) in STEM through tauhi vā. The subthemes are Transforming STEM Through Tauhi Vāa and Responsibility and Reciprocity in STEM. The subthemes define and show examples of tauhi vā through responsibility and reciprocity and preparing vā for other Pacific Islanders. The themes and subthemes of the findings are found in Table 6 .

\section{Table 6}

Themes and Subthemes of PIs and Wayfinding STEM

\begin{tabular}{ll}
\hline \multicolumn{1}{c}{ Themes } & \multicolumn{1}{c}{ Subthemes } \\
\hline Navigation and Wayfinding: & - Navigation: Following a Forged Path \\
Following a Forged Path to Forging & - Barriers in STEM as a Pacific Islander \\
Your Own Path & - Wayfinding: Pacific Islanders Forging Their \\
& Own Path
\end{tabular}


Vā: Creating Vā (space) Through

Interpersonal Relationships and

Social Connections
- Importance of Social Connections

- Pacific Islanders' Experiences in STEM

- Pacific Islanders Creating Vā (Space) in STEM
Tauhi Vā: Taking Care of

Relationships Within These Spaces

Through Reciprocity
- Transforming STEM Through Tauhi Vā

- Responsibility and Reciprocity in STEM

\section{Restatement of Research Questions}

To examine the experiences of Pacific Islanders in STEM, this study was guided by the following research questions:

1. How do community cultural wealth and tauhi vā influence the navigation of Pacific Islanders in STEM?

2. And how does tauhi vā create vā specific to Pacific Islanders to wayfind STEM and develop community cultural wealth?

\section{Theme 1: Navigation and Wayfinding: Following a Forged Path to Forging Your Own Path}

My parents ... always stressed that education is the key. So college kind of seems like the obvious path for me.

—Penina, Biomedical Engineering-BS

Navigation is progress on a path that others have traveled using information that has been shared to guide others down a similar path. Pacific Islanders have navigated the Moana (Pacific Ocean) by wayfinding, using signs and landmarks to guide them. This knowledge was then passed down to prepare the next generation to be successful navigating the Moana. Pacific Islanders have also navigated their way to the United States for more opportunities and resources, and they want the same for their children. Growing up in a close-knit community, the 
younger generation is raised by parents, grandparents, aunts, and uncles who play a prominent role in helping to raise them, including inspiring children to go to college to become a doctor or lawyer. Parents and family members hope that telling children what they can become will bring their hopes to fruition.

As recent immigrants to the United States, parents know that the signs and landmarks for opportunity and a successful career are accessible with a good K-12 education for college preparation. Living in the diaspora, PI families and children are using aspirational, familial, navigational, and social capital to navigate the U.S. educational system. These capitals are used independently or together in a particular order. In this study, PIs who are following a planned and well-navigated path are encountering setbacks and detours that have led these students to begin navigating STEM as a form of resistance, using wayfinding like their ancestors before them.

The first theme of my findings reveal how PIs in this study changed from navigating STEM to wayfinding to overcome the barriers met in STEM. Table 7 shows the subthemes of how PIs in STEM are following a path forged with support and aspirations and how PIs are forging a new path as dictated by the obstacles and supports encountered along their STEM journey.

\section{Table 7}

Navigation and Wayfinding Theme and Subthemes

\begin{tabular}{ll}
\hline \multicolumn{1}{c}{ Theme 1 } & \multicolumn{1}{c}{ Subthemes } \\
\hline Navigation and Wayfinding: Following a & Navigation: Following a Forged Path \\
Forged Path to Forging Your Own Path & $\begin{array}{ll}\text { - Precollege investments and sacrifices } \\
\text { - Familial aspirations to navigate }\end{array}$ \\
& - Navigational support agents \\
\hline
\end{tabular}


Barriers in STEM as a Pacific Islander

- Pacific Islander stereotype

- Institutionalized STEM gatekeeper

- Institutionalized STEM gatekeeping courses

Wayfinding: Pacific Islanders Forging Their Own Path

- Resistance through wayfinding

- Finding Pacific Islander-culturally relevant signs

\section{Navigation: Following a Forged Path}

Navigation involves knowing where one wants to go, knowing what tools or supplies are needed for the journey, and knowing the directions for how to get there. To persist and navigate STEM successfully, precollege experiences must include factors such as earning a high GPA, taking high-level mathematics and AP courses, and attending a good school. In this study, 84\% of the 31 participants had a GPA of 3.5 and above; $97 \%$ had taken calculus, precalculus, or algebra II/trigonometry; and most participants reported having taken AP courses. Drawing on the educational experiences of their parents, family, and friends, and using information shared by navigational agents who include faculty and staff, PIs are doing exactly what they need to do to navigate their education to prepare for majoring in STEM.

Precollege Investments and Sacrifices. Although 70\% of PIs in this study attended a public high school, their parents made sure to live in a good school district or found ways to enroll their children in a good high school. Most participants attended a predominately White high school in a neighborhood with a high socioeconomic level and known for its academics or for having strong STEM programs. Langi shared how her family found affordable housing to reside in a good school district. According to Langi's educational trajectory map (see Figure 5), Langi began navigating STEM in elementary school, where she attended science summer camps, 
Kumon for Math and Reading, and completed Algebra I Series in fifth grade. During her seventh and eighth grade years, Langi won awards in math. Another participant shared how his mother accessed her social capital and used her employer's address so her children could attend one of the best high schools in the area. These are two examples of how families have been accumulating navigational capital with and without social capital and passing these capitals, including familial, on to their children to navigate education.

\section{Figure 5}

Langi's Educational Journey Map

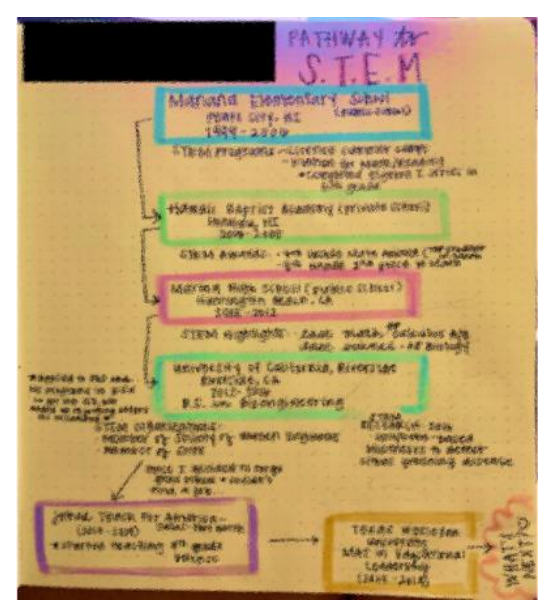

Note. The image was blurred to protect Langi's identity.

PIs understand that attending a good school will prepare them for college and see their sacrifices as investment for the future, the family, and the community. Participants shared how they were encouraged by family members to become doctors and engineers to help the family and PI community. Elisiva's father drilled into her that her educational attainment was to benefit the community and her family. When I asked Elisiva what had sparked her interest in STEM, she emotionally shared what her father and family gave up so she could attend one of the most 
prestigious private schools on the island: “My dad couldn't pay electricity for six months. I think we lived without a lot of things, and he would rather go homeless to be able to afford me these opportunities." Elisiva's familial capital provided the aspirational and navigational capital that she used to get into a good college and medical school. Elisiva had gone away for college, so when she struggled with her STEM courses or with financial aid, she remembered the sacrifices her family made and her Dad telling her to become a doctor. She persevered by finding a way to pay for school and visiting her professors during office hours and at their homes for extra support.

PI families play a key role in affording and providing precollege experiences for their children to navigate STEM. PI parents want their children to have the opportunities they were not able to have for themselves. Several participants shared how their parents when to college but often did not have a career or job related to their major or degree. Hamani's father got a job in accounting right out of college but did not like it and started his own iate (landscaping) company. Hamani admired his father and how hard he worked. Hamani recounted his father's response when he told his father that he wanted to be like him and do iate (landscaping):

"Don’t do what I do. Go work your brain. You can do anything you want ... We brought you here to America so you guys could have the opportunity to go to college. And you can be a lawyer. You can be a pilot. You can be a doctor. You can be a scientist ... But don't do iate. Look at—." And he just pointed to his knees and just showed me it's taken wear and tear on his body. And so I started at a young age. I was like, "I like math ... I want to be a doctor one day."

Hamani's father endured physical hardship on his body so that his children would have opportunities to be what they wanted to be. PI parents' American dream is to see their children 
live the American dream of going to college and becoming whatever they want to be.

Participants recognized the sacrifices that their families made for them, which increased their aspirational capital to navigate STEM. Not finishing was not an option.

Familial Aspirations to Navigate. In PI families, the older generations exert much influence on the younger generation, which includes sharing their aspirations for the future. In a collective culture, grandparents and older members of the community have experienced and seen much and are viewed as a source of wisdom and knowledge. One PI saying goes, "We look to the past, to move forward," meaning that PIs often look to the older generations or to ancestors to find direction for the future. Langi's grandfather complained that his breathing tube was painful to use and asked her to go to college to learn how to build a better one. Langi researched on her own and found out that she would have to major in bioengineering, which she did because of her grandfather.

Parents and family members foster aspirations, which inspires navigational capital through their example and interactions with their children and the younger generation. Nienkapi's parents were medical doctors, and she grew up watching science programs with her family. Naturally, she and all her siblings majored in STEM. Kiteau's uncles were experienced mechanics who told him to go into engineering, which he did. For Toahola, his grandfather that raised him told him to become a doctor. This stuck with Toahola, because he was close to his grandfather and looked up to him because his grandfather helped so many people in the community. Toahola shared how his grandfather inspired him to major in STEM:

It really started with my grandpa ... he had so many illnesses-diabetes, blood pressure - the prevalent diseases in the community, he had all of them . . And his feet kind of over time just got really big and painful, and he always wanted me to fota 
(massage) his feet because it always was hurting ... I was like six, maybe seven. And he would just say, "Ah, you're going to be the doctor of our family. I want you to be the doctor and then come and take care of all of us," while I would be massaging his feet. And as a little kid, for some reason, that just stuck with me: "Oh, Grandpa really wants this for me."

Toahola's grandfather's health was declining, so he would foto (massage) his grandfather's feet to comfort him. As Toahola massaged, he listened to his grandfather attentively. Toahola's aspirations to major in STEM came from an innate responsibility to fulfill his grandfather's request and from wanting to be like his grandfather in the community. Aspirational capital was powerful for many PIs in STEM because it is deeply rooted in the close relationship with their family. In this study, PI families were the major source of community cultural wealth, which motivated a majority of the participants to navigate their way to college and major in STEM.

Navigational Support Agents. In this study, 65\% of the participants were firstgeneration college students who were high achievers, were self-motivated, had high aspirations, and had a supportive navigational system. This supportive navigational system included navigational support agents, or individuals who had navigated themselves or had knowledge and information about how to get into college and major in STEM and who genuinely wanted PIs to succeed. For most of the participants, their first navigational support agent was their family. In the interviews, participants shared the various ways their parents supported their navigation in STEM. For example, parents provided a college-going culture in the home, developed relationships with teachers and counselors, were a member of the school's parentteacher group, attended their child's performances and athletic competitions, and encouraged their child to join clubs and extracurricular programs. Toakase's mother worked in 
administration at the community college, so she knew about college admission. She guided Toakase to take extra classes during the summer and helped her child apply to college. Talia's parents did not go to college, but they prepared their children for college by doing their own research and by building rapport with teachers and counselors, being present in the school, and volunteering to assist in the classroom and at school events. As participants reflected on their high school experience, they acknowledged that their parents wanted them to have the best chance to get into a good college to further their navigation in STEM.

As highly motivated students, the participants figured out how to apply for college and major in STEM from older siblings, family members, close family friends, community members, and supportive teachers and counselors. Evidently, PIs were utilizing social capital by networking and reaching out to social contacts to navigate STEM. As a communal culture, PIs were using what was familiar to them by seeking out accessible resources they trusted to help them apply for college and major in STEM. Teuila's high school counselor helped her choose classes and apply for college and scholarships. Kiaria's brother, a college graduate, helped her with college applications. And her close high school friend who was in AVID, a program that helps students from historically underachieving groups get into college, shared with Kiaria everything she learned, such as information about financial aid. Further, PIs who had graduated in STEM reached back to mentor and help several participants in this study get into graduate school and medical school programs.

\section{Barriers in STEM as a Pacific Islander}

I asked my science teacher if I could do an honors biology . . . and he told me he didn't think I would do well in it. So I think from there ... I didn't want to try hard in science 
classes, so I stayed in the normal — I didn't go for the honors or AP science classes because ... Just hearing that, I was like, I'm not good enough. Why would I do it?

—Makana, Biology-BA; MD

Pacific Islander Stereotype. For PIs, barriers in STEM have taken place at school from peers, teachers, guidance counselors, introductory STEM courses, and an unwelcoming and competitive STEM major culture. Being told that they should not pursue STEM became the motivation for Pacific Islanders to forge their own path through wayfinding, drawing on the resistant capital derived from their strong aspirational and familial capital. PIs have been stereotyped as being good at sports but not smart enough to be on honor roll, to go to college, or to major in STEM. Teuila played softball, volleyball, piano, took AP courses, and received an early college admission into an engineering program, but during an award ceremony a student sitting next to her asked, "Oh, are you sure you're supposed to be sitting here? This is the 3.7 and above section." Other participants shared similar experiences from their AP courses or STEM program.

Most of the participants attended high schools and colleges in the United States that were predominately White. Seeing little to no representation of PIs in $\mathrm{K}-12$ and higher education and having few interactions with or knowledge of PIs, others in these educational institutions did not associate PI students with educational achievement, college aspiration, or majoring in STEM. Participants shared how they had to fight off imposter syndrome and advocate for themselves, seeking out navigational support agents who understood and knew their potential in STEM. Elisiva wanted information about medical school and her advisor told her that "Hawaii kids aren't smart to get into med school." 
Langi, who was inspired to major in bioengineering because her grandfather wanted her to invent a breathing tube that did not hurt, stated:

And so I started researching, researching, researching, [and] found bioengineering. I didn't really have any teachers in high school that looked like me. When I had gone to the counselor's office and I had asked her for help to help me with my applications, she was like, "Well, aren't you going to get a sports scholarship?," making assumptions that I was an athlete. And I was like, “Why do you think that?" ... And she's like, “Aren't you Polynesian or something?" And I was like, "And I'm the most unathletic Polynesian." [laughter] I was like, "So I'm going to school on my brains." And she was like, "Oh.” And so that was kind of a dead end for me.

Langi attended a predominately White high school, which negatively impacted her experience as a self-motivated and high-achieving underrepresented student. She had solid grades, had completed AP courses, and had done her research on which colleges to attend, but she needed help with applying for college. Langi's experience of being stereotyped by her guidance counselor as an athlete because she was a PI almost discouraged her from majoring in STEM. Fortunately, her AP biology teacher, her navigational support agent, encouraged her.

STEM Gatekeepers. Pacific Islanders have had to face numerous gatekeepers as a STEM major, from middle school through high school to college and into graduate school. For this research, STEM gatekeepers are defined as individuals and as common and normalized practices that control access to STEM. STEM gatekeepers include peers, faculty, and advisors. Fetu shared his experience with STEM gatekeepers and how he had to prove to them that he belonged in STEM: 
It really messes with your head because it makes you rethink why you're there, or is this the right decision, or there's something I did. But at the end of the day, it's not you. It's a flawed system that oppresses others ... I think those are the types of barriers.

As PIs navigate their way to major in STEM, individuals such as guidance counselors are supposed to advise students on how to map out the semester and the school year. For PIs who were the first in their family to attend college, an academic advisor played a key role in navigating college. But unfortunately and too often, some students were discouraged and misinformed. Experiencing similar circumstances as expressed in Makana's quote, several participants were advised to leave STEM. In Hamani's case, his guidance counselor ignored his request to meet about college. For Heilala, the community college counselor assigned to her was the same counselor that had misguided her friends, also PIs, to spend an extra year before transferring. Heilala researched the catalog, chose her classes on her own, and got her class schedule for the semester approved with another college counselor. Heilala did not trust her assigned counselor and did not feel that he had her best interests in mind or that he wanted PIs to succeed.

In another example, Latai was looking for guidance on what her next steps should be in transferring to a 4-year college. She told her guidance counselor about her future goals of being a doctor and majoring in physiology. Advisors and counselors have a critical role in how PIs are perceived and advised, which impacts how they navigate STEM. Latai shared:

So at the community college, I talked to a guidance counselor about it and told him, "Do you think I could ever become a doctor?" He was like, "No. That's not going to happen." $\ldots$ The campus that I was at ... is mostly known as the poor school ... And so I don't think he was being malicious. I think he's been jaded after seeing so many students come 
from these poor backgrounds - I mean poor educational-wise — and not be able to succeed in college, and so I think he was trying to be realistic when he told me. And I told him about the physiology major, and he was like, "No, don't do that major. It's really hard. Do something a little easier. Like why don't you become a teacher or like a nurse or something?” And I was like, “Oh, okay.”. . . So I didn’t know anybody who ever had STEM background, and ... I just believed him, and I was, “Okay, I guess I won’t ever be able to become a doctor." And so I just set that aside because they're the professionals. They're the ones that are supposed to know.

Latai described the reputation of her community college to rationalize why her guidance counselor would shoot down her goals of becoming a doctor and majoring in STEM and instead suggest several other majors in which she had no interest. The underrepresentation of PIs in STEM seemed to justify the counsel she had received, and PIs want to believe that those in positions of power and experience are looking out for them. Fortunately, Latai told her physiology professor what the counselor said and was told to ignore his advice. The participants who had been ignored, misled, treated unfairly, or discouraged by faculty, staff, or peers reached a point at which they stopped navigating under the influence of negative gatekeepers and began wayfinding their own path.

STEM Gatekeeping Courses. Most students take 4 to 6 years to earn a degree in STEM because some majors require many math courses and several general introductory STEM courses. Failing one course can set a student back, especially if that course is part of a series and not offered every semester. For instance, Mareva majored in environmental science but did not like math. She shared: "I suffered through, I think, nine math classes to get through because they 
were required." Had Mareva failed one math class, that would have set her back for requirements for other courses and, ultimately, delayed her graduation.

STEM is notorious for requiring courses that weed out students. For instance, a general biology or general chemistry course held in a large lecture hall could serve as a STEM gatekeeping course because it is commonly known and accepted to reserve space for students who are "made for" STEM. The size of these courses can be intimidating, as Tuitavuki shared about his first introductory STEM course, saying, "So you can only imagine this kid from Tonga walking into a lecture room filled with 250 people. But, hey, you've got to adjust. You learn to adjust to the environment. That's how we survive." Tuitavuki's weeder course was as large as his graduating class in Tonga. Like many students in STEM, Tuitavuki understood that part of the STEM culture is to discourage him and that he has to acclimate to make it in STEM.

\section{Wayfinding: Pacific Islanders Forging Their Own Path}

There's not a straight line from high school to college ... it's just this huge curve upwards.

—-Toahola, Biology-BA; Medical Student

Wayfinding is how PIs were able to navigate the Moana (Pacific Ocean). PIs would leave their home island in groups consisting of family members and close friends, with essential supplies, experienced navigators who could read the stars and understand the currents and the temperature of the water, and a strong vaka (canoe). Today, PIs who have immigrated to the United States and PIs who have majored in STEM are wayfinders in that they have had to navigate systems to survive and thrive. Some systems that PIs have had to navigate through wayfinding are immigration, economic matters, health care, and education. Some people within 
these systems have been helpful, and PIs have been able to navigate. Some have been less than helpful, and PIs have had to create their own solutions through wayfinding. In wayfinding, PIs try to figure out the system on their own or, more often, work with those they trust, those who have successfully navigated the system.

Resistance Through Wayfinding. Navigation and wayfinding are interrelated in that both find direction based on knowledge, but wayfinding "has the dimension of being a type of wisdom grounded in collective past experiences that creates resourcefulness" (Page-Reeves et al., 2019, p. 188). The participants in this study had the precollege experiences to persist in STEM, even through the experiences associated with being marginalized, such as dealing with gatekeepers, navigating resources on campus, enduring unwelcoming STEM culture, and managing through attacks on mental health and isolation.

Echa was a biology major on the pre-medicine track, who described her class of more than 200 students as very competitive and cutthroat. She became disinterested in the topics and was not able to connect with her STEM major. Echa said, "Then I found ethnic studies, so I felt drawn to that and building community through academia." Because of her PI cultural background, Echa had missed the sense of community lacking in her STEM major, which was the reason for her resonating with ethnic studies. As shown in Echa's educational trajectory map (see Figure 6), she took a route into the social sciences from STEM as a form of resisting the STEM culture. She managed to graduate with degrees in both ethnic studies and biology, with high honors. Similar to Echa, several participants completed coursework in ethnic studies or PI studies to find some kind of connection to or validation of their identity in higher education, which helped them to resist and look to wayfinding in STEM. 


\section{Figure 6}

Echa's Educational Journey Map

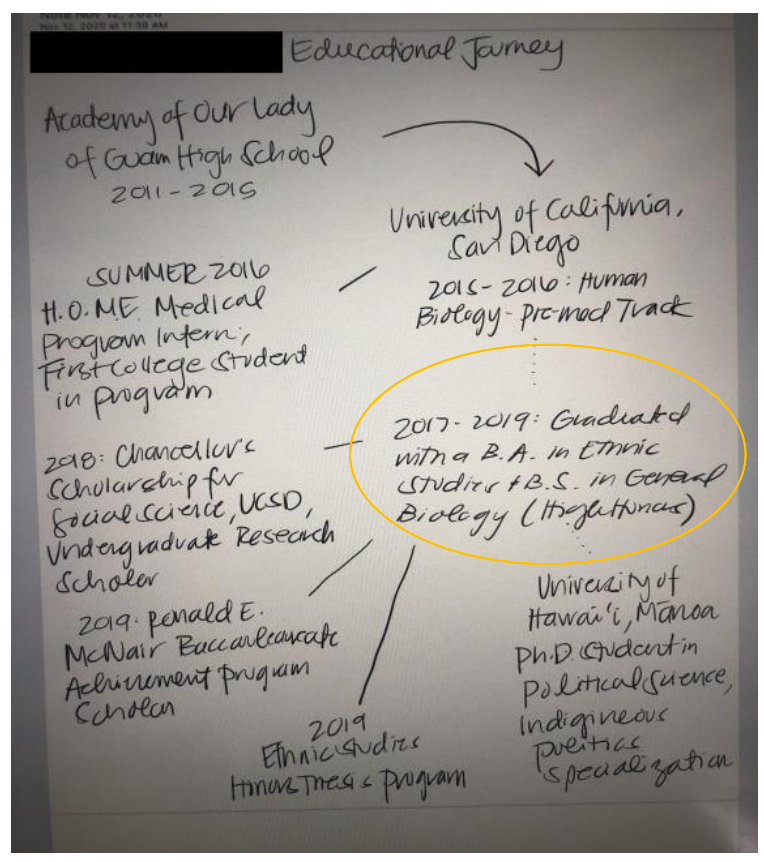

Participants overwhelmingly talked about the STEM culture at their intuitions as unfriendly and competitive. For instance, Manu could not see the board and asked a student if he could see his notes. Manu said, "Coming from a communal-based community-you know what I'm saying? - You're like, 'Damn, why can't we all just work together, and all get good grades?' But people be like, 'No, you can’t copy my notes,' type, right?’

The lack of confidence and microaggressions from peers, faculty, and staff at their institution, and especially in STEM, empowered PIs to resist and revert to creating their own path using wayfinding. Yosso (2005) refers to this as resistant capital, or "those knowledges and skills fostered through oppositional behavior that challenges inequality" (p. 80). For PIs in STEM, wayfinding is a form of resistance that has inspired them to successfully navigate STEM. 
Over half of the participants in this study were in some way discouraged from majoring in STEM, which only motivated them to go beyond an undergraduate degree to earn a graduate or professional degree. PIs in this study were expected to go to college and were told by their family to become engineers and doctors to help the family and the community, exemplifying familial and aspirational capital as motivation. There is such a strong sense of respect, responsibility, and love in a PI family that the idea of not being able to fulfill a role in the family had not been an option. The participants knew that their family wanted the best for them, because their family told them that they chose to leave their home island and move to the United States so that their children could have more opportunities. Although participants were encouraged to drop out of STEM, they were raised to succeed, and so they respectfully resisted by finding resources and networks of support on their own. Additionally, participants used their resistant capital to tutor and mentor PIs on campus and in the community to encourage more PIs to major in STEM.

Finding Pacific Islander-Culturally Relevant Signs. Wayfinding expands navigation in giving the wayfinder the agency to use past experiences and cultural knowledge to create a path that is more familiar and more effective. The wayfinding ancestors of the Moana, used natural cues such as the stars for direction, ocean swells to locate invisible low-lying islands, and birds that signal that land is near (Duncan Seraphin et al., 2021). Most of the participants attended large predominately White institutions and shared how they were unable to connect with or relate to their peers, staff, faculty, institution, or their STEM major. But seeing or meeting another PI on campus solidified their decision to attend that school. Knowing that another PI was in STEM was also reassuring. PI representation helped participants feel some connection to their campus and STEM major and encouraged them to navigate STEM. Coming from cultures with a common history and shared values, from where relationships extend beyond 
the nuclear family and the community, being able to connect with or relate to others is a culturally relevant sign for a PI.

For Langi, her PI-culturally relevant sign was finding a PI who had graduated with a degree in STEM. Langi talked about her mentor, who was a PI who had graduated with a degree in STEM:

And she was one of the first people that I had ever seen succeed in a STEM degree who was PI. And that was the biggest thing to me. I had never met somebody who knew the struggle ... And it was a refreshing thing to me to be able to speak to another person who was like, "You made it. Okay." So I know I'm not out here just treading-Yeah. Just not treading water, low-key drowning all the time ... So she has always inspired me, and I will always aspire to be like her because she is so community driven. Everything she does is with the community in mind. And that is somebody I will always aspire to be.

Langi met her mentor during her junior year, when she was struggling to stay motivated in her STEM major. Langi's mentor was a reminder that Langi was still a PI in STEM who valued community, a concept that Langi felt had been missing or not emphasized in her major.

For participants who felt disconnected to their school and STEM major because of being discouraged, underserved, ignored, and advised to leave STEM, the negativity led them to wayfinding. Participants had been searching for PI-culturally relevant signs that they could connect and feel that they belonged. Participants enrolled in ethnic courses and PI ethnic studies, joined PI clubs or organizations, did study abroad or research in PI states and countries, and volunteered to mentor and tutor in PI communities. Tania shared how she "naturally gravitated" to the Indigenous community on campus because "they're like Polynesian Pacific Islanders." Being a part of the Indigenous community was "very siloed, very comfortable" for Tania, and 
importantly, it was the sign that she belonged in STEM and felt the support to navigate STEM through wayfinding.

For some participants, college choice was determined by knowing another PI attending that school or seeing a PI during a college visit. PIs have often chosen a college because it had offered a better financial aid/scholarship package, its athletic programs drew them, or often it was where their family members or PI friends had attended. For instance, Manu's college choice was based on the athletic program, but he had doubts after his injury prevented him from playing football. Manu met a PI who was a sophomore at the school he was interested in. He shared, "And so he was cool ... He was also majoring in STEM, and he told me he had a really positive experience. And so that's ultimately why I chose UCLA.” Manu felt he could relate because they were both approachable PIs who were interested in STEM, which made the decision for him.

Participants shared that experiences of seeing PIs or PI clubs on campus during a campus visit gave them a good feeling about the campus. Fetu said:

When I went to Otemanu College for my interview, it was amazing . . . there was a big Pacific Islander Student Association at Otemanu College, and . . they were having a meeting. So all of that actually made that experience very positive for me ... I had said no to Otemanu College, right, because I accepted another school . . . So it was such a hard decision ... I rejected the offer, and I called Otemanu College again like, "Oh, do you still have the position?"

Fetu's experience of encountering the Pacific Islander Student Association (PISA) during an on-campus visit for an interview was a feeling that he did not experience at the other school campus whose admittance he had accepted. He was elated that there was more than only a single PI but a large group of PIs, which looked like a community he identified with and could speak 
Samoan with. Before visiting Otemanu College, Fetu had rejected their offer but did not hesitate to ask if there was still a space for him. PIs are wayfinders who look for signs for direction or warning, and like Fetu, seeing PIs on campus was a sign that he should attend Otemanu College.

\section{Theme 2: Vā: Creating V̄̄ (Space) Through Interpersonal Relationships and Social}

\section{Connections}

I had another advisor, and she was Black, and she's like, "Look at your classes. Do you see anyone else who looks like you?" And I was like, “No.” She's like, “Think about all the brown girls out there who need you." And I was like, "Okay."

-Langi, Bioengineering-BS

Social connections and relations are important in PI culture and also for PIs in STEM. Social capital for PIs is creating meaningful relationships that are reciprocated to maintain a strong connection and accountability. The ability to connect is a PI-culturally relevant sign that indicates to PIs of being in the right vā (space) and on track in their navigation and wayfinding in STEM. This is important because the competitive and individualistic culture of STEM is not inviting or conducive to PIs, so they are transforming the culture to create vā (space) through PI cultural capital and tauhi vā.

Langi, featured in the quote introducing the second theme, searched for the right advisor and found one who she could connect and relate to, a woman of color in STEM. Her advisor knew she was struggling to stay motivated in her STEM major and inspired Langi to understand that her presence in STEM was important. The advisor nudged Langi to take up space and encourage the upcoming generation of women of color. Langi's relationship with her academic advisor reminded her of her mentor, who was the first PI she met who had graduated in STEM. 
Langi's social capital came in the form of women of color in that she was able to have

meaningful vā (relationship) with others who wanted her to succeed like her family.

$\mathrm{V} \overline{\mathrm{a}}$ (space to relate) are found in personal and social connections with peers and faculty and in PI clubs or groups. Vā provides support and a sense of belonging in STEM that allows PIs to succeed through navigating and wayfinding. Echa shared, "Interpersonal relationships is how I best thrive and how I learn the best, because that's just our sense of community that we've been raised with." Creating vā (space) through interpersonal relationships and social connections is social capital and is prevalent in PIs' navigation in STEM.

Demonstrating Theme 2, the PIs in this study needed a vā that was supportive, where they could connect with others because of the obstacles they had experienced in STEM. Table 8 summarizes the themes and subthemes of why and how participants were creating vā, addressing their experiences as a PI in STEM, support systems, and STEM sense of belonging.

\section{Table 8}

Creating Vā Theme and Subthemes

\begin{tabular}{ll}
\hline \multicolumn{1}{c}{ Theme 2} & \multicolumn{1}{c}{ Subthemes } \\
\hline Vā: Creating Vā (Space) & $\begin{array}{l}\text { Finding Vā (Space) to Connect and Nurture Relationships } \\
\text { and Well-Being }\end{array}$ \\
Through Interpersonal & - Why Vā Matters \\
Relationships and Social & - Vā (Space) to Connect and Relate \\
Connections & - Vā (Space) to Nurture Relationships and Well-Being \\
& Pacific Islanders’ Experiences in STEM \\
& Pacific Islander Cultural Capital: Creating Vā (Space and \\
Relationships) & - Pacific Islander STEM Support System \\
& - Pacific Islander STEM Sense of Belonging \\
\hline
\end{tabular}




\section{Finding Vā (Space) to Connect and Nurture Relationships and Well-Being}

"In Tongan culture 'relationship is described by the concept of 'vā'”, (Taufe'ulungaki, 2004, as cited in Mila-Schaaf, 2006, p. 11). Pacific Islanders are a communal and collective peoples, for whom connecting and building meaningful relationships with others is a way of life and survival. As PIs migrated to other islands and countries, connecting became even more important as a way to help one another find work, housing, and support. To maintain those connections, PIs strengthened the bonds through reciprocity by exchanging services, attending life events, and giving monetary or materialistic gifts to acknowledge and nurture those relationships. Similar to how their parents and ancestors thrived, all 31 participants shared how social connections and interpersonal relationships helped them to survive a STEM environment that was not encouraging of or related to PI culture.

Why Vā Matters. Research shows that students who live on campus are more likely to persist than students who commute. This is because resident students have the opportunity to build relationships with peers, staff, and professors through participating in extracurricular campus events and taking on leadership roles (Astin, 1999). In this study, 76\% of the participants lived on campus for the first year and participated in sports, dance groups, study groups, orchestra, clubs, and first-year mentoring programs, but most did not feel like they fit in at school. Hamani shared his campus experiences:

They're the typical third-, fourth-generation White kids who are there. And I felt like there's a lot of entitlement there. Even at times racist, really racist vibes ... getting stared at everywhere you walk on campus. But the sad thing is, I feel like a lot of that attitude was portrayed by professors. I just felt this wall between me and professors. And so I could never connect with them, even if I went to office hours. 
Hamani’s experience was common to many PIs who had a difficult time connecting with professors and peers. Hamani was able to connect with PIs through extracurricular activities and clubs, which helped him to stay focused and reminded him that he rightfully belonged on campus and in STEM. Also, having one professor remember his name validated him as a student at the university.

To be fully integrated in a predominately White college as a Pacific Islander was challenging to say the least. Several participants shared similar experiences of being turned down by peers when they asked if they could be lab partners or if they could join their study group. Most participants complained about how competitive and cutthroat their STEM major was, and peers and professors treated them like they were not intelligent enough to be in STEM. Aloha shared sentiments that other participants also sensed: "I always felt like I was judged, like they automatically assumed I wouldn't be smart." Experiences like these made going to class less appealing, which had a negative impact on the mental health and academics of many of the participants. Physical and verbal cues had the same effect, particularly if the majority of peers, faculty, and staff were behaving negatively and the behavior had been normalized as part of the campus culture. Participants began creating vā (space) through wayfinding to connect and heal with others who they could identify with ethnically or who had had similar negative experiences.

Vā: (Space) to Connect and Relate. As a collective culture, community is how we as PIs thrive. Community takes up and makes space for those who share a common history and values and who create meaningful and supportive relationships. PIs are a minoritized population on most colleges and universities, so seeing another PI was validating for the participants. Echa shared: "Whenever I did meet someone who was a Pacific Islander-I was so homesick—it made me feel so much better.” Although Echa felt homesick whenever she ran into another PI, 
she sensed a special vā, a connection that reminded her of home back in the islands. Several participants admitted that their college choice was confirmed from seeing a PI on campus or knowing that a PI attended the school. PI representation is a sign that there is vā (space) to connect and find support and an opportunity to build relationships, which is important to PIs culturally, socially, mentally, and emotionally.

As a freshman, Manu was introduced to the Pacific Islanders Student Association by another PI who was an upperclassman. Manu stated:

It's really cool to be with your peoples, considering that there's not really many of us. We don't even make up like $1 \%$ here at Otemanu College, and that's Otemanu College-wide, too ... But it's kind of funny because there's about, what, like 20,30, and that's kind of a lot to me because I didn't go to school with that many Pacific Islanders, so I still feel like we're blessed to even be around our peoples and see them in higher education.

Similar to many of the participants in this study, Manu finally had the opportunity to attend school with other PIs. Although PIs are highly marginalized at his institution, the small population was larger than Manu had expected and was inspiring for him.

During the interview, I asked participants to provide an artifact (see Figure 7) that represented their underrepresented identity in STEM. Aloha shared a picture of Dr. Kiana Frank, a Native Hawaiian assistant professor in the Pacific Biosciences Research Center at the University of Hawaii, Manoa. Aloha said:

She just does cool cultural stuff but ... she's still super knowledgeable. But the way she presents herself isn't this really hierarchical, egoistical person. She does dances to show people how to understand science ... And she's just in the water. And I really like that since I study water rights. 


\section{Figure 7}

Aloha's Artifact of Dr. Kiana Frank

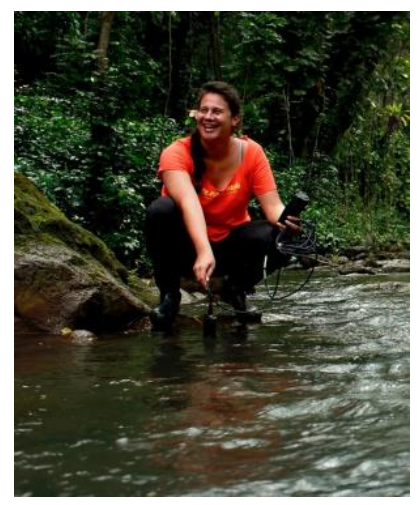

For Aloha, she was able to relate to Dr. Frank because they were both Native Hawaiian with similar interests in STEM. As a Native Hawaiian who grew up in Hawaii, Dr. Frank felt a responsibility to conduct research that acknowledges Native Hawaiian ways of knowing and that benefits Hawaii and Native Hawaiians. Dr. Frank used hula to teach STEM, which resonated with Aloha and provided vā in STEM for her to do the same.

Most participants attended predominately White high schools and had few interactions with PIs until coming to college. Participants who were able to connect with other PIs on campus were able to build meaningful relationships of support and healing. For instance, Hina was an athlete who grew up in a predominately White town and attended a predominately White high school. She lived on campus where she met four PIs during her first year, and they studied, played volleyball, and hung out a lot. As an athlete and a STEM major, most of her peers were 
White. She made time to bond and build relationships with her PI friends and found out just how special her vā was with them when she was injured. Hina shared:

I saw my palangi [White] friends, my teammates, who I thought were close. They didn’t even care when I tore my ACL. But my Tongan, Samoan friends, they were there when I had surgery. They slept with me. They'd wake me up to give me my meds, and they would make breakfast for me, and they would drive me to my classes. And that's our community. That's how we treat each other and stuff. Anyways, that's what led me to a lot of - "I finally found a piece of myself that I don't even know was missing growing up and stuff." And I finally felt like I filled that void a little. I don't know. Just finally being true to who I was, being someone from a Latinx and a Polynesian community, I had hid that for so long.

Finding out who her real friends were helped Hina define what it meant to be a PI. The care that was administered by her PI friends helped her heal physically and emotionally, and importantly, she admitted that she found something about herself that was always there. This was a pivotal point in Hina's life, because she began to see how she could create that same vā (relationships and space) in a major that was individualistic and competitive.

Vā: (Space) to Nurture Relationships and Well-Being. For the participants, on-campus PI clubs or groups provided a much needed space for PIs who needed a community to relate to and connect with. PI clubs or groups became a safe vā (space) for PIs to be their true selves, to support one another, and to serve their PI community. PIs were so highly underrepresented at the colleges and universities that the participants attended that one participant based his college decision on seeing a PI group during a campus visit. Mentors and members of these clubs 
insisted that it should be a vā to motivate and support each other academically, vā to enjoy being a PI student, and vā to help and inspire the next generation.

Langi was a member of a couple of STEM-related organizations, including the PI club at her university. Langi said:

So we always were really cognizant about academics first, and then we can do all the things that are fun. And so we were like, "We can't be mentors to our younger generation if we, ourselves, are not getting it together." So we always made sure that we would have get-togethers. There were only 10 of us on campus. There were only 10 Pacific Islanders on campus. We were 10 . We were 10 strong, but there were only 10 of us. So that was like my secondary family as well. We were always really encouraging ... we were supporting each other ... just reciprocity.

Langi emphasized the purposes of having a PI club and the number of PIs in the club and on campus. Langi wanted to point out that although the group was highly marginalized on campus, it was the vā that she looked to as a family because of the strong and meaningful relationships they had formed by encouraging and supporting one another. Reciprocity is Pacific Islander culture, community, and vā.

The PI groups were not limited to a formal PISA or PI club but included athletic, study, performance, and social groups. PIs found vā with other PIs who shared the same values and had similar upbringings, where they could meet other PIs and laugh and vent together. It was a space where they did not have to constantly explain what it means to be a PI. This idea extended outside of the community as well, with having a PI in other spaces being seen as a close protective ally or family member.

\section{Pacific Islanders' Experiences in STEM}


In chemistry, I was the only Pacific Islander there, but nobody gave me ish. It just seemed like my background was never like an issue. So even though nobody else was a Pacific Islander, I never felt left out. But in chemical engineering ... I just kind of felt left out, and my feelings of being left out kind of felt like they accumulated over time. And so senior year of college, I sent a kind of like an angry email out to one of my professors. Okay. I wasn't angry at her, but I was angry in general about how I didn't feel like I fit in.

—Noa, Chemical Engineering-BS; Chemistry, graduate student

The STEM culture has been described as chilly and individualistic, which is opposite to the warm, collective culture of Pacific Islanders. As described in Noa's quote, the participants felt similarly in that their underrepresentation in STEM was not a factor, but when the culture in their STEM classes was unwelcoming, competitive, and cutthroat as the norm, PIs felt like they did not belong. Echa described the feeling: "It does get lonely in STEM ... And it can get emotionally overwhelming." Many PIs have felt isolated and depressed with a case of imposter syndrome, which impacted their mental health. Kiaria said:

But especially if you're in STEM, and if you have impostor syndrome, it's really hard not to feel—get that low self-esteem. And sometimes some people will slip into depression. I know I did my sophomore year, and so I think the feeling of not being able to express it as well as I could because ... I didn't know how to because that's just how I was, I guess, raised.

Kiaria courageously shared her story of how imposter syndrome impacted her mental health. She was able to recognize what she was experiencing but somehow struggled through it 
because of her upbringing. It is prevalent in PI culture to endure the struggle and not talk about it. Younger generations of PIs are more knowledgeable about mental health and are able to talk more about it, often in hopes of helping others.

\section{Pacific Islander Cultural Capital: Creating Vāa (Space and Relationships)}

If we can build that community and feel the interconnectedness with the people around us, with the professors, with the things we're learning, I feel like the same thing goes. We will feel healed. We will feel able to do whatever it is, any challenge that we come across.

—Hamani, Biology-BS; Medical Student

Pacific Islander cultural capital is how participants in this study were creating vā in STEM to transform the unfriendly, individualistic, and competitive culture of STEM to resemble PI culture, which is more relational, community-like, and beneficial for all. Participants recognized that to successfully navigate STEM, they needed to create vā, a space with others who they could relate to, build meaningful relationships with, and nurture well-being. Those within the vā understand that to maintain vā requires reciprocity. For example, Holu was born and raised in Hawaii and had a very close relationship with her family. When Holu moved from Hawaii to the continental United States for graduate school, she knew that to succeed she needed to be herself and to create, as she quoted, a "surrogate family." Holu explained:

I feel like with people, if I'm with you, you're now a good friend. You're like my family. And so even my advisor here ... I'm just like, "Oh, you're going to get to know me, and I'm going to get to know you." I know his kids, his wife, his family, the dog. You don't just take the science part of me. You're my advisor. You're going to get all of me ... 
And he kind of reciprocated, and from then, I'm able to be really open and be like, "I'm not doing okay, and I cannot." And he's like, “Okay.” He gets it.

Holu needed to create a vā that was familiar to her PI culture and family back in Hawaii, so she was intentional in developing a meaningful relationship with her advisor outside of STEM that included knowing about each other's families. Several other participants were able to do the same with peers, advisors, and professors.

In the demographic survey, participants were asked to rank the most important factor that impacted their success in STEM, and you (meaning the participants themselves) was ranked first, followed by family second, and classmates/peers third. Participants said that they ranked themselves first because they were the ones in STEM but still ranked their family and classmates/peers in the top three because those factors provided two different types of support. Participants shared that families provided moral and emotional support and their classmates/peers who were in STEM understood the barriers and challenges, and they could support each other. This demonstrated that PIs creating family/community-like vā with peers/classmates was essential to navigate and persist in STEM.

In the demographic survey, some participants ranked their professors in the top three, for similar reasons related to having a supportive relationship. Elisiva ranked her professors second because they helped her so much, even meeting outside of school for help. Elisiva said, "I was there in their offices so often that they would just invite me over to their house because I was struggling a lot ... My professors really helped me through." Hina struggled in her first-semester introductory chemistry course and asked her professor for help, which really set a standard for her to meet all her professors. Hina shared, "It's always better just to get to know the professor, and they're going to recognize your effort." Toakase's professors helped her with applying for 
graduate school and finding a job. Elisiva, Hina, and Toakase learned how important it was to develop a relationship with their professors. Participants in this study understood that to create vā in STEM they needed to cultivate meaningful relationships with peers, advisors, and professors.

Pacific Islander STEM Support System. As more Pacific Islanders successfully navigate STEM, they come to understand that taking up space in STEM is important for other prospective PIs. Vā means the space between, so for PIs to occupy vā in STEM, it requires taking care of social connections and relations to create vā, so that other PIs may also find vā in STEM. This concept is tied to responsibility as a PI being part of a collective culture: to reciprocate what we have learned to others so that the community may benefit.

PI groups became a resource for information and opportunities for the participants. This wealth was vital, especially to first-year college students who had a difficult time navigating systems such as the financial aid office, registration, or course selection as a STEM major. Bob was grateful that she found PISA because there she found two other PIs who were pre-medicine that helped her plan out her classes. Many participants, including Tania, Bob, and Toahola, were able to find on-campus jobs, internships, research opportunities, and scholarships through their PI groups. Most PI groups were organic in that they usually started with a couple of people and then grew as folks got to know each other while building a sense of community and support. Heilala was part of a study group that consisted of PIs at her community college. She explained: So me, my sister, and ... a Palauan guy—and we were all pretty nerdy—so we would hang out at the library and then hang out at the English Center ... We became really good friends with the other islanders. Some were football players or volleyball players ... We started hanging out with them at the cafeteria. And then, eventually, we started to move closer and closer to the library. And then we all started hanging out in the library 
conference room. So then we ended up creating this huge study group, all of us. And we were helping each other out, right? So somebody would be like, "Oh, did you have soand-so last year for this class?" "Oh, yeah." "Can you help me with this?" So we really built this really beautiful collaborative friendship with everybody. Every Tuesday, everybody goes to lunch. "If you're not in class, come. Let's go to Denny's," things like that.

Heilala's PI group started out as a study group with three people and grew into a large learning community that migrated from the cafeteria to the library to meeting off-campus at Denny's. The group included athletes and other PIs on campus. Heilala mentioned in the interview that their support included attending their peers' football and volleyball games to sharing their lunch on a regular basis. The study session also included academic advising because Heilala and her sister had read the campus manual and become familiar with which courses were transferable and which were not. Learning and social communities are important for PIs in higher education.

Pacific Islander STEM Sense of Belonging. Internships and research opportunities, which Pacific Islanders are becoming heavily involved in, have been emphasized as a factor that increases persistence in STEM. Just over $40 \%$ of the PIs in this study had participated in some type of research or internship, which granted them needed experience in their field of study, insight into a future in STEM, and especially, creating a STEM sense of belonging that validated PIs doing STEM. Mareva shared her experience in the Research Experience for Undergraduate Program, stating:

I always saw science as like someone that wasn't me ... I didn't feel smart enough or good enough to be able to do that type of thing just because it wasn't something that I 
saw within my community ... that people like me or even us can do those types of things, and it's just not limited to race or anything. It's just a whole [mis]conception. And especially the whole presentation research, I didn't even know that was something that really existed. Well, I kind of knew, but I was just like, “I don’t even see myself doing that." And then the fact that I'm creating these presentations and sharing my research experiences and stuff like that, I feel like is really impactful because just, to me, it reminds me of kind of indigenous knowledge.

Mareva was a transfer student who did not think that research was possible logistically, and she did not see herself as a PI in STEM. She rationalized that PIs had not been known for being in STEM and that she did not have the knowledge or background in STEM. Mareva reflected on how doing and presenting the research helped her to connect STEM to her PI cultural knowledge. In fact, Ta'ata's research on using traditional medicinal plants in Hawaii as a sunscreen that did not destroy the corals in the ocean allowed him to travel and present at conferences, where he won multiple awards. PIs are highlighting PI traditional knowledge in STEM through research.

Research and internships have provided mentorship and guidance that PIs would have not otherwise received. Mentors have been navigational agents in helping PIs visualize themselves in STEM by giving them experience in how to apply STEM in the real world and by opening doors to opportunities. Talia worked with Dr. Samoa, who is a leading expert in the COVID-19 Pacific Islander Task Force. Talia described the experience:

So I got to work with him during my undergraduate, and that has led to more opportunities. So I'm still supporting him with those national calls . . . with the response team and the data policy team that we're a part of through UCLA. So he's really been a 
huge mentor throughout my entire undergraduate and graduate professional experience.

So mentors really played a huge role in terms of the opportunities I was learning about.

Talia's undergraduate internship with the City of Hope focused on the noncommunal diseases of diabetes and obesity, both prevalent in the PI community. Her internship afforded her the opportunity to work with Dr. Samoa, which led her to gathering data and doing research to inform PIs about COVID-19. Although her internship ended, Talia created a relationship with her mentor, who has continued to guide her.

Participants used wayfinding to make vā (space) in STEM that resonated with Pacific Islander cultural identity. As participants began to connect and build meaningful relationships with peers, advisors, and professors, they created a support system and sense of belonging in STEM, and developed navigational capital, social capital, aspirational capital, resistant capital, and PI cultural capital. Participants learned to navigate educational spaces by developing social capital through connecting with peers, advisors, and faculty because they were motivated by their aspirations to succeed in STEM, desired strong family support, and wanted to debunk the PI stereotype.

\section{Theme 3: Tauhi Vā: Taking Care of Relationships Within These Spaces Through}

\section{Reciprocity}

Pacific Islander to me is not just who I am but what I can do to, sort of, represent the Samoan community, the Pacific Islander communities, in terms of how decisions are made that can impact at least the drug discovery or the medical development of these drugs for us.

—Fetu, Biology-BS; Biochemistry-PhD 
The participants wanted to give back to the communities from the islands they come from. Some have gone back to the islands to do research, learn from the elders about medicine, or figure out how they can apply their STEM degree to help. In the quote that opens this section, Fetu's identity is connected to his PI values of using his STEM degree to represent his community and make decisions that impact PIs' health. Fetu is taking care of his relationships by fulfilling his responsibility to address the needs of PIs in his area of expertise.

\section{Table 9}

Tauhi Vā Themes and Subthemes

\begin{tabular}{lc}
\hline \multicolumn{1}{c}{ Theme 3} & Subthemes \\
\hline $\begin{array}{l}\text { Tauhi Vā: Taking Care of Relationships } \\
\text { Within These Spaces Through Reciprocity }\end{array}$ & Transforming STEM Through Tauhi Vā \\
& Responsibility and Reciprocity in STEM \\
\hline
\end{tabular}

\section{Transforming STEM Through Tauhi Vā}

PIs on college campuses have been taking care of vā (space) outside of campus and serving their PI community. PIs in STEM have gained a wealth of knowledge through overcoming many obstacles and discovering resources that have helped them navigate STEM. The participants remembered how others supported them, recalled friends who dropped out, and understood how PIs are underrepresented on campus. They have encouraged prospective students and mentored and tutored first-year students on campus and high school students in the community. On-campus PI clubs have sponsored and facilitated high school outreaches and conferences as a way to bring PIs to campus to experience a typical day of college. And PIs in 
STEM have been finding ways to bring more PIs into STEM. Langi, as the president of the Pacific Islander Student Alliance on her campus, was inspired by her mentors to practice outreach to her community. Langi shared one such interaction:

So I was also in PISA, the Pacific Islander Student Alliance ... The one theme that one of my mentors had always talked about was reciprocity. Reciprocity: how are we reciprocating what is given to us and giving it to the younger generation, right? How are we giving back to the community? ... And so it was always to me like, "How am I going to give back to students?" And so during PISA, we had outreaches. And that's when I would go to the local high schools in Taki Falls. And I tell them, like, "I'm studying engineering. Let's talk about what that means." They're like, "Oh, I really like math." And I'm like, "Great. Do you know who really likes math? Engineers.” And so I pushed my agenda of engineers and STEM on them. And they were like, "Do you know how much money engineers make?" I was like, "Exactly. Do you know how much money is waiting for you?"

Langi lived in an affluent White neighborhood and knew only one PI family. So when Langi's mentor asked about her giving back to the PI community to share her knowledge, Langi did not know how. Thanks to the PISA club and her mentor, Langi and the PISA members began to tutor high school students in the local community and share their college experiences. Langi remembered how her older sister had graduated from college and helped her with applying for college. Langi realized that as a PI it was her responsibility to reciprocate what had been done for her.

Younger generations of PIs in STEM have gained a wealth of knowledge from mentors, PI role models in STEM, and personal experiences. There was a sense of humility among the 
participants; they always recognized those who had helped them navigate STEM, such as their family, peers, teachers, advisors, and PIs before them, who had laid down a path for them to follow. As a collective culture, PIs shared how their journey to STEM was not for their own benefit but for their community, feeling a responsibility to their PI community. Aloha said, "If I do this, then maybe I can make way for someone else. Maybe if I push the edge a little bit, it'll be a little easier for someone else." Aloha wanted to increase the representation of PIs so that PIs in STEM become the norm and not a novelty.

\section{Responsibility and Reciprocity}

But I think, more culturally, something I've noticed, not just within my own community but meeting other Pacific Islanders, it's just this sense of interdependency and helping each other out when we need it, which is so big. And you don't quite find that anywhere else.

—Leihana, Microbiology-BS

The participants recognized that going to college was a privilege and felt a sense of responsibility to share what they knew with their community, so that others might have aspirations to go to college. Nienkapi, the daughter of parents who were both medical doctors, attended one of the best private schools on the island, and she and her siblings were college graduates, so she knew that she had more privilege than most PIs. During the interview, I asked Nienkapi if she was actively engaged on campus with school events or activities. She talked about how her Micronesian Club volunteered in the Micronesian communities:

All of the Micronesian college students would go feed the homeless or go to low-income housing, and just volunteer to tutor and just be around Micronesian kids to let them know 
that even though you're Micronesian [and] you're discriminated against, you can go to college ... Parents really liked that their kids had that—because in low-income housings, not a lot of people go on to attend college.

Nienkapi, as well as her Micronesian schoolmates, did not like seeing their community being discriminated against and wanted to inspire the kids to go to college by helping out and getting to know them. Nienkapi got to know the community well because she volunteered all 4 years of college.

PIs were paving the way for other PIs, to reciprocate the actions of those who helped them navigate STEM. Through PI clubs and groups, PIs were reaching out to high schools and informing their students about STEM, tutoring and mentoring PIs on college campuses, serving their highly vulnerable communities, and reimagining other pathways for giving back. Hina voiced why it was her responsibility to give back and to represent PIs making it in STEM through navigation and wayfinding. Hina said:

So I truly feel I wouldn't have gotten to this point without the people who came before me. I had mentioned Dr. Pua and all those professors that helped me, but Dr. Pua was a really crucial role in my application process. And there was a Samoan med student ... he took his time to edit my application and gave me really good feedback, things you pay money for other people to do. And even the things Dr. Pua did for me, without them, there's no way I would have ever been accepted to medical school. And so I feel like I am a product of the sacrifices of my ancestors but also those people who came before me. And so I mean, when you get to that point, to make sure you turn around and you open the door for those behind you, because we're a community. And that's a really important thing to me. And so, yeah, that's how I met Toahola. We started this group, Polynesians 
in Medicine, an Instagram page ... we've met so many students from it already, like premed students. And it's been really fulfilling for me ... because it's that feeling of the community... . Those behind us will do it so much better than we did. It's okay if their journey takes them several places, but at least, they know they have people ahead of them who are here to help and support them.... There's always a way to figure it out. And once you arrive there, it's important to turn around and open the door for everyone else. Hina's recognizing those who had helped her was a way of showing gratitude and acknowledging the knowledge that was passed down to her. It was Hina's way of telling the PI community that these individuals created vā for her in STEM by helping her apply for medical school, and in return, Hina was tauhi vā, or taking care of her sociospatial relations by inspiring and inviting other PIs into STEM and medical school through Instagram.

\section{Summary}

In this chapter, I presented the three main findings, or themes, of this study: Navigation and Wayfinding: Following a Forged Path to Forging Your Own Path, Vā: Creating Vā Through Interpersonal Relationships and Social Connections, and Tauhi Vā: Taking Care of Relationships Within These Spaces Through Reciprocity. The findings included data from demographic surveys, educational trajectory maps, artifacts, and one-on-one interviews provided by 31 participants who revealed how they navigated STEM through their lived experiences. Throughout this qualitative study, I examined extensive samples of narratives, artifacts, and educational trajectory maps from participants guided by these research questions:

1. How do community cultural wealth and tauhi vā influence the navigation of Pacific Islanders in STEM? 
2. How does tauhi vā create vā specific to Pacific Islanders to wayfind STEM and develop community cultural wealth?

The first finding of this study, Navigation and Wayfinding: Following a Forged Path to Forging Your Own Path, addressed the first research question in that PIs began navigating by following a path that many had previously used to navigate STEM: attending a good school, achieving a high grade point average, completing AP courses, taking high-level math courses (e.g., algebra/trigonometry, precalculus, calculus), taking science courses, meeting with a guidance counselor or an advisor, meeting with professors during office hours, living on campus, and participating in extracurricular events and activities.

The navigation of the participants in this study was strongly influenced by familial, aspirational, social, and navigational capital. PI families played a key role in prioritizing education by sending their children to good schools, meeting with teachers and counselors, and providing a college-going culture in the home. Families used and developed social and navigational capital for their children to utilize and benefit from. Aspirations to attend college and to major in STEM originated with their families, which inspired participants to navigate STEM. As members of a highly marginalized population, participants faced barriers of being stereotyped as only being good in sports but not smart enough to major in STEM. Some were advised to leave STEM. At this point, participants stopped navigating and began creating their own path by wayfinding as a form of resistance.

The study's second finding, Vā: Creating Vā Through Interpersonal Relationships and Social Connections, answers part of the first and second research questions. Participants realized that the individualistic and cutthroat STEM culture did not align with their collective and community-like culture, which is maintained by taking care of sociocultural relationships, or 
tauhi vā, a PI cultural value. Through wayfinding, participants looked for PI-culturally relevant signs, or aspects of their cultural upbringing that were familiar and supportive, to create a vā (space) to navigate STEM. Vā is defined as (space) to relate and to nurture relationships and well-being. Participants connected with other PIs and individuals on campus through clubs, study groups, and extracurricular activities. By creating vā (space) through tauhi vā, participants developed PI cultural capital to transform STEM to work for them. This included building a support system that was community-like, one in which they could vent their frustrations and share resources, and where every person benefitted and reciprocated the help they received to another person. Through internships and research opportunities, participants took up vā (space) in STEM and developed a PI STEM sense of belonging as a result of being able to see that PIs belong in STEM.

The third finding, Tauhi Vā: Taking Care of Relationships Within These Spaces Through Reciprocity, answers the second research question in that tauhi vā transforms STEM to be less individualistic and cutthroat and more reflective of PI culture and community. By taking care of relationships with peers, advisors, and professors, or tauhi vā, participants developed community cultural wealth (e.g., navigational capital, social capital, aspirational capital, resistant capital) by wayfinding to create vā (space) in STEM for themselves and other PIs. As a collective and communal people, participants felt a sense of responsibility to share and help others succeed, to reciprocate in sharing the resources they had received in order to benefit the whole community.

Findings from the educational trajectory maps, demographic surveys, and artifacts supported the findings from the interviews. The study demonstrated that successful navigation of PIs in STEM has been strongly influenced by the application and accumulation of community cultural wealth and the transformation of STEM through tauhi vā. 


\section{Chapter 5: Discussion, Reflections, and Recommendations}

In this study, I set out to examine how community cultural wealth and tauhi vā influence how PIs navigate STEM. The PIs in this study described how familial and aspirational capital prepared them to navigate STEM with strong precollege experiences, but they still faced obstacles and barriers before and during college. PIs in this study were discouraged to major in STEM and stereotyped by counselors, professors, and peers, which became a motivating factor for PIs to use their resistant capital and change the narrative that PIs do not belong in STEM. Their experiences centered on how these setbacks inspired them to use what was culturally familiar to them to transform STEM to be more relevant to PI culture and to make space for other PIs. The findings of this study fall around three themes: 1) Navigation and Wayfinding: Following a Forged Path to Forging Your Own Path, 2) Vā: Creating Vā (Space) Through Interpersonal Relationships and Social Connections, and 3) Tauhi Vā: Taking Care of Relationships Within These Spaces Through Reciprocity.

\section{Navigation and Wayfinding: Following a Forged Path to Forging Your Own Path}

The PIs in this study had strong precollege experiences, such as high SAT scores, high GPA, family support, and completion of high-level math courses and AP courses, which predicts high persistence and degree completion in STEM (Bonous-Hammarth, 2000a; Chang et al., 2014; Chen, 2009; Cole \& Espinoza, 2008; Ehrenberg, 2010; Palmer, Davis, \& Maramba, 2011; Palmer, Maramba, \& Dancy, 2011). Yet even with strong precollege experiences, PIs have had negative experiences that are consistent with high-achieving students of color in STEM, such as stereotype threat and negative racial experiences with peers, advisors, and professors on campus, in the classroom, and during advising, which act as barriers in STEM (Allaire, 2017; BonousHammarth, 2000a; Chang et al., 2011). Unfortunately, highly achieving students of color are 
susceptible to stereotype threat for not fitting society's description of a person in STEM and are told that they do not belong in STEM or are not smart enough to be in STEM, which can negatively impact their persistence in STEM (Allaire, 2017; Bonous-Hammarth, 2000a; Chang et al., 2011; Spencer et al., 1999; Steele \& Aronson, 1995).

Familial capital played a key role in how PIs were persisting and navigating STEM. Although $65 \%$ of participants were first-generation college students, parents' education levels did not negatively impact their precollege experiences. In fact, PI families prioritized education and supported their children to go to college by creating a college-going culture at home, providing emotional support, and making financial and physical sacrifices. Similarly, research has found that familial capital helps to cultivate and maintain early interest in STEM and provide support and motivation to persist, with family being extended to include trusted peers, advisors, professors, and supportive community found in student clubs and organizations (Burt \& Johnson, 2018; Denton et al., 2020; Duran \& Pérez II, 2017; Rincón et al., 2020; Samuelson \& Litzler, 2016). Grandparents, parents, and uncles shared their aspirations with participants for them to become a doctor or engineer, which developed a sense of obligation to the family because of the sacrifices they made and support they provided, which Uehara et al. (2018) discussed in his research on PIs' experiences in higher education.

Reflecting the results of research on high achieving students of color (Allaire, 2017; Bonous-Hammarth, 2000b; Chang et al., 2011), 28 of the 31 participants enrolled in college immediately after high school despite stereotype threat, inadequate advising from guidance counselors, and lack of support from teachers to go to college. Ah Sam and Robinson's (1998) list of barriers that NHPIs faced at UH are relevant today, including "inadequate academic advising and counseling due to cultural barriers and and/or lack of knowledge, ... little 
encouragement to pursue higher education while in primary or secondary education, ... [and] the lack of communication, information dissemination, and outreach relating to educational opportunities and programs" (p. 44).

Several participants shared how they were told and treated by peers, teachers, and counselors that they were only good in sports but not intelligent enough to go to college because they were Native Hawaiian and Pacific Islander. Having strong familial capital and high aspirations due to their familial obligations, PIs were motivated and encouraged by their family to persist and navigate STEM. Moments like these were pivotal because they were often the point at which most PIs became determined to persist in STEM and turned to wayfinding, researching how to apply for college on their own or with trusted friends and family members who were also applying or had gone to college. PIs are utilizing social capital by drawing upon their social network of trusted individuals and groups who have the same cultural background, who have had similar experiences of barriers in STEM, and who may have experienced navigating STEM, which is prevalent among underrepresented students in STEM and higher education (Ayala \& Contreras, 2019; Denton et al., 2020). Social capital is "positive peer pressure" (Denton et al., 2020, p. 569) that provides emotional support, a sense of belonging, and informs navigational capital (Ayala \& Contreras, 2019; Denton et al., 2020; Rincón et al., 2020), which has been essential for STEM wayfinding.

Some participants shared how they were told about majors or careers in STEM during high school but found their way by coincidence. Inoke, who majored in accounting, shared how he knew he liked math and did well in high school but was never told about STEM or careers associated with mathematics. This was typical of several participants, who majored in STEM because they took a STEM-related course or met a peer or another PI who was in STEM. 
"Inequitable access to quality science learning experiences combined with deficit-oriented ideologies that fail to recognize and support youth of color as 'science-type' people, suggests learning environments much like mathematics classrooms are racialized spaces" (Visintainer, 2020, p. 394). This deficit view or thinking about students of colors is associated with low achievement, low income, and not being good enough to major in STEM as experienced by participants in this study, a concept Valencia (2010) supported in that "macro- and microlevel educational policies/practices fueled by class and racial prejudice kept economically disadvantages students of color in their place" (p. 10). STEM teachers and guidance counselors with a deficit view of PIs as students of color are gatekeepers for judging who belongs or does not belong in STEM, which further standardizes the hegemonic view of the White male persona of STEM(Carter et al., 2019).

Most of the PIs in this study were highly marginalized in their predominately White high schools and institutions, which was similar to the experiences of their parents and grandparents who had recently immigrated to the United States from the islands. Witnessing how their parents and grandparents had overcome the challenges of being newcomers and knowing their ancestors navigated the vast Pacific Ocean when others hugged the coast was resistant capital inherited by the participants in this study. For them, STEM was their Moana, their ocean to wayfind. Their preparation for the journey did not exempt them from the storms or the waves of discouragement and microaggressions but emboldened them to resist and not give in. The stereotype threat that the participants experienced was one of the motivating factors to resist and rewrite the narrative that PIs can successfully navigate STEM.

Chang et al. (2014) found that underrepresented students with strong precollege experiences may persist through their first year but often did not last. Participants came to realize 
that having the grades to get into college did not change the fact that being a student of color would be an obstacle in navigating STEM. A majority of the PIs in this study attended predominately White institutions, where campus climate and STEM culture were not welcoming. Participants found it difficult to connect to their school and were unable to find a sense of belonging in STEM, even though $76 \%$ lived on campus during their first year, worked on campus, joined clubs and organizations, and conducted research for their professors. Many felt isolated, so they took an ethnic studies course, joined a PI club or study group, studied abroad, or did research in New Zealand, Samoa, or Tonga. As a communal people, participants were looking for vā (space) to connect with others who were PIs, had similar upbringing, and had similar negative experiences. Noa was the only PI in his STEM major, but he was able to find peers that he could relate to. Noa shared:

When I was a chemical engineer, there weren't other Pacific Islanders, but I guess I did feel like I had a connection with the other kids that came from some maybe rural little town that nobody's ever heard of, because even though they're not Pacific Islander, we all kind of ran into the same issue of we didn't know about this when we were growing up. ... We probably didn't come from high-income, developed areas, so I just felt like I had a connection with these random country kids, even though they weren't Pacific Islanders.

For Noa, being able to connect with a particular group of peers because they had a similar upbring was important in validating that he was not alone in knowing little about chemical engineering growing up. Noa's peers who grew up in a more developed area had a greater advantage over him and his friends from rural little towns, which added to the competitive and 
cutthroat culture in STEM. Overcoming barriers in STEM through wayfinding with resistant capital became finding a vā (space) that was culturally relevant for them as PIs.

Navigating STEM requires wayfinding people and spaces that align with collective values. As members of a highly marginalized population in STEM, PIs were creating vā (space) through wayfinding, space that encouraged, embraced their cultural identity, and emphasized community to combat the chilly, individualistic, and meritocratic culture in STEM. Similarly, Page-Reeves et al.'s (2019) research revealed that Native Americans overcame barriers by using their experiences to adapt and transform dominant STEM cultural norms. Page-Reeves et al. (2019) defined Native American success in STEM to wayfinding as a process of transformation that involves using contextual cues in the environmental and experiential field to agentively weave the fabric of one's life and to create one's own path in way that connect with culturally defined values and relationships. (p. 184)

Participants shared experiences of finding signs such as supportive peers, professors, and advisors who helped them navigate and find a sense of belonging in STEM. Upperclassmen PIs or those who had graduated in STEM inspired and mentored younger PIs in STEM. PIs recognize that institutions and their faculty are doing little to change the campus climate or the STEM culture to be more inclusive and supportive of underrepresented students, so PIs are creating their own paths to navigate STEM that validates their cultural identity and values.

\section{Vā: Creating Vā (Space) Through Interpersonal Relationships and Social Connections}

Vā is a PI concept defined as the space between and not the space that separates but space that relates, unifies, provides well-being, and gives meanings to things (Ka'ili, 2005; MilaSchaaf, 2006). In Tongan, vā is referred to as relationship between individuals, groups, and the 
community, to which Taufe'ulungaki added, "maintaining, nurturing and developing vā, so that it remains strong and flexible. The well-being or health of the community is measured, therefore by contextualized and acceptable behavior and actions that are meaningful, worthwhile and beneficial to others" (Taufe 'ulungaki, 2004, as cited in Mila-Schaaf, 2006, p. 11). Students of color that attended PWIs formed social and academic counterspaces because of constant negative racial experiences in and outside of the classroom and the "competitive, individualistic, and solitary" culture in STEM (Ong et al., 2018, p. 207). Counterspaces for African Americans, Latinxs, and women of color in STEM have been formal and informal, included ethnic-specific peer and study groups, STEM and non-STEM campus student groups, and national STEM diversity conferences, which provided a supportive space where students could share their experiences, find validation, and seek encouragement (Grier-Reed, 2010; Nuñez, 2011; Ong et al., 2018; Solórzano et al., 2000).

Vā for PIs in STEM is similar to counterspaces. For participants highly underrepresented in their classes and majors, seeing another PI in class or on campus helped to connect them with the campus and STEM. Astin's (1999) theory of student involvement claimed that the more that students are involved in school, such as with student government, student-faculty interactions, and living on campus, the more that students interact with peers, persist, and aspire to attain a graduate degree. Several participants who did live on campus, played sports, and joined student clubs, still had negative racial experiences. It is only when they found peers that looked like them or could relate to or connect with them that they were able to create a supportive vā (space), where folks could vent and share information about classes, research opportunities, internships, and graduate school. As a communal and collective culture, PIs studied together, shared food, and attended each other's events, such as a basketball game or a dance show. These relationships 
allowed for reaching out for support and information about graduate school from PIs who had graduated in STEM and for mentoring and tutoring first- and second-year college students and high school students.

Counterspaces and vā serve similar purposes for marginalized and Pacific Islander students to overcome the isolating and competitive culture in STEM, which creates and perpetuates barriers for communities of color that thrive in community-like environments. Solórzano et al. (2000) defined counterspaces as safe academic and social spaces for underrepresented students to vent about negative racial experiences, share knowledge, and find support. In STEM, counterspaces provided a space for women to share their insights and strategies to persist in STEM, foster a supportive community for holistic well-being (Davis et al., 2020), and develop peer-to-peer and mentoring relationships (Ong et al., 2018). Counterspaces can be physical spaces such as research labs that allowed Black students to test out their curiosity and develop a science identity (Lane, 2016) or a National Diversity in STEM Conference, where students of color found a sense of belonging and a safe space in STEM (Ong et al., 2018). Counterspaces and vā provide a space to connect and nurture relationships and foster personal and community well-being.

$\mathrm{Vā}$ is based on interpersonal relationships and social connections, where trust and cooperation is necessary for vā to exist. PIs have strong family and community ties. Connecting with others is a way of creating vā through attending weddings, graduations, and birthday celebrations. PIs are creating that same vā in STEM as a means of maintaining their cultural identity, but it has evolved to become space to share resources, help others navigate STEM, and to study together. Vā is how PIs are persisting in STEM through wayfinding, because being a PI is a visible threat to success in STEM. Until institutions and STEM transform to be more 
welcoming, less competitive, and more encouraging of working together, PIs will create their own vā (space) in STEM.

\section{Tauhi Vā: Taking Care of Relationships Within These Spaces Through Reciprocity}

To preserve vā that has been created through interpersonal relationships and social connections, tauhi vā is instrumental. Tauhi vā is taking care of or nurturing the space that connects and relates people to one another (Ka'ili, 2008). Palmer, Maramba, and Dancy (2011), listed factors for students of color to persist in STEM, which includes supportive educational environments, role models of color, knowledge and lesson sharing from advanced students of similar ethnic groups, and research opportunities. Chang et al. (2014) added that being part of supportive groups increases confidence and motivation to succeed in STEM through networking and creating meaningful relationships through social engagement.

To maintain a positive vā in STEM, PIs tauhi vā by replicating and perpetuating the family and community support that they are familiar with and that comes with a sense of responsibility to look out for each other and to give back to their PI community. As a member of the Pacific Islander Student Alliance at her campus, Langi was asked by her mentors, "How are we reciprocating what is given to us and giving it to the younger generation, right? How are we giving back to the community?" Having been raised in a collective culture, PIs who graduate in STEM, are in graduate school, or have a career in STEM feel obligated to mentor and share knowledge with PI students who are in college or high school.

In overcoming obstacles and barriers in higher education and STEM, PIs have gained experiential wisdom and are transformed. This transformation was further explained by PageReeves et al. (2019) from their examination of the success of Native Americans in STEM:

“Transformational personal experience is accumulated iteratively over time, allowing 
interviewees to develop strategies and new perspectives to dialectically (re)connect their lives and work with the culturally defined purpose of giving back" (p. 191). In PI communities and families, elders are often looked to for experiential wisdom. Similarly, PIs who have graduated from college are in a position to share what they know so that the community may benefit and prosper. Sharing knowledge and resources is tauhi vā, because ensuring that the needs of those within the vā are being met and also reciprocated is quintessential to nurturing a safe and supportive vā.

Langi was the PISA president during her last 2 years of college, and she shared how tauhi vā reminded her of her responsibility:

So, being Pacific Islander, I always think of the fact that we're so community-based.

Because it was so hard for me to navigate getting to higher ed, I always felt like it was also part of that to make sure that the kids that we were tutoring didn't feel like they were lost any type of the way - any part of the way. That they felt like they had someone else that they could go to beside someone who was on their campus.

PIs who have been mentored and tutored by other PIs are reciprocating what was done for them. PIs in this study have exemplified tauhi vā through mentoring, tutoring, and reaching out to high school students and through social media to share their educational journey and inspire PIs to major in STEM.

\section{For Future Policy, Research, and Practice}

Findings from this qualitative research study can contribute to a better understanding of PIs in STEM through their precollege and college experiences and the influences of community cultural wealth and tauhi vā. Data from this study showed how PIs have the precollege experiences as prescribed by researchers to persist in STEM but that PIs continue to experience 
barriers that weed them out of STEM. As such, implications for policy, future research, and practice should be considered in conversations about the success of PIs in STEM.

\section{Policy: Disaggregate Pacific Islanders Data From Asian Americans}

PIs have been misidentified, misrepresented, and underserved, making data disaggregation for Native Hawaiian and Pacific Islanders (NHPIs) a civil rights issue (Hafoka et al., 2020; Museus \& Kiang, 2009; Teranishi et al., 2009, 2019). The aggregation of PIs with Asian Americans has done little to identify the disparities that impact NHPIs and how they are overcoming obstacles, especially in STEM, where Asian Americans are overrepresented in STEM degree attainment and NHPIs are overlooked (Maramba, 2013). NHPIs are made up of over 20 groups, whose demographics data should be further disaggregated to understand how diverse NHPIs are in their experiences, and to research the assets and gaps at the economic and educational levels. Maramba (2013) emphasized the importance of disaggregating Pacific Islanders from Asian Americans in order to research what type of resources and institutional changes are needed to better serve NHPIs and to inform institutions and the government to have a broader understanding of NHPIs.

After disaggregating AAPI data, claiming indigeneity is important because there are nonIndigenous individuals who claim to be Hawaiian or Samoan simply because of being born on the island. Hafoka et al. (2020) pointed out that Pacific Islanders must be recognized as Indigenous people to validate our identity and cultural ways of knowing as knowledge, which can inform educational policies and strategies. Hafoka et al. (2020) stated:

Disaggregating Pacific Islander data from Asian Americans is a necessary first step in acknowledging Pacific Islanders as Indigenous people. Understanding the importance of Indigenous education, culturally relevant outreach and retention models specifically for 
Pacific Islanders will assist in empowering the community in finding solutions and addressing specific needs. (p. 74)

\section{Research: Native Hawaiian and Pacific Islanders in Higher Education and STEM}

The findings in the study have shown a need for research regarding NHPIs in higher

education and STEM. Not often researched, NHPIs are navigating established paths and creating new paths via wayfinding, both on their own and with help from supportive faculty, staff, and peers. More qualitative and quantitative research on NHPIs is needed to better understand the barriers they face and the strength and abilities they possess or might develop to overcome them; the impact of colonization and imperialism; (im)migration experiences; and the nuances and diverse experiences of NHPIs.

Although the experiences of the participants were similar in navigating STEM and higher education, there were unique differences in those who were born and raised in the mainland United States and those who (im)migrated from various islands in the Pacific to attend college. I am using the term (im)migration because the immigration status differs depending on the U.S. relationship to those Pacific Islands (EPIC \& AAAJ, 2014; Hafoka et al., 2020). For instance, Native Hawaiians and some Pacific Islanders have U.S. citizenship, but many have immigration status, such as U.S. national for Samoans and migrant for people from the Federated States of Micronesia, the Marshalls Islands, and Palau.

\section{Research: Pacific Islander Families' Influence on College Access and Success}

The findings also centered on the importance of families and community relationships.

Most Pacific Islanders are raised in a close-knit family and community, both of which participants shared as a major source of inspiration, motivation, and support. Going to college became a family affair, with the family invested in encouraging each other and making sacrifices 
so that others could attend private school and college. Participants paid their familial capital forward by helping their younger siblings and friends and by volunteering on campus and off campus in the community. I would like to research this family and community dynamic in prioritizing education, such as their role and motive, because the PIs in STEM are creating similar vā (spaces) on and off campus.

Education is ranked highly in PI families, and I would like to understand why this is true by researching the collegiate experiences and degree attainment of PIs who migrated to the United States to attend college during the 1960s and 1970s. As a PI, I believe that to understand the present I must look to the past. For instance, I recently found out that my mother had completed 2 years of college at the Church College of Hawaii, which she never shared with me when she was alive. She dropped out of college to work and bring her younger siblings to the United States, where they attended high school and some college. Growing up, my parents always pushed my siblings and me to go to college, which has continued to stick with me as I earn my $\mathrm{PhD}$. Some participants in this study shared similar parental experiences. As important as it is to research PIs who have successfully navigated higher education, so it is to examine the experiences of PIs who were not successful in navigating STEM and higher education. This research would serve to understand barriers, to increase retention, and to increase college degree attainment.

Several participants made a unique reference to male/paternal figures as role models to major in STEM. These role models included grandfathers, fathers, uncles, male professors, and male community members who had majored in STEM. Inspiring messages driving participants to major in STEM included desiring to help the family and the community and hearing reminders that PIs belong in STEM. Again, there has been little research on PIs, and especially so on the 
impact of families, male figures, and members of the community on college access and success in education in PIs.

Research on NHPIs must acknowledge the wealth of cultural knowledge they bring to college, because this asset has been devalued and ignored. Researching NHPIs from a deficit lens would only add to the stereotype threat that NHPIs have experienced from advisors and professors. As a PI, I strongly advise that research on NHPIs should use an asset-based framework to highlight our strengths and cultural knowledge in order to help institutions provide culturally relevant strategies to support NHPIs.

\section{Practice: Implications for $\mathrm{K}-12$}

Only one participant in this study had a parent with a career in STEM, unlike some of their peers who had parents with careers in STEM. This is significant because several participants in this study mentioned that their school, counselors, and teachers provided little to no information about STEM majors, careers in STEM, or STEM-related programs in schools. Participants who had good grades and were taking AP courses were discouraged to major in STEM by counselors and teachers. With a majority of the PIs in this study enrolling into a 4-year college immediately after high school, they clearly understood what it took to get into college but had only a general knowledge about STEM. I suggest that $\mathrm{K}-12$ school systems encourage teachers who teach STEM-related subjects to provide more opportunities to learn about the types of STEM careers and majors that exist. This can include hosting special guest speakers such as parents who are in STEM, taking STEM-related field trips, developing an engaging STEM curriculum, and promoting STEM-related programs after school or during the summer. Teachers and counselors must do a better job to encourage all students, specifically PIs who are interested in STEM. 


\section{Practice: Pacific Islander Bridge to STEM Programs}

Although the participants had the precollege experiences to persist in STEM, those experiences did not remove the barriers in STEM that are associated with underrepresented students. With over half of the PIs in this study having high GPAs, taking AP courses and calculus or pre-calculus in high school, and attending high schools with strong college preparation curriculum and college-going culture, they were prepared for the rigor of college, this preparation being one of the contributing factors that helped them overcome barriers to successfully navigate and wayfind STEM. The participants, who shared experiences of isolation, depression, and imposter syndrome, were able to find vā, a supportive community, and encouraging advisors and mentors, which helped them persist. It is possible that PIs who have departed from STEM were unable to find vā.

To retain PIs in STEM, institutions, student affairs, and STEM departments must create STEM bridge programs that are PI-centric and culturally relevant for PIs in order to provide a connection for PIs to the institution and to STEM. Such a PI STEM bridge program would include a space for studying, tutoring, academic advising, office hours for professors, and connecting with other PIs in STEM for resources and encouragement. The space would allow for PI cultural events; talanoa; guest speakers from the community; PI scholars to encourage, inspire, and teach; and a space to practice cultural traditions, such as dancing, storytelling, and art. This would help PI students connect their cultural identity to STEM, responding to the narrative of several participants who shared that they majored in ethnic studies, took PI ethnic courses, and traveled abroad to the Pacific because they did not see themselves represented or belonging in STEM. 
The PI STEM bridge program could provide a precollege summer program that informs PIs about types of STEM majors, careers, research opportunities, and supplemental STEM courses to prepare for gatekeeping STEM entry courses. The precollege program could also prepare PI students who may not have strong precollege experiences by offering supplemental math and science courses, linking students to resources on campus, offering campus orientations, arranging introductions and meetings with STEM department staff and faculty, and creating cohorts so that students have a support system before their first semester in college. The participants in this study have created their own kind of bridge program by creating vā, but institutions must do more to support and increase the degree attainment of PIs in STEM.

\section{Practice: Pacific Islander Cultural Relevance}

The participants in this study had the precollege experiences necessary to persist in STEM, but because of a dearth of research on PIs to inform policy and provide support, limited interaction or experience with PIs at predominantly White institutions, and negative stereotyping, PIs experienced barriers similar to other students of color. Participants shared experiences of microaggressions, racism, and stereotype threat from students, advisors, and faculty that had a negative impact on their navigating STEM and fostering their sense of belonging in college and in STEM. Institutions with NHPI populations should offer professional development opportunities that are culturally relevant to NHPIs. Institutions must do better in providing interventions for faculty and staff who use NHPIs' cultural identity as a barrier instead of an asset.

Pacific Islanders are a communal people with a collective culture, which is contrary to the individualistic culture of STEM. PIs prioritize relationships, family, and community over the individual (Kana'iaupuni \& Ledward, 2013; McElfish et al., 2019), which participants confirmed 
in this study. Participants took courses, conducted research, studied abroad, and took part in community outreach to find some connection to their community and PI culture. NHPI scholars Thaman (2008) and Kana'iaupuni et al. (2011) described how PIs feel disconnected with Western culture and education because neither values or acknowledges other cultures or ways of knowing. PIs are more engaged when their teachers know their culture enough to connect their education to their home, family, or community.

Pacific Islander culturally relevant practice at the collegiate level would take a strengthbased approach that acknowledges and values other cultures and ways of knowing; offer community style learning that exhibits some aspect of "talkstory" or opportunity for conversations "involving a reciprocal, symbiotic exchange of thoughts, beliefs, and feelings" (McElfish et al., 2019); and challenge students to find ways to connect their learning to their culture or community through research or service. As NHPIs are one of the fasting-growing populations in the United States, it is imperative that institutions of higher learning be proactive in providing professional development that centers on understanding the assets that PI students bring with them, such as their cultural knowledge and obstacles they face as underrepresented students. The professional development should be a communal and collaborative effort between student affair practitioners and faculty, because each has knowledge from which the other can benefit through creating vā (space) to relate to each other and enhance their practice and PI student achievement. Student affairs and faculty are often siloed and disconnected, which can be a hindrance for students who come from a close-knit family and community. Thus, creating genuine vā or relationship between faculty and student affairs can be advantageous for all, specifically PIs students, because working together comes from a familiar place that they can relate to and trust. 


\section{Concluding Thoughts}

My findings reflects my upbringing, community, family, and ancestors. With each generation of PIs, I feared that we as a collective and traditional people were losing a part of our culture, but I was wrong. I am proud and humbled by the data that I collected and the stories and experiences that my participants entrusted me to share. These words shared by Heilala sums up my research:

Pikipiki hama kae vaevae manava. It's a proverb that if you fail or succeed, you're not by yourself. There's always this sense of always being linked or tethered to what's in the past and also your responsibility in the future.

This Tongan proverb is based on the life-threatening situation at sea when a Kalia, or a large canoe holding many passengers, was low on food rations and would call out for help to the other Kalias who were traveling with them. With no land in sight, the other canoes were also in the same situation, but the nearest canoe would respond by coming alongside of the Kalia in distress and grab hold of it, linking them together. "Pikipiki hama" refers to this gesture, with pikipiki meaning to stick, to bind, or to link strongly, and hama meaning the bow of the canoe.

Once the Kalia had been secured, then rations would be shared. The rations were not extras from the other canoe but rather its own critical source of life, with vaevae meaning to share, to separate, or to pull apart, and manava meaning womb, life, or breath. The combination and use of these words of the proverb reflect accurately the kind of reciprocity that took place. For the canoe that responded to the call for help, it would mean that they too would be in danger of perishing because they were not sharing their excess but rather what they were giving could be more appropriately described as their actual life (Faupula, n.d.). 
This proverb depicts how the participants in this study managed to help and create vā for other PIs and peers when they themselves were struggling to navigate STEM. PIs are a collective people, where tradition and cultural knowledge of helping one another succeed is passed down from generation to generation and that has evolved in the capitalistic diaspora as cultural capital. The PIs in this study have inherited the capitals of their parents, grandparents, and ancestors, which has allowed them to wayfind STEM and develop their own community cultural wealth to share with other PIs through tauhi vā.

The purpose of this study was to examine how community cultural wealth and tauhi vā are influencing the navigation of PIs in STEM and to document the experiences of PIs in higher education and STEM. I began each interview with a cultural protocol aligned with talanoa, introducing myself, my positionality, and my intent to create vā (space) to connect and freely speak. Most importantly, I expressed that I would tauhi vā and protect this vā (space), using it to benefit our community. It is through tauhi vā that I was able to draw on the experiences of the PIs in this study, which presented various themes and subthemes providing insight in how they were navigating STEM.

Precollege experiences and preparation played a key role in the persistence of the PIs in this study, who completed AP courses, achieved high GPAs, and attended the best schools. Unfortunately, several factors undermined the confidence and self-perceptions of intelligence of the participants in this study, but with strong aspirations and family support, they were able to use their resistant capital to overcome these barriers. Participants experienced the barriers and saw the sacrifices their families had overcome when they immigrated to the United States, or their land being stolen and used for profit by imperialistic foreign invaders at the expense of their livelihood and culture, which inspired them to resist the stereotype and prove to the gatekeepers 
(e.g., faculty, counselors, advisors, and peers) in STEM that they belonged. This study reminds us that higher education and STEM must do better to address the hostile and uninviting campus climate, inadequate advising, and culturally incompetent teaching by creating a safe and supportive space for PIs and providing professional development on culturally relevant practices that use an asset-based lens in teaching, advising, and supporting PI students.

This study validates the experiences of PIs in STEM and higher education as knowledge that is needed to understand why PIs are underrepresented in STEM in order to develop interventions to retain PIs in STEM. PIs bring a unique lens, tapping into their cultural ways of knowing to transform STEM to be more culturally relevant to them. PIs in STEM are drawing upon aspirational, familial, navigational, social, and resistant capital as well as tauhi vā to navigate STEM. We, who educate, advise and research NHPI students must work together to shine the light on the tremendous amount of community cultural wealth that NHPIs bring to the STEM college and career experience and provide a basis of evidence that informs institutions for the development and implementation of policy that better supports NHPIs in higher education and STEM. 


\section{References}

Ah Sam, A. L. F., \& Robinson, N. B. (1998). Pacific Islanders in Higher Education: Barriers to Recruitment and Retention. Pacific Educational Research Journal, 9(1), 39-49.

Airini, Anae, M., Mila-Schaaf, K., Coxon, E., Mara, D., Sanga, K., New Zealand, \& Ministry of Education (Eds.). (2010). Teu le va -: Relationships across research and policy in Pasifika education : a collective approach to knowledge generation \& policy development for action towards Pasifika education success. Auckland Uniservices Ltd, University of Auckland.

Allaire, F. S. (2017). Navigating Uncharted Waters: First-Generation Native Hawaiian College Students in STEM. Journal of College Student Retention: Research, Theory \& Practice, 152102511770795. https://doi.org/10.1177/1521025117707955

Amelink, C. T., Artis, S., \& King Liu, T.-J. (2015). Examining the Self-Efficacy of Community College STEM Majors: Factors Related to Four-Year Degree Attainment. Community College Journal of Research and Practice, 39(12), 1111-1124. https://doi.org/10.1080/10668926.2014.941514

Anaya, G., \& Cole, D. G. (2001). Latina/o student achievement: Exploring the influence of studentfaculty int... Journal of College Student Development, 42(1), 12.

Astin, A. W. (1999). Student Involvement: A Developmental Theory for Higher Education. Journal of College Student Development, 40(5), 12.

Au, K. H.-P. (1980). Participation Structures in a Reading Lesson with Hawaiian Children: Analysis of a Culturally Appropriate Instructional Event. Anthropology \& Education Quarterly, 11(2), 91-115. JSTOR.

Auerbach, S. (2004). Engaging Latino Parents in Supporting College Pathways: Lessons From a College Access Program. Journal of Hispanic Higher Education, 3(2), 125-145. https://doi.org/10.1177/1538192703262514

Ayala, M. I., \& Contreras, S. M. (2019). It's Capital! Understanding Latina/o Presence in Higher Education. Sociology of Race and Ethnicity, 5(2), 229-243. https://doi.org/10.1177/2332649218757803 
Bahr, P. R., Jackson, G., McNaughtan, J., Oster, M., \& Gross, J. (2017). Unrealized Potential: Community College Pathways to STEM Baccalaureate Degrees. The Journal of Higher Education, 88(3), 430-478. https://doi.org/10.1080/00221546.2016.1257313

Beede, D., Julian, T., Khan, B., Lehrman, R., McKittrick, G., Langdon, D., \& Doms, M. (2011). Education Supports Racial and Ethnic Equality in STEM (ESA Issue Brief No. 05-11; p. 11). U.S. Department of Commerce, Economics and Statistics.

Benham, M. K. P. (2006). A challenge to Native Hawaiian and Pacific Islander scholars: What the research literature teaches us about our work. Race Ethnicity and Education, 9(1), 29-50. https://doi.org/10.1080/13613320500490705

Blickenstaff, J. (2005). Women and science careers: Leaky pipeline or gender filter? Gender and Education, 17(4), 369-386. https://doi.org/10.1080/09540250500145072

Bloomberg, L. D., \& Volpe, M. (2019). Completing your qualitative dissertation: A road map from beginning to end (Third edition). SAGE.

Bonous-Hammarth, M. (2000). Pathways to Success: Affirming Opportunities for Science, Mathematics, and Engineering Majors. The Journal of Negro Education, 69(1/2), 92-111.

Bourdieu, P., \& Passeron, J. (1977). Reproduction in education, society and culture. London, Sage. Brandt, A. M. (1978). Racism and Research: The Case of the Tuskegee Syphilis Study. The Hastings Center Report, 8(6), 21-29. https://doi.org/10.2307/3561468

Brayboy, B. M. J. (2005). Toward a Tribal Critical Race Theory in Education. The Urban Review, 37(5), 425-446. https://doi.org/10.1007/s11256-005-0018-y

Burt, B. A., \& Johnson, J. T. (2018). Origins of early STEM interest for Black male graduate students in engineering: A community cultural wealth perspective. School Science and Mathematics, 118(6), 257-270. https://doi.org/10.1111/ssm.12294

Cabrera, A. F., Nora, A., Terenzini, P. T., Pascarella, E., \& Hagedorn, L. S. (1999). Campus racial climate and the adjustment of students to college: A comparison between White students and African-American students. The Journal of Higher Education; Columbus, 70(2), 134-160. 
Cannady, M. A., Greenwald, E., \& Harris, K. N. (2014). Problematizing the STEM Pipeline Metaphor: Is the STEM Pipeline Metaphor Serving Our Students and the STEM Workforce? Science Education, 98(3), 443-460.

Cappello, M. (2005). Photo Interviews: Eliciting Data through Conversations with Children. Field Methods, 17(2), 170-182. https://doi.org/10.1177/1525822X05274553

Carter, D. F., Razo Dueñas, J. E., \& Mendoza, R. (2019). Critical Examination of the Role of STEM in Propagating and Maintaining Race and Gender Disparities. In M. B. Paulsen \& L. W. Perna (Eds.), Higher Education: Handbook of Theory and Research: Volume 34 (pp. 39-97). Springer International Publishing. https://doi.org/10.1007/978-3-030-03457-3_2

Chang, M. J., Eagan, M. K., Lin, M. H., \& Hurtado, S. (2011). Considering the Impact of Racial Stigmas and Science Identity: Persistence Among Biomedical and Behavioral Science Aspirants. The Journal of Higher Education, 82(5), 564-596. https://doi.org/10.1353/jhe.2011.0030

Chang, M. J., Sharkness, J., Hurtado, S., \& Newman, C. B. (2014). What matters in college for retaining aspiring scientists and engineers from underrepresented racial groups. Journal of Research in Science Teaching, 51. https://doi.org/10.1002/tea.21146

Charleston, L., George, Phillis, Jackson, J., Berhanu, J., \& Amechi, M. (2014). Navigating Underrepresented STEM Spaces: Experiences of Black Women in U.S. Computing Science Higher Education Programs Who Actualize Success. Journal of Diversity in Higher Education, 7(3), 166-176.

Chen, X. (2009). Students Who Study Science, Technology, Engineering, and Mathematics (STEM) in Postsecondary Education. Stats in Brief. NCES 2009-161. National Center for Education Statistics. https://eric.ed.gov/?id=ED506035

Chen, X. (2013). STEM Attrition: College Students' Paths into and out of STEM Fields. Statistical Analysis Report. NCES 2014-001. National Center for Education Statistics. https://eric.ed.gov/?id=ED544470 
Cintina, I., \& Kana'iaupuni, S. M. (2019). Finishing Strong: GPA and Timely College Graduation Outcomes among Native Hawaiian STEM Majors. The Review of Higher Education, 42(4), 1459-1487. https://doi.org/10.1353/rhe.2019.0072

Clark-Ibanez, M. (2004). Framing the Social World With Photo-Elicitation Interviews-Marisol ClarkIbáÑez, 2004. American Behavioral Scientist, 47(12), 1507-1527. https://doiorg.ccl.idm.oclc.org/10.1177/0002764204266236

Cole, D., \& Espinoza, A. (2008). Examining the Academic Success of Latino Students in Science Technology Engineering and Mathematics (STEM) Majors. Journal of College Student Development, 49(4), 285-300. https://doi.org/10.1353/csd.0.0018

Creswell, J. . W., \& Creswell, J. D. (2018). Research design: Qualitative, quantitative, and mixed methods approaches (5th ed.). SAGE.

Crisp, G., Nora, A., \& Taggart, A. (2009). Student Characteristics, Pre-College, College, and Environmental Factors as Predictors of Majoring in and Earning a STEM Degree: An Analysis of Students Attending a Hispanic Serving Institution. American Educational Research Journal, 46(4), 924-942.

Davis, B., Wilkins-Yel, K., \& White, F. (2020). Supporting STEM Identity Development Among Women of Color Through Engagement in a Transformative Counterspace. 2.

Denton, M., Borrego, M., \& Boklage, A. (2020). Community cultural wealth in science, technology, engineering, and mathematics education: A systematic review. Journal of Engineering Education, 109(3), 556-580. https://doi.org/10.1002/jee.20322

Douglas, E. P. (2015). Artifact elicitation as a method of qualitative inquiry in engineering Edu-cation. Age, 26, 1 .

Duncan Seraphin, K., Philippoff, J., Pottenger, F. M., Kaupp, L., Lurie, M. H., Lin, D., \& Baumgartner, E. (2021). Wayfinding and Navigation [Curriculum Research \& Development Group]. Exploring Our Fluid Earth, Univeristy of Hawaii. 
https://manoa.hawaii.edu/exploringourfluidearth/physical/navigation-andtransportation/wayfinding-and-navigation

Duran, A., \& Pérez II, D. (2017). Queering la Familia: A Phenomenological Study Reconceptualizing Familial Capital for Queer Latino Men. Journal of College Student Development, 58(8), 11491165. https://doi.org/10.1353/csd.2017.0091

Dutt, K. (2020). Race and racism in the geosciences. Nature Geoscience, 13(1), 2-3. https://doi.org/10.1038/s41561-019-0519-z

Ehrenberg, R. G. (2010). Analyzing the factors that influence persistence rates in STEM field, majors: Introduction to the symposium. Economics of Education Review, 29(6), 888-891. https://doi.org/10.1016/j.econedurev.2010.06.012

EPIC, \& AAAJ. (2014). A Community of Contrasts: Native Hawaiians and Pacific Islanders in the United States. Empowering Pacific Islander Communities \& Asian Americans Advancing Justice.

Fa'avae, D., Jones, A., \& Manu'atu, L. (2016). Talanoa'i ‘A e Talanoa-Talking about Talanoa: Some dilemmas of a novice researcher. AlterNative: An International Journal of Indigenous Peoples, 12(2), 138-150. https://doi.org/10.20507/AlterNative.2016.12.2.3

Faupula, S. (n.d.). Pikipiki Hama kae Vaevae manava.

Finlay, L. (2014). Engaging Phenomenological Analysis. Qualitative Research in Psychology, 11(2), 121-141. https://doi.org/10.1080/14780887.2013.807899

Flower, A. M. (2016). Building an Academic Community: Minority Serving Institutions and How They Influence Students Pursuing Undergraduate Degrees in STEM. Multicultural Learning and Teaching, 9(2), 187-201. https://doi.org/10.1515/mlt-2012-0042

Gonzalez, N., Moll, L. C., Tenery, M. F., Rivera, A., Rendon, P., Gonzales, R., \& Amanti, C. (1995). Funds of Knowledge for Teaching in Latino Households. Urban Education, 29(4), 443-470. https://doi.org/10.1177/0042085995029004005 
Graham, M. J., Frederick, J., Byars-Winston, A., Hunter, A.-B., \& Handelsman, J. (2013). Increasing Persistence of College Students in STEM. Science, 341(6153), 1455-1456. https://doi.org/10.1126/science.1240487

Grier-Reed, T. L. (2010). The African American Student Network: Creating Sanctuaries and Counterspaces for Coping With Racial Microaggressions in Higher Education Settings. The Journal of Humanistic Counseling, Education and Development, 49(2), 181-188. https://doi.org/10.1002/j.2161-1939.2010.tb00096.x

Hafoka, I., Kehaulani, V., Aina, I., \& Alcantar, C. M. (2020). The "Invisible” Minority: Finding a Sense of Belonging After Imperialism, Colonialism, and (Im)migration for Native Hawaiian and Pacific Islanders in the United States. In Measuring Race: Why Disaggregating Data Matters for Addressing Educational Inequality. Teachers College Press.

Halapua, S. (2000). Meaning in Unity-Building: A Holistic Talanoa Perspective. Pacific Islands Development Program, East-West Center, Korolevu, Sigatoka, Fiji.

Halapua, Sitiveni. (2013, February 4). Talanoa in Building Democracy and Goverance [Conference]. Future Leaders of the Pacific, Pago Pago, American Samoa.

Hall, L. K. (2015). Which of These Things Is Not Like the Other: Hawaiians and Other Pacific Islanders Are Not Asian Americans, and All Pacific Islanders Are Not Hawaiian. American Quarterly, 67(3), 727-747,989.

Harper, D. (2002). Talking about pictures: A case for photo elicitation. Visual Studies, 17(1), 13-26. https://doi.org/10.1080/14725860220137345

Hau'ofa, E. (1994). Our Sea of Islands. The Contemporary Pacific, 6(1), 148-161. JSTOR.

Hau'ofa, E. (1998). The Ocean in Us. The Contemporary Pacific, 10(2), 32-43.

Herrera, F. A., \& Rodriguez-Operana, V. C. (2020). A National Portrait of STEM Trajectories Through Two- and Four-Year Hispanic Serving Institutions. Hispanic Educational Technology Services, XI(Fall 2020), 7-33. 
Ho’omanawanui, K. (2004). Ha, Mana, Leo (Breath, Spirit, Voice): Kanaka Maoli Empowerment through Literature. The American Indian Quarterly, 28(1), 86-91. https://doi.org/10.1353/aiq.2005.0011

Hurtado, S., Carter, D. F., \& Spuler, A. (1996). Latino student transition to college: Assessing difficulties and factors in successful college adjustment. Research in Higher Education, 37(2), 135-157. https://doi.org/10.1007/BF01730113

Hurtado, S., Han, J. C., Sáenz, V. B., Espinosa, L. L., Cabrera, N. L., \& Cerna, O. S. (2007). Predicting transition and adjustment to college: Biomedical and behavioral science aspirants' and minority students' first year of college. Research in Higher Education, 48(7), 841-887. https://doi.org/10.1007/s11162-007-9051-x

Jones, T. C. (2019). Creating a World for Me: Students of Color Navigating STEM Identity. Journal of Negro Education, 88(3), 358-378.

Ka'ili, T. (2014, February 28). Talanoa: Orality as Critical Pedagogy [Video]. BYU-H Symposuim on Learning and Teaching, BYU-Hawaii. https://youtu.be/kbm1dC95K60

Ka'ili, T. O. (2005). Tauhi va: Nurturing Tongan Sociospatial Ties in Maui and Beyond. The Contemporary Pacific, 17(1), 83-114. https://doi.org/10.1353/cp.2005.0017

Ka'ili, T. O. (2008). Tauhi vā: Creating beauty through the art of sociospatial relations [Ph.D., University of Washington]. https://search.proquest.com/docview/304439670/abstract/87A1537B60F64A97PQ/1

Kana'iaupuni, S. M., \& Ledward, B. (2013). Ho'opilina: The Call for Cultural Relevance in Education. Hūlili: Multidisciplinary Research on Hawaiian Well-Being, 9, 153-204.

Kana'iaupuni, S. M., Ledward, B., \& Keohokalole, K. (2011). New Research on the Impact of Cultural Influences in Education on Native Hawaiian and Other Pacific Islanders Examined. AAPI Nexus: Policy, Practice and Community, 9(1 \& 2), 221-228.

Kēpa, M., \& Manu'atu, L. (2006). Indigenous Maori and Tongan Perspectives on the Role of Tongan Language and Culture in the Community and in the University in Aotearoa-New Zealand. The American Indian Quarterly, 30(1), 11-27. https://doi.org/10.1353/aiq.2006.0004 
Kiyama, J. M. (2010). College Aspirations and Limitations: The Role of Educational Ideologies and Funds of Knowledge in Mexican American Families. American Educational Research Journal, 47(2), 330-356. https://doi.org/10.3102/0002831209357468

Kricorian, K., Seu, M., Lopez, D., Ureta, E., \& Equils, O. (2020). Factors influencing participation of underrepresented students in STEM fields: Matched mentors and mindsets. International Journal of STEM Education, 7(1), 16. https://doi.org/10.1186/s40594-020-00219-2

Kukahiko, K. T. (2017). Staying In: The Study of Pacific Islanders in College Football Using Indigenous Methodologies. Asian Journal of Social Science Studies, 2(4), 19. https://doi.org/10.20849/ajsss.v2i4.231

Ladson-Billings, G., \& Tate, W. F. (1995). Toward a Critical Race Theory of Education. Teachers College Record, 97(1), 47-68.

Ladson-Billings, Gloria. (1995). Toward a Theory of Culturally Relevant Pedagogy. AERA, 32(3), 27.

Lane, T. B. (2016). Research Environments as Counterspaces? EXamining Spaces that Inhibit and Support Science Identity Development for Black Students in STEM. Urban Education Research and Policy Annuals, 4(1), 10.

Māhina, 'Okusitino. (2007). Part III: In occasion for celebration: Reflections on the Tongan theories of education. In Ātea, Moana and Vanua: Voices from the brown edge (pp. 217-236). O Lagi 'Ātea Moana Press.

Manen, M. van. (2017). Phenomenology in Its Original Sense: Qualitative Health Research. https://doi.org/10.1177/1049732317699381

Maramba, D. C. (2008). Immigrant Families and the College Experience: Perspectives of Filipina Americans. Journal of College Student Development, 49(4), 336-350. https://doi.org/10.1353/csd.0.0012

Maramba, D. C. (2013). Creating successful pathways for Asian Americans and Pacific Islander (AAPI) community college students in STEM. In In R. Palmer \& L. Wood, Community college and STEM: Examining underrepresented racial and ethnic minorities (pp. 156-171). Routledge. 
Maton, K., Hrabowski III, F., \& Schmitt, C. (2000). African American college students excelling in the sciences: College and postcollege outcomes in the Meyerhoff Scholars Program. Journal of Research in Science Teaching, 37(7), 629-654.

Mau, W.-C. J. (2016). Characteristics of US Students That Pursued a STEM Major and Factors That Predicted Their Persistence in Degree Completion. Universal Journal of Educational Research, 4(6), 1495-1500. https://doi.org/10.13189/ujer.2016.040630

McElfish, P. A., Yeary, K., Sinclair, K. A., Steelman, S., Esquivel, M. K., Aitaoto, N., Kaholokula, K., Purvis, R. S., \& Ayers, B. L. (2019). Best Practices for Community-Engaged Research with Pacific Islander Communities in the US and USAPI: A Scoping Review. Journal of Health Care for the Poor and Underserved, 30(4), 1302-1330. https://doi.org/10.1353/hpu.2019.0101

McGee, E. O. (2016). Devalued Black and Latino Racial Identities: A By-Product of STEM College Culture? American Educational Research Journal, 53(6), 1626-1662. https://doi.org/10.3102/0002831216676572

Mejia, J. A., Wilson, A., Hasbún, I., \& Householder, D. (2014). Funds of knowledge in Hispanic students' communities and households that enhance engineering design thinking. 360 Degrees of Engineering Education, 1-20.

Merriam, S. B., \& Tisdell, E. J. (2015). Qualitative Research: A Guide to Design and Implementation. John Wiley \& Sons.

Metcalf, H. (2010). Stuck in the Pipeline: A Critical Review of STEM Workforce Literature. InterActions: UCLA Journal of Education and Information Studies, 6(2), 21.

Metcalf, H. E. (2014). Disrupting the Pipeline: Critical Analyses of Student Pathways Through Postsecondary STEM Education. New Directions for Institutional Research, 2013(158), 77-93. https://doi.org/10.1002/ir.20047

Mila-Schaaf, K. (2006). Vä-centred social work: Possibilities for a Pacific approach to social work practice. Social Work Review, 6. 
Moll, L. C., Amanti, C., Neff, D., \& Gonzalez, N. (1992). Funds of Knowledge for Teaching: Using a Qualitative Approach to Connect Homes and Classrooms. Theory Into Practice, 31(2), 132-141. JSTOR.

Morgan, P. L., Farkas, G., Hillemeier, M. M., \& Maczuga, S. (2016). Science Achievement Gaps Begin Very Early, Persist, and Are Largely Explained by Modifiable Factors. Educational Researcher, 45(1), 18-35. https://doi.org/10.3102/0013189X16633182

Museus, S. D. (2014). Asian American Students in Higher Education. Routledge. https://doi.org/10.4324/9780203753002

Museus, S. D., \& Kiang, P. N. (2009). Deconstructing the model minority myth and how it contributes to the invisible minority reality in higher education research. New Directions for Institutional Research, 2009(142), 5-15. https://doi.org/10.1002/ir.292

Museus, S. D., Maramba, D. C., \& Teranishi, R. T. (2013). The Misrepresented Minority: New Insights on Asian Americans and Pacific Islanders, and the Implications for Higher Education. Stylus Publishing, LLC.

NCES. (2019). Indicator 26: STEM Degrees. National Center for Education Statistics. https://nces.ed.gov/programs/raceindicators/indicator_REG.asp

NCES. (2020). Undergraduate Degree Fields. National Center for Education Statistics. https://nces.ed.gov/programs/coe/indicator_cta.asp

Nuñez, A.-M. (2011). Counterspaces and Connections in College Transitions: First-Generation Latino Students' Perspectives on Chicano Studies. Journal of College Student Development, 52(6), 639655. https://doi.org/10.1353/csd.2011.0077

Olmedo, I. M. (1997). Family Oral Histories for Multicultural Curriculum Perspectives. Urban Education, 32(1), 45-62. https://doi.org/10.1177/0042085997032001003

Olson, R. D. (1961). HISTORY OF THE CHURCH COLLEGE OF HAWAII 1955-1960 [Master's thesis, Utah State University]. digitalcommons.usu.edu 
Ong, M., Smith, J. M., \& Ko, L. T. (2018). Counterspaces for women of color in STEM higher education: Marginal and central spaces for persistence and success: COUNTERSPACES FOR WOMEN OF COLOR IN STEM EDUCATION. Journal of Research in Science Teaching, 55(2), 206-245. https://doi.org/10.1002/tea.21417

Pacific-Media.org. (n.d.). Map of the Pasifika Region [Pinterest]. Retrieved 4 April, 2021

Page-Reeves, J., Marin, A., Moffett, M., DeerInWater, K., \& Medin, D. (2019). Wayfinding as a concept for understanding success among Native Americans in STEM: "Learning how to map through life." Cultural Studies of Science Education, 14(1), 177-197. https://doi.org/10.1007/s11422-0179849-6

Paik, S. J., Kula, S. M., Saito, E., Rahman, Z., \& Witenstein, M. (2014). Historical Perspectives on Diverse Asian American Communities: Immigration, Incorporation, and Education. Teachers College Record, 116(080308), 45.

Palmer, R. T., Davis, R. J., \& Maramba, D. C. (2011). The Impact of Family Support on the Success of Black Men at an Historically Black University: Affirming the Revision of Tinto's Theory. Journal of College Student Development, 52(5), 577-597. https://doi.org/10.1353/csd.2011.0066

Palmer, R. T., \& Maramba, D. C. (2015). The Impact of Social Capital on the Access, Adjustment, and Success of Southeast Asian American College Students. Journal of College Student Development, 56(1), 45-60. https://doi.org/10.1353/csd.2015.0007

Palmer, R. T., Maramba, D. C., \& Dancy, T. E. (2011). A Qualitative Investigation of Factors Promoting the Retention and Persistence of Students of Color in STEM. The Journal of Negro Education, $80(4), 491-504$.

Palmer, R. T., Maramba, D. C., Gasman, M., \& Lloyd, K. (2012). Charting the course: The role of minority serving institutions in facilitating the success of underrepresented racial and ethnic minority students in STEM. In In R. T., Palmer., D. C. Maramba, \& M. Gasman. (Eds.). Fostering success of ethnic and racial minorities in STEM: The role of minority serving Institutions (pp. 1-16). Routledge. 
Pascarella, E. T., Pierson, C. T., Wolniak, G. C., \& Terenzini, P. T. (2004). First-Generation College Students: Additional Evidence on College Experiences and Outcomes. The Journal of Higher Education, 75(3), 249-284. https://doi.org/10.1080/00221546.2004.11772256

Patton, M. Q. (1999). Enhancing the quality and credibility of qualitative analysis. Health Services Research, 34(5 Pt 2), 1189-1208.

Pérez Huber, L., \& Solorzano, D. G. (2015). Racial microaggressions as a tool for critical race research. Race Ethnicity and Education, 18(3), 297-320. https://doi.org/10.1080/13613324.2014.994173

Perna, L. W., Gasman, M., Gary, S., Lundy-Wagner, V., \& Drezner, N. D. (2010). Identifying strategies for increasing degree attainment in STEM: Lessons from minority-serving institutions. New Directions for Institutional Research, 2010(148), 41-51. https://doi.org/10.1002/ir.360

Prescott, S. (2008). Using Talanoa In Pacific Business Research in new Zealand: Experiences with Tongan Entrepreneurs. AlterNative: An International Journal of Indigenous Peoples, 4(1), 127148. https://doi-org.ccl.idm.oclc.org/10.1177/117718010800400111

Research \& Equity Scholarship Institute. (2021). ED-SYSTEMS: Educational Settings Yielding Science, Technology, Engineering, and Math Success [Interview]. https://www.nsf.gov/awardsearch/showAward?AWD_ID=1644990\&HistoricalAwards=false

Reyes, N. A. S. (2018). A space for survivance: Locating Kānaka Maoli through the resonance and dissonance of critical race theory. Race Ethnicity and Education, 21(6), 739-756. https://doi.org/10.1080/13613324.2017.1376632

Rincón, B. E., Fernández, É., \& Dueñas, M. C. (2020). Anchoring comunidad: How first- and continuinggeneration Latinx students in STEM engage community cultural wealth. International Journal of Qualitative Studies in Education, 33(8), 840-854. https://doi.org/10.1080/09518398.2020.1735567

Rios-Aguilar, C., \& Kiyama, J. M. (2012). Funds of Knowledge: An Approach to Studying Latina(o) Students' Transition to College. Journal of Latinos and Education, 11(1), 2-16. https://doi.org/10.1080/15348431.2012.631430 
Ross, T., Kena, G., Rathbun, A., KewalRamani, A., Zhang, J., Kristapovich, P., \& Manning, E. (2012). Higher Education: Gaps in Access and Persistence Study (p. 329) [Statistical Analysis]. National Center for Education Statistics.

Rust, S. (2019, November 10). How the U.S. betrayed the Marshall Islands, kindling the next nuclear disaster. Los Angeles Times. https://www.latimes.com/projects/marshall-islands-nuclear-testingsea-level-rise/

Saelua, N., Wright, E. K., Kukahiko, K. T., Thornton, M. M., \& Aina, I. (2016). Pacific Islander Education and Retention: The Development of a Student-Initiated, Student-Run Outreach Program for Pacific Islanders. In In Ching, D., Museus, S., \& Agbayani, A. (Eds). Underserved AAPIs in Higher Education. Information Age Publishing.

Saldaña, J. (2009). The coding manual for qualitative researchers. Sage.

Samuelson, C. C., \& Litzler, E. (2016). Community Cultural Wealth: An Assets-Based Approach to Persistence of Engineering Students of Color: Cultural Wealth, Undergraduate Persistence, and Students of Color. Journal of Engineering Education, 105(1), 93-117. https://doi.org/10.1002/jee.20110

Shaw, E. J., \& Barbuti, S. (2010). Patterns of Persistence in Intended College Major with a Focus on STEM Majors. NACADA Journal, 30(2), 19-34. https://doi.org/10.12930/0271-9517-30.2.19

Smith, P. L. T. (2013). Decolonizing Methodologies: Research and Indigenous Peoples. Zed Books Ltd. Solórzano, D., Ceja, M., \& Yosso, T. (2000). Critical Race Theory, Racial Microaggressions, and Campus Racial Climate: The Experiences of African American College Students. The Journal of Negro Education, 69(1/2), 60-73.

Solórzano, D. G. (1998). Critical race theory, race and gender microaggressions, and the experience of Chicana and Chicano scholars. International Journal of Qualitative Studies in Education, 11(1), 121-136. https://doi.org/10.1080/095183998236926

Solórzano, D. G., \& Ornelas, A. (2002). A Critical Race Analysis of Advanced Placement Classes: A Case of Educational Inequality. Journal of Latinos \& Education, 1(4), 215. 
Spencer, S. J., Logel, C., \& Davies, P. G. (2016). Stereotype Threat. Annual Review of Psychology, 67(1), 415-437. https://doi.org/10.1146/annurev-psych-073115-103235

Spencer, S. J., Steele, C. M., \& Quinn, D. M. (1999). Stereotype Threat and Women's Math Performance. Journal of Experimental Social Psychology, 35(1), 4-28. https://doi.org/10.1006/jesp.1998.1373

Steele, C. M., \& Aronson, J. (1995). Stereotype threat and the intellectual test performance of African Americans. Journal of Personality and Social Psychology, 69(5), 797-811. https://doi.org/10.1037/0022-3514.69.5.797

Sue, D. W., Bucceri, J., Lin, A. I., Nadal, K. L., \& Torino, G. C. (2007). Racial microaggressions and the Asian American experience. Cultural Diversity and Ethnic Minority Psychology, 13(1), 72-81. https://doi.org/10.1037/1099-9809.13.1.72

Sundler, A. J., Lindberg, E., Nilsson, C., \& Palmér, L. (2019). Qualitative thematic analysis based on descriptive phenomenology. Nursing Open, 6(3), 733-739. https://doi.org/10.1002/nop2.275

Swain, L. (2010). Pacific Islander Americans-History, Modern era, The first pacific islanders in america. S and Their Cultures. https://www.everyculture.com/multi/Le-Pa/Pacific-IslanderAmericans.html

Tamaira, M. A. (2009). The Space Between: Negotiating Culture, Place, and Identity in the Pacific [Occasinal Paper 44].

Tecun (Daniel Hernandez), A., Hafoka, 'Inoke, 'Ulu'ave, L., \& 'Ulu'ave-Hafoka, M. (2018). Talanoa: Tongan epistemology and Indigenous research method. AlterNative: An International Journal of Indigenous Peoples, 14(2), 156-163. https://doi.org/10.1177/1177180118767436

Teranishi, R., \& Kim, V. (2017). The Changing Demographic Landscape of the Nation: Perspectives on College Opportunities for Asian Americans and Pacific Islanders. The Educational Forum, 81(2), 14 (204-216). https://doi.org/10.1080/00131725.2017.1280759

Teranishi, R., Le, A., Gutierrez, R. A., Venturanza, R., Hafoka, I., Gogue, D., \& Uluave, L. (2019). Native Hawaiians and Pacific Islanders in Higher Education: A Call to Action (p. 20). University of California, Los Angeles. 
Teranishi, R. T. (2012). Asian American and Pacific Islander Students and the Institutions that Serve Them. Change, 44(2), 16-22. https://doi.org/10.1080/00091383.2012.655233

Teranishi, R. T., Behringer, L. B., Grey, E. A., \& Parker, T. L. (2009). Critical race theory and research on Asian Americans and Pacific Islanders in higher education. New Directions for Institutional Research, 2009. https://doi.org/10.1002/ir.296

Teranishi, R. T., Maramba, D. C., \& Ta, M. H. (2012). Asian American and Native American Pacific Islander Serving Institutions (AANAPISIs): Mutable Sites for Science, Technology, Engineering, and Math (STEM) Degree Production. In Fostering Success of Ethnic and Racial Minorities in STEM (1st ed., p. 13). Routledge.

Thaman, K. H. (1997). Reclaiming a Place: Towards a Pacific Concept of Education for Cultural Development. The Journal of the Polynesian Society, 106(2), 119-130. JSTOR.

Thaman, K. H. (2008). Nurturing Relationships And Honouring Responsibilities: A Pacific Perspective. International Review of Education, 54(3-4), 459-473. https://doi.org/10.1007/s11159-008-90921

Torres, J. B., \& Solberg, V. S. (2001). Role of Self-Efficacy, Stress, Social Integration, and Family Support in Latino College Student Persistence and Health. Journal of Vocational Behavior, 59(1), 53-63. https://doi.org/10.1006/jvbe.2000.1785

Uehara, D. L., Chugen, J., \& Raatior, V. (2018). Perceptions of Pacific Islander students in higher education. Journal of Diversity in Higher Education, 11(2), 182-191. https://doi.org/10.1037/dhe0000057

Vaioleti, T. M. (2006). Talanoa Research Methodology: A Developing Position on Pacific Research. Waikato Journal of Education, 12. https://doi.org/10.15663/wje.v12i1.296

Vakalahi, H. F. O., Toafa, S. G., \& Moala, K. O. (2008). Grandparenting in the Tongan Community: A Cultural Model. Journal of Intergenerational Relationships, 6(3), 305-319. https://doi.org/10.1080/15350770802157885 
Vakalahi, H., Heffernan, K., \& Niu Johnson, R. (2007). Pacific Island Elderly: A Model for Bridging Generations and Systems. The Journal of Baccalaureate Social Work, 12(2).

Valencia, R. R. (2010). The Construct of Deficit Thinking. In Dismantling Contemporary Deficit Thinking Educational Thought and Practice (pp. 1-18). Routledge.

Vélez-Ibáñez, C. G., \& Greenberg, J. B. (1992). Formation and Transformation of Funds of Knowledge among U.S.-Mexican Households. Anthropology \& Education Quarterly, 23(4), 313-335. JSTOR.

Visintainer, T. (2020). "I think at first glance people would not expect me to be interested in science": Exploring the racialized science experiences of high school students of color. Journal of Research in Science Teaching, 57(3), 393-422. https://doi.org/10.1002/tea.21597

Wang, X. (2015). Pathway to a Baccalaureate in STEM Fields: Are Community Colleges a Viable Route and Does Early STEM Momentum Matter? Educational Evaluation and Policy Analysis, 37(3), 376-393. https://doi.org/10.3102/0162373714552561

Yosso, T. J. (2005). Whose culture has capital? A critical race theory discussion of community cultural wealth. Race Ethnicity and Education, 8(1), 69-91. https://doi.org/10.1080/1361332052000341006 


\author{
Appendix A \\ Consent Form \\ San Diego State University \\ INFORMED CONSENT FORM \\ $12 / 1 / 19$
}

\title{
Navigation and Persistence: Pacific Islander STEM Students' Experiences \\ in Higher Education
}

\section{IMPORTANT THINGS TO KNOW ABOUT THIS STUDY:}

We are inviting those who self-identify as Pacific Islanders, specifically from the islands of Hawaii, Fiji, Aotearoa, Samoa, Tahiti, and Tonga who have had at least 3 years of college in STEM at a 4-year institution or have graduated with a degree in STEM. You must be 18 years of age or older to join this research study. The purpose of the research is to understand the college experiences of STEM students who are Pacific Islanders.

We are asking people who join this study to attend 1 one-on-one interview session over a period of 2 hours. The study involves a brief online pre-interview survey and 1 one-on-one interview.

You do not have to join this study. These are the reasons you may want to participate in this study: reflecting on your experiences as a current or past STEM student may yield a deeper understanding of your persistence and retention as an undergraduate STEM major. The reason you may not want to participate in this study is the potential that you may experience discomfort during the interview; however, you may elect to not answer any of the questions.

We will give you details about the purposes, procedures, risks, and possible benefits related to this study. We will explain other choices you have. We will also give you any other information that you need to make an informed decision about joining this study.

The following information is a more complete description of the study. Please read this description carefully. We want you to ask us any questions that will help you decide whether you want to join this study. If you join the study, we will give you a signed copy of this form to keep for reference in the future.

\section{WHO SHOULD I CONTACT IF I HAVE QUESTIONS OR CONCERNS?}

Primary-Investigator: Marlena Wolfgramm 
SDSU Department: College of Education

Address: 5500 Campanile Drive, San Diego, CA 92182-1127

Phone: (510) 967-6916

Email: mwolfgramm@cgu.com

\section{WE ARE INVITING YOU TO JOIN THIS RESEARCH STUDY.}

We are inviting you because you have identified as a Pacific Islander from the islands of Hawaii, Fiji, Aotearoa, Samoa, Tahiti and/or Tonga, have had at least 3 years of college in STEM at a 4year institution or have graduated with a degree in STEM. You must be 18 years of age or older to join this research study. Up to 15 participants will be included.

Research is not the same as treatment or other medical or psychological care or therapy. The purpose of research is to answer scientific questions.

You do not have to be in this study. You are free to say "yes" or "no", or to drop out of the study after joining.

\section{WHY ARE WE DOING THIS STUDY?}

We are doing this study to find out the experiences of STEM students who have successfully navigated and persisted in STEM. We want to know from your experiences as a Pacific Islander STEM student and investigate the factors for navigation and persistence.

\section{WHAT IS THE TIME COMMITMENT IF I JOIN THIS RESEARCH STUDY?}

Your entire participation will last 2 hours (including completion of the online pre-interview survey and interview). Conducted in a private/quiet office or conference room, you will participate in one in-person interview ( 90 minutes).

\section{WHAT WILL I BE ASKED TO DO IN THIS RESEARCH STUDY?}

If you volunteer to participate in this study, the researcher will ask you to do the following:

- Complete a brief questionnaire that includes demographic information (age, gender, race, major, etc.)

-Participate in an audio- or video-recorded interview describing an artifact related to your educational experiences as a STEM major. 


\section{WHAT ARE THE RISKS OR DISCOMFORTS INVOLVED IN THE RESEARCH?}

Because of the personal nature of the questions to be asked, you might reflect on unpleasant memories while completing a questionnaire or participating in an interview. If you feel uncomfortable you may decline to answer any questions that make you feel uncomfortable, or you may discontinue your participation in this study. Even though we will take measures to keep private information collected in surveys/interviews, there is a possible risk of loss of privacy.

\section{ARE THERE ANY BENEFITS TO PARTICIPATION?}

There are no benefits for being in this study; however, by joining this research study, you are helping to provide information that may help science and society.

\section{ARE THERE ANY ALTERNATIVES TO JOINING THIS RESEARCH STUDY?}

An alternative is to not join the research study.

\section{WILL MY INFORMATION BE PRIVATE?}

We will keep your information private, but there are limits to what we can keep private. If we think child or elder abuse is occurring, California law requires that we report the suspected abuse to the authorities.

Because this study involves audio- or video-recorded interviews, your participation will not be anonymous. However, your personal contact information (e.g., phone number and/or email address) will remain confidential. Your signature on this informed consent from indicates that you are allowing your de-identified data to be shared with other researchers.

Research records, including audio and electronic files, will be stored on a secure, passwordprotected server managed by San Diego State University's College of Education (Technology Support). Each participant will be given an opportunity (a period of 10 days) to review the video prior to release. All research data will be destroyed at least three years after the end of this study.

We will use the results of the study for publication or scientific purposes. This information could be used for future research studies. In this case, you won't be asked to consent to the future research.

\section{DO I HAVE TO JOIN THIS STUDY?}

You do not have to participate in this research study. If you choose not to participate there is no penalty or loss of benefits to which you are otherwise entitled. Additionally, you may refuse to answer any questions that you do not want to answer and remain in the study. 


\section{WILL I BE TOLD ABOUT THE RESEARCH RESULTS?}

We will not contact you with results of this study after this study is completed.

WILL IT COST ME ANYTHING IF I JOIN THE RESEARCH?

No.

\section{WILL I BE PAID IF I JOIN THE RESEARCH?}

You will not be paid to participate in this study.

\section{WHOM DO I CONTACT IF I HAVE QUESTIONS OR CONCERNS?}

If you have any questions about the research now, please ask. If you have questions later about the research, you may contact Marlena Wolfgramm at (510)967-6916 or mwolfgramm@cgu.edu or Dr. Felisha Herrera Villarreal at (619) 594-1956 or Felisha.Herrera@sdsu.edu. If you have any questions about your rights as a participant in this study, or in the event of a research related injury, you may contact the Division of Research Affairs at Claremont Graduate University (telephone: 909-607-9406; email: IRB @ cgu.edu). At any time during the research you can contact the IRB for questions about research rights, to discuss problems, concerns, or suggestions, or to offer input.

\section{CONSENT TO PARTICIPATE:}

Your signature below indicates that you have read the information in this document and have had a chance to ask any questions you have about the study. Your signature also indicates that you agree to join the study and that the study team has told you that you can change your mind and withdraw your consent to participate at any time. The investigator or a member of his/her research team has provided you with a copy of this consent form with information about who to contact in the event you have questions.

Name of Participant (please print)

Date

Signature of Participant

Date

Signature of Investigator

Date 


\section{Appendix B}

\section{Recruitment Email}

To Pacific Islander STEM major students:

I'm emailing to see if you would be interested in participating in a research study entitled Persistence and Retention of STEM Majors. The purpose of the study is to examine STEM pathways of Pacific Islander students in higher education. For this reason, we will be conducting one-on-one interviews with those who self-identify as Pacific Islanders, specifically from the islands of Hawaii, Fiji, Aotearoa, Samoa, Tahiti, and Tonga, who have had at least 3 years of college in STEM at a 4-year institution or have graduated with a degree in STEM. You must be 18 years of age or older to join this research study.

If you choose to participate, your entire participation will take approximately 90 minutes. Your contribution will involve filling out a brief questionnaire and completing a one-on-one virtual interview via Zoom. During the interview, you will be asked questions about your background and college experience.

If you have any questions or would like to schedule a focus group, please contact Marlena Wolfgramm at (510) 967-6916 or mwolfgramm@sdsu.edu or Dr. Felisha Herrera Villarreal at Felisha.Herrera@sdsu.edu.

For more information about this study, please see the attached flyer. Feel free to share with others who also may be interested in participating.*

Thank you for your time.

Marlena M. Wolfgramm, M.A.

*Emails must be forwarded using blind copy to ensure privacy for research purposes.

Attached: PI-STEM Recruitment Flyer 
Appendix C

PI-STEM Recruitment Flyer

Pacific Islanders in STEM

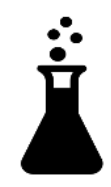

PARTICIPANTS NEEDED FOR RESEARCH STUDY

Looking for participants who identify as Pacific Islander (Hawaiian, Fijian, Maori, Samoan, Tahitian, Tongan, etc.)

Interviews will last 60-90 minutes and will be done via Zoom. Participation is confidential and your name will not be associated with the study.

Must have at least 3 years of college as a STEM (Science, Technology, Engineering, Mathematics), majoring at a 4-year institution or graduated with a degree in STEM, and be at least 18 years old.

For additional information, please contact Marlena Wolfgramm at mwolfgramm@sdsu.edu. 


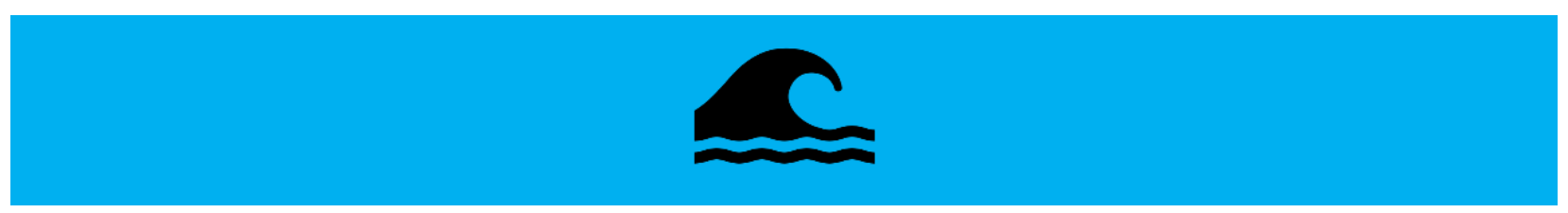

\section{Appendix D}

\section{Demographic Survey}

\section{$\underline{\text { Demographic Survey }}$}

Welcome to the research study!

I am interested in understanding the navigation of Pacific Islander STEM (Science, Technology, Engineering and Mathematics) majors. You will be presented with information relevant to Pacific Islander navigation in STEM and asked to answer some questions about it. Please be assured that your responses will be kept completely confidential.

The survey should take you around 12 minutes to complete. Your participation in this research is voluntary. You have the right to withdraw at any point during the study, for any reason, and without any prejudice. If you would like to contact the Principal Investigator in the study to discuss this research, please e-mail Marlena Wolfgramm at mwolfgramm@sdsu.edu.s[epi]

Checking the box below serves as your signature and indicates that you have read the information in this document and have had a chance to ask any questions you have about the study. Your signature also indicates that you agree to join the study and that the study team has told you that you can change your mind and withdraw your consent to participate at any time. The investigator or a member of the research team has provided you with a copy of the Consent Form with information about who to contact in the event you have questions.

Please note that this survey will be best displayed on a laptop or desktop computer. Some features may be less compatible for use on a mobile device.

I consent, begin the study

I do not consent, I do not wish to participate (2) 
Q50 Please note that you must type your electronic signature in the space below in order to participate in this study. You can change your mind and withdraw your consent to participate at any time.

\section{End of Block: Informed Consent}

Start of Block: Contact Info

Q3 Please enter your full name and contact information.

First name (1)

Last name (2)

Q4 Email

Q5 Phone (XXX) XXX - XXXX

\section{End of Block: Contact Info}

\section{Start of Block: Screening Questions}


Q6 Do you self-identify as a Pacific Islander, which may include: Hawaiian, Fijian, Maori, Samoan, Tahitian or

Tongan?

Yes (1)

No (2)

Q7 Have you completed at least 3 years of college as a STEM (Science Technology Engineering Mathematics) major at 4-year institution or graduated with a degree in STEM?

Yes (1)

No (2)

Q8 Are you 18 years old or older?

Yes (1)

No (2) 
Q9 Please specify your Pacific Island region of heritage. Check all the apply.

\section{Hawaii (1)}

Samoa (2)

Tahiti (3)

Tonga (4)

Aotearoa/New Zealand (5)

Fiji (6)

Other, please specify. (7) 
Q10 How do you identify yourself racially/ethnically? Please check all that apply.

White/Caucasian (1)

Black/African American (2)

Native American/Alaskan Native (3)

Asian (e.g. Cambodian, Chinese, Filipino, Japanese, Indian, etc.) (4)

Pacific Islander (Native Hawaiian, Maori, Tongan, Samoan, etc.) (5)

Arab American/ Middle Eastern (6)

Hispanic/Latinx/Chicanx (7)

Other, please specify. (8)

\section{End of Block: Race/ Ethmicity}

Start of Block: $\mathbb{K}-12$ Education

Q11 Did you complete most of your K-12 education in the U.S.? If 'No', please specify which country.

Yes (1)

No. Please specify country. (2) 
Q12 Where did you earn your high school diploma or the equivalent (i.e. GED)

United States. Please type name of school, city and state. (1)

Outside of the United States (please specify country) (2)

Q13 From what kind of high school did you graduate? Select one.

Public school (not charter or magnet) (1) ... Did not graduate high school but passed the GED or high school equivalency test (7)

Q14 What year did year (yyyy) earn your high school diploma or the equivalent (i.e. GED)?

Q15 What was your highest level of math in high school?

Algebra 1 (1)

Geometry (2)

Algebra 2/ Trigonometry (3)

Pre-Calculus (4)

Calculus (5)

Other (please specify) (6) 
Q16 What was your high school non-weighted GPA?

4.0 and above (1) ... Below 2.0 (6)

\section{End of Block: K-12 Education}

Start of Block: Post-Secondary Education

Q17 When did you enroll in college for the first time?

Immediately after high school (1)

Delayed 1 year (2)

Delayed 2 years (3)

Delayed 3 years (4)

Delayed 4 years (5)

Delayed 5 or more years (6)

Q51 What year are you in college?

3 - 4 (Junior) (3)

4 or more years (Senior) (4)

Graduate Student (e.g. MA, PhD, MD, DD) (5)

Graduate (6) 
Q18 What is the highest level of school you have completed or the highest degree you have received?

Some college but no degree (1)

Associate degree in college (2-year) (2)

Bachelor's degree in college (4-year) (3)

Master's degree (4)

Doctoral degree (5)

Professional degree (JD, MD) (6)

Q54 Please tell me about your postsecondary educational background. If the degree is not applicable, please leave the spaces blank on that line.

\begin{tabular}{|c|c|c|c|c}
$\begin{array}{c}\text { Name of } \\
\text { Institution } \\
\text { where you } \\
\text { obtained your } \\
\text { degrees (if } \\
\text { applicable): }\end{array}$ & $\begin{array}{c}\text { Total number } \\
\text { of years at this } \\
\text { institution }\end{array}$ & $\begin{array}{c}\text { Major / Area of } \\
\text { Study }\end{array}$ & $\begin{array}{c}\text { Country where } \\
\text { degree was } \\
\text { obtained if } \\
\text { outside the } \\
\text { U.S. }\end{array}$ \\
\hline Enter Text (1) & & Indicate major: \\
& & (1) & Country: (1)
\end{tabular}




\begin{tabular}{|c|c|}
\hline $\begin{array}{c}\text { Vocational/Technical } \\
\text { (1) }\end{array}$ & $\begin{array}{l}\nabla \text { Less than } 1 \\
\text { year }(1 \ldots 5 \text { or } \\
\text { more years }(6)\end{array}$ \\
\hline Associate's (2) & $\begin{array}{l}\nabla \text { Less than } 1 \\
\text { year }(1 \ldots 5 \text { or } \\
\text { more years }(6)\end{array}$ \\
\hline Bachelor's (3) & $\begin{array}{l}\nabla \text { Less than } 1 \\
\text { year }(1 \ldots 5 \text { or } \\
\text { more years }(6)\end{array}$ \\
\hline Master's (4) & $\begin{array}{l}\nabla \text { Less than } 1 \\
\text { year }(1 \ldots 5 \text { or } \\
\text { more years }(6)\end{array}$ \\
\hline $\operatorname{PhD}(5)$ & $\begin{array}{l}\nabla \text { Less than } 1 \\
\text { year }(1 \ldots 5 \text { or } \\
\text { more years }(6)\end{array}$ \\
\hline EdD (6) & $\begin{array}{l}\nabla \text { Less than } 1 \\
\text { year }(1 \ldots 5 \text { or } \\
\text { more years }(6)\end{array}$ \\
\hline $\begin{array}{l}\text { Other (please specify } \\
\text { degree earned): }(7)\end{array}$ & $\begin{array}{l}\nabla \text { Less than } 1 \\
\text { year }(1 \ldots 5 \text { or } \\
\text { more years }(6)\end{array}$ \\
\hline
\end{tabular}




\begin{tabular}{c|c|c|} 
& \\
$\begin{array}{c}\text { Other (please specify } \\
\text { degree earned): (8) }\end{array}$ & $\mid \begin{array}{c}\boldsymbol{\nabla} \text { Less than } 1 \\
\text { year }(1 \ldots 5 \text { or } \\
\text { more years }(6)\end{array}$ \\
\hline $\begin{array}{c}\text { Other (please specify } \\
\text { degree earned): (9) }\end{array}$ & $\begin{array}{c}\boldsymbol{\nabla} \text { Less than } 1 \\
\text { year }(1 \ldots 5 \text { or } \\
\text { more years }(6)\end{array}$ \\
\hline
\end{tabular} \mid

Q58 If you could rank these factors from the most important (number 1) to least important (number 10), which do you think have the most significant impact on your success in STEM: you, family, classmates, professor, teaching assistant, department, and institution?

Instructions: Please rank these factors by dragging the most important factor to the top of the list and the least important factor to the bottom of the list.

You (Student) (1)

Family (2)

Classmates/Peers (3)

Professor (4)

Counselors/Advisors (5)

Department (6)

Entire Institution (7)

Student Success Program(s) (8)

Administration (9)

Teaching Assistant (10) 
Q20 Almost DONE! I appreciate your responses about your educational background. I just have a few more questions about your personal background.

Page Break

Q21 Birth year (YYYY)

Q22 Place of birth

If United States, please list city and state. (1)

If outside of United States, please list which country. (2)

Q23 First language spoken

English (1)

Other (Please specify) (2) 
Q24 Gender: (please select one)

Male (1)

Female (2)

Nonbinary (3)

Prefer not answer (4)

Not listed (5)

Q25 Information about your parent's median income during your $\mathrm{K}-12$ education is very important to understand. Would you please give your best guess?

Less than $\$ 20,000$

$\$ 20,000$ to $\$ 34,999$ (2)

$\$ 35,000$ to $\$ 49,999$ (3)

$\$ 50,000$ to $\$ 74,999$

$\$ 75,000$ to $\$ 99,999$

Over $\$ 100,000(6)$

\section{End of Block: Basic Demographic Information (Birth year, etc)}


Q26 Current Marital Status

Single (1)

Married (2)

Divorced/Separated/Widowed (3)

Q27 Do you have children?

Yes (1)

No (2)

\section{End of Block: Family / Marital Status}

Start of Block: Language

Q28 Would you consider yourself a multilingual person?

Yes (1)

No (2)

\section{Display This Question:}

Would you consider yourself a multilingual person? = Yes 
Q29 If yes, what primary language do you speak OTHER THAN English:

Hawaiian (1)

Fijian (2)

Maori (3)

Samoan (4)

Tahitian (5)

Tongan (6)

Other (please specify): (7)

Display This Question:

If Would you consider yourself a multilingual person? = Yes

Q30 With regards to this primary language OTHER THAN English, how would you rate your bilingualism?

Click to write Column 1

\begin{tabular}{|c|c|c|c|c|c|}
\hline & \multicolumn{5}{|c|}{ Click to write Column 1} \\
\hline & $\begin{array}{l}\text { Beginner - } 1 \\
\text { (1) }\end{array}$ & $2(2)$ & $3(3)$ & $4(4)$ & $\begin{array}{c}\text { Proficient - } 5 \\
\text { (5) }\end{array}$ \\
\hline Speaking (1) & $\bigcirc$ & $\bigcirc$ & $\bigcirc$ & $\bigcirc$ & $\bigcirc$ \\
\hline Reading (2) & $\bigcirc$ & $\bigcirc$ & $\bigcirc$ & $\bigcirc$ & $\bigcirc$ \\
\hline Writing (3) & $\bigcirc$ & $\bigcirc$ & $\bigcirc$ & $\bigcirc$ & $\bigcirc$ \\
\hline
\end{tabular}


Q31 In the questions below, please indicate who you are referring to as Parent 1.

Mother (1)

Father (2)

Stepmother (3)

Stepfather (4)

Foster Mother (5)

Foster Father (6)

Grandmother (7)

Grandfather (8)

Aunt (9)

Uncle (10)

Other Relative or Legal Guardian (specify their role/relationship to you) (11)

Q33 Where was Parent 1 born?

In the US (1)

Outside of the US (Specify country) (2) 
Q34 What is Parent 1's native language?

English (1) ... Other (8)

Display This Question:

If What is Parent 1 's native language? = Other

Q35 If you selected "Other," please specify Parent 1's native language:

Q37 Where did Parent 1 complete their highest level of education?

In the United States (1)

Outside of United States (please specify country) (2) 
Q70 What is the highest level of formal education completed by Parent 1?

No formal schooling (1)

Elementary/middle school (2)

Some high school (3)

Graduated from high school/ GED

Trade/technical/vocational training (5)

Some college (specify major): (6)

Associate's Degree (specify major): (7)

Bachelor's Degree (specify major): (8)

Some graduate school (specify field of study): (9)

Master's Degree (specify field of study): (10)

Professional/Doctorate Degree (PhD, JD, MD, etc.) (specify field of study): (11) 
Q40 In the questions below, please indicate who you are referring to as Parent 2.

Mother (1)

Father (2)

Stepmother (3)

Stepfather (4)

Foster Mother (5)

Foster Father (6)

Grandmother (7)

Grandfather (8)

Aunt (9)

Uncle (10)

Other Relative or Legal Guardian (specify their role/relationship to you) (11)

None or N/A (12) 
Q42 Where was Parent 2 born?

In the US (1)

Outside of the US (Specify country) (2)

N/A (3)

Q43 What is Parent 2's native language?

English (1) ... N/A (9)

Display This Question:

If What is Parent 2's native language? = Other

Q44 If you selected “Other," please specify Parent 2's native language:

Q46 Where did Parent 2 complete their highest level of education?

In the United States (1)

Outside of United States (please specify country) (2)

N/A (3) 
Q67 What is the highest level of formal education completed by Parent 2?

No formal schooling (1)

Elementary/middle school (2)

Some high school (3)

Graduated from high school/ GED (4)

Trade/technical/vocational training (5)

Some college (specify major): (6)

Associate's Degree (specify major): (7)

Bachelor's Degree (specify major): (8)

Some graduate school (specify field of study): (9)

Master's Degree (specify field of study): (10)

Professional/Doctorate Degree (PhD, JD, MD, etc.) (specify field of study): (11)

N/A (12) 


\section{Appendix E}

\section{Interview Protocol}

\section{PI-STEM INTERVIEW PROTOCOL}

---Start of the interview---

Thank you for volunteering your time and allowing me to ask you some questions about your experiences as a Pacific Islander STEM major. Please remember there is no wrong or right answers and that I want to hear your story.

\section{Introduction/STEM Trajectory}

1. Please tell me your name and university you currently attend? PROBES:

a. Ask about major/program of study

b. Ask about year in school

c. Ask about previous majors

d. Ask about previous community colleges or universities

2. Tell me something about yourself. PROBES:

a. Please describe your racial/ethnic identity.

i. Do you identify as a Pacific Islander? If yes, what does being a Pacific Islander mean to you?

b. How would others describe you? Why?

c. What kind of student are you? Why?

d. What kind of student would your professor say you are? Why?

3. In reference to attending college, what you would say is your generational status is?

a. Did your grandparents, parents, and/or siblings attend college?

4. What language (or languages) did you grow up speaking?

5. What role if any, does this language have in your journey to college for you?

6. Are there other ways of identifying yourself that are significant to you that you feel comfortable discussing or sharing with me?

Thank you for sharing. Now, I would like to ask you questions about your high school experience and journey to college.

\section{Precollege Experience}

7. How would you describe your high school experience? PROBES:

a. What type of student were you in high school? 
b. How involved were you in high school activities, like attending events, being part of a club, sports or school government or committee?

c. Were you involved in a STEM or college bridge program (e.g. summer program, club, internship, etc.) or attended a STEM-specific high school?

d. Do you feel that your high school prepared you for college and/or to major in STEM?

e. Did you take any AP courses? If so, which courses?

8. What was your college planning process? PROBES:

a. How did you to figure out what college to attend? Did someone help you?

b. How did you figure out to apply for college, financial aid and/or scholarships?

9. We often hear about one's journey to college, how did I get here? Please describe your Journey Map and discuss what your college was like? PROBE:

a. What were some major milestones in developing your interest in STEM? Begin before high school (e.g. clubs, summer programs, internship, science experiment/research, science class, teacher, mentor, family/friend in STEM, etc.)

b. Include any early experiences that may not be STEM related but is somehow connected? (e.g. cancer in the family, discrimination, lack of representation, etc.)

c. Which college did you attend after high school? Give us a chronological trajectory and how long you were at each college.

d. What was the role of your parents, guardians, or other people played in this journey?

e. If you attended more than one college, please explain why.

10. When and why did you decide to go to college? Who planted that seed to go to college?

a. Were you expected to go to college growing up? If yes, who and how did they emphasize going to college?

b. Did your family support your decision to go to college? Why or why not?

c. Did you have any family members or friends that attended college? Did they inspire or help you with college?

Thank you again for sharing your story. Now I'll ask you some questions about your college experience as a STEM major.

\section{College Experience}

11. What type of college student are/were you (e.g. active or passive, collaborative or independent, study group, etc.)? PROBE:

a. Did you live on campus? Why or why not?

b. Did you attend orientation? Why or why not? If yes, was it helpful in knowing where to find support, utilize resources such as the library or advisor's office? 
c. Did you work on campus? If yes, what was your job and how did that impact your college experience?

d. Did you meet with professors outside of class for office hours, internships or worked on research with your professor? If yes, how did impact your experience as a STEM major?

e. Did you have an opportunity to work in a lab or research in STEM? If yes, how did this impact your experience as a STEM major?

12. How would you describe your campus environment?

a. What is the demographic make-up on campus? In your STEM courses (e.g. ethnicity/race, traditional/non-traditional students, SES, STEM background, etc.)?

b. How would you describe the culture within your STEM major/classes (e.g. collaborative or competitive, warm or chilly, friendly or unfriendly, etc.)?

13. How did you figure out how to register for school, enroll in classes or figure out which courses to take for your major?

a. Did you apply for financial aid, scholarships, grants or internships?

14. What sparked your interest in majoring in STEM in college? (e.g. science class, STEM program, teacher, advisor/mentor in STEM, friends)? PROBE:

a. Why did you choose to major in [field of study]?

b. Did you know someone in your [field of study]? Were your parents in your [field of study]?

c. Was your journey toward [field of study] different than your journey to college? Why or why not?

d. Where do you see yourself after graduating with a degree in STEM? (Include on Journey Line/Map.)

15. Would you consider your journey as a/an [field of study] or an aspiring [field of study]?

a. Can you describe what it means to be or aspire to be a/an [field of study]?

16. What does your support system look like to an outsider? PROBE:

a. What were some of the major supports for you as a STEM major (e.g. academic advisor, administration, faculty, staff, peers, STEM support program, PI-specific program, family, etc.)?

b. Is your family part of your support system? If so, how would describe your family?

17. Can you describe the interactions that you have had with your support system?

18. Have you been away from home since starting your STEM major at your university?

a. What has the experience like for you?

19. If you could change one thing about your experience as a STEM major in the university, what would it be? 
20. What are some of the challenges or barriers that you experienced as a STEM major (e.g. counselors, academic advisors, administration, faculty, peers, STEM support program, PI-specific programs, family, etc.)?

a. How have you dealt with those barriers?

b. Were there safe spaces on campus or off-campus that you could go to share any frustrations or negative experiences at school as a STEM major. Please describe.

21. What people or resources have been beneficial to your success as a STEM major?

22. Who do you admire or aspire to (e.g. family, community, discipline, colleagues, mentors)? Why are these qualities and characteristics of this person important to you as a Pacific Islander in STEM?

\section{Pacific Islander Identity}

23. What do you feel is the most important thing about your culture? Give an example. (e.g. respect, family, honor, holidays, etc.)

a. How do you maintain your cultural identity/background?

24. As a Pacific Islander, has your cultural identity, values or traditions impacted your educational experience? (e.g., family obligations, cultural values, etc.) If yes, explain.

a. Do you feel that your Pacific Islander identity allow you to build rapport with your peers, faculty or staff or does it make it more challenging?

25. Research has stated that close family relationships and inclusive communities are important to Pacific Islanders. Does this hold true for you? Why or why not?

a. Have you created this for yourself on campus? If yes, how?

\section{Underrepresented Identity Experience with STEM Discipline}

Artifact: Please provide an artifact that represents your experience as a person who self-identifies with a group (i.e., URM, female, first generation college student, etc.) that is underrepresented in STEM disciplines. Provide one artifact and prepare to discuss the questions below.

26. Please describe your artifact.

27. Why did you choose it to represent your experience as someone whose identity is underrepresented in STEM?

a. How important is it be a Pacific Islander (e.g. Samoan, Maori, etc.) in STEM?

28. Pacific Islander culture is reciprocated in nature in that giving back or passing down knowledge is a way to enrich and inspire the next generation. How important is this to you?

a. What are the expectations or obligations (if any) that your family or community has of you? (e.g. advise, mentor, speak at church, etc.)

b. Have you been able to witness or observe the fruits of your labor in your family or community? 
Example artifacts: Picture of you or someone that you identify with in class or working within your STEM discipline, picture that illustrates your successes/challenges as a person who selfidentifies with a group that is underrepresented in STEM

Interview Wrap-up/Reflection on the Interview Experience. Is there anything else that you think we should know about how you have persisted as a Pacific Islander in STEM or advice that you would give to an incoming freshmen based on your experience? 